$$
\text { DOE/EM--52368-Pt. } 1 \text {. }
$$

\title{
Life Cycle Cost Report or VHLW Cask
}

June 1995

Revision 0

Prepared by:

Chem Nuclear Systems, Inc. Columbia, SC 
Mr. Roger Cartee

Energy \& Technology Development Dept.

Department of Energy

PO Box 5400

Albuquerque, NM 87115

Dear Mr. Cartee:

\section{SUBJ: VHLW CASK LIFE CYCLE COST REPORT FOR CONTRACT DE- AC04-53689}

Enclosed is the Life Cycle Cost Report for the VHLW Cask. The Life Cycle Costs developed in this report are based upon the VHLW Cask designed under the subject contract and described in the Draft Safety Analysis Report submitted to you on March 23. 1995. This submittal completes the requirements of Phase 1, Task 5 of the subject contract.

This Life Cycle Cost Report is being forwarded even though the VHLW Cask contract expired on June 30, 1995. All costs for developing the Report were incurred before the contract expired.

Sincerely,

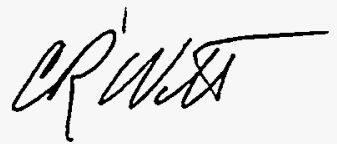

Charles R. Witt

Sr. Project Engineer

Encl: Life Cycle Cost Report for VHLW Cask, Rev. 0, June 1995

A17:LTR2 


\section{DISCLAIMER}

Portions of this document may be illegible in electronic image products. Images are produced from the best available original document. 


\section{Table of Contents}

List of Tables..................................................................................

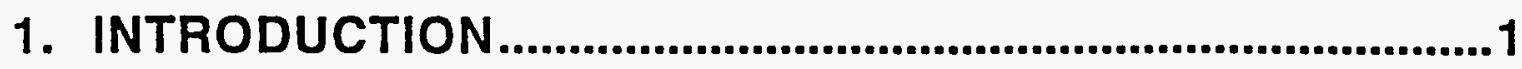

1.1 Purpose

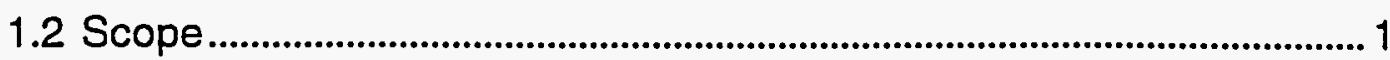

2. BASES FOR LIFE CYCLE COSTS.........................................2

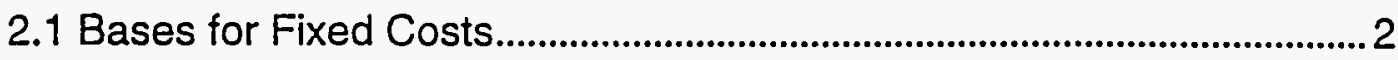

2.2 Bases for Variable Costs ...................................................................... 3

2.3 Costs Not Included.................................................................................... 6

3. UNIT COSTS FOR DEVELOPMENT OF LIFE CYCLE COSTS ............................................................................... 7

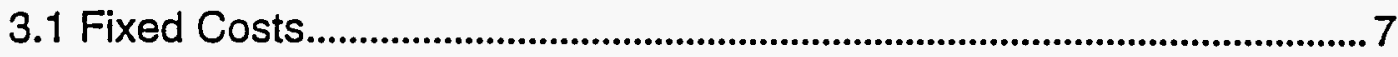

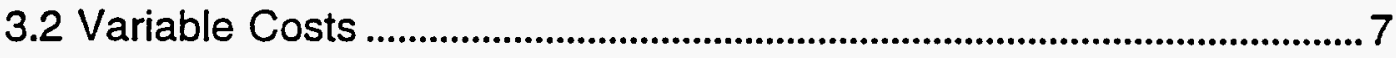

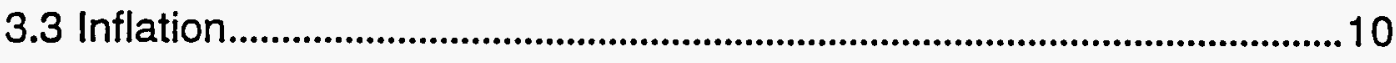

4. SUMMARY OF LIFE CYCLE COSTS ................................11

4.1 Quantity of Waste to Be Transported ...................................................11

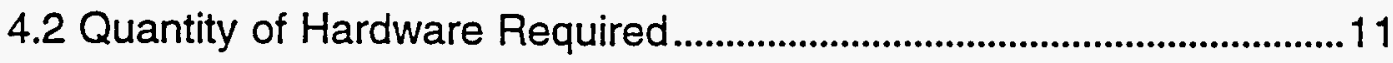

4.3 Total Life Cycle Cost...........................................................................11

5. REFERENCES ................................................................15

Appendix A - Life Cycle Cost Calculations for 10 Year

Shipping Campaign............................................................. A.1

Appendix B - Life Cycle Cost Calculations for 15 Year Shipping Campaign. 


\section{Table of Contents (continued)}

Page

Appendix C - Life Cycle Cost Calculations for 20 Year Shipping Campaign. C.1

Appendix D - Life Cycle Cost Calculations for 25 Year Shipping Campaign

\section{List of Tables}

Table 2-1 Life Expectancies of Transportation Hardware..............4 4

Table 3-1 VHLW Transportation Package Fixed Costs ..................7

Table 3-2 Hardware and Consumables Acquisition Costs.............8

Table 3-3 Operations and Maintenance Labor ${ }^{\circ}$ Costs....................9

Table 3-4 One-Way Mileage from VHLW Production Sites to Yucca Mountain ............................................................................. 10

Table 4-1 Quantity of VHLW Canisters to Be Shipped.................12

Table 4-2 Hardware Quantity Requirements.............................13

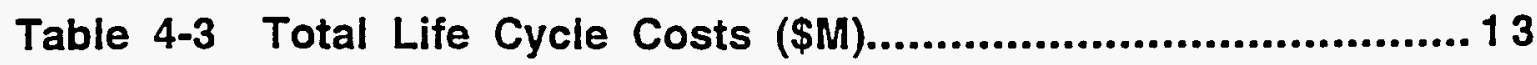

Table 4-4 Unit Life Cycle Costs (per VHLW Cask) (\$) ................ 14 


\section{INTRODUCTION}

This document. the Life Cycle Cost Report (LCCR) for the VHLW Cask. presents the life cycle costs for acquiring, using, and disposing of the VHLW casks. The VHLW cask consists of a ductile iron cask body, called the shielding insert, which is used for storage and transportation, and ultimately for disposal of Defense High Level Waste which has been vitrified and placed into VHLW canisters. Each ductile iron VHLW shielding insert holds one VHLW canister. For transportation, the shielding insert is placed into a containment overpack. The VHLW cask as configured for transportation is a legal weight truck cask which will be licensed by NRC. The cask was designed under DOE contract DE-AC04-89L53689 by Chem Nuclear Systems, Inc.

\subsection{Purpose}

The purpose of this LCCR is to present the development of the life cycle costs for using the VHLW cask to transport VHLW canisters from the generating sites to a disposal site. Life cycle costs include the cost of acquiring, operating, maintaining, and ultimately dispositioning the VHLW cask and its associated hardware.

\subsection{Scope}

This report summarizes costs associated with transportation of the VHLW casks. Costs are developed on the basis of expected usage, anticipated source and destination locations, and expected quantities of VHLW which must be transported. DOE overhead costs, such as the costs associated with source and destination facility handling of the VHLW, are not included. Also not included are costs exclusive to storage or disposal of the VHLW waste.

The costs in this report inciude estimates based on quotations for goods yet to be delivered. Also. costs are included for anticipated maintenance. Since the VHLW cask is a new design, maintenance costs must be estimated based on experience with similar equipment. 


\section{BASES FOR LIFE CYCLE COSTS}

This section of the LCCR describes the bases for development of the life cycle costs for the VHLW cask.

\subsection{Bases for Fixed Costs}

Fixed costs include those costs which are independent of the number of VHLW shielding inserts required. These include one time fixed costs and fixed costs which occur on a scheduled recurring basis. For the VHIW shielding insert and associated hardware, fixed $c$...its include the cost of designing the VHLW shielding insert and associated hardware, the costs of licensing the VHLW cask package, and the cost of renewing the package license. Each of these is discussed in more detail in the following sections. Note that all costs are developed in 1995 dollars. Adjustments for inflation are discussed in Section 3.3 of this report.

\subsubsection{Design Cost}

The design cost is based on actual costs incurred to date, and projected costs to complete. DOE contract DE-AC04-89L_53689 for the VHILW cask. The present design for the VHLW cask was initiated with Modification 004 of this contract. so the incurred and projected costs are based on postModification 004. The tasks included in this cost are preliminary design, test planning, testing, preparation of the draft Safety Analysis Report (SAR), and preparation of the Life Cycle Cost Report. The design cost is a one time fixed cost.

\subsubsection{Licensing Costs}

This cost includes the preparation of the final SAR and the effort to obtain the Certificate of Compliance ( $C$ of $C$ ), which includes NRC review and Chem Nuclear support of the NRC review and licensing effort. Since this effort has yet to be completed. and si- . it is performed by NRC on a time and materials basis, it is a best estim.... . ased on experience licensing other transportation packages. This is a one ume fixed cost.

\subsubsection{License Renewal Costs}

Psr NRC regulations, the $C$ of $C$ for a transportation packages is only valid for 5 years. Continued usage of a transportation package requires renewal of the $\mathrm{C}$ of $\mathrm{C}$. Estimated costs for preparation of the renewal application and NRC review costs form the basis for this cost.

\subsubsection{Shielding insert Set Up Charge}

Competitive bids were obtained from three different vendors for the cast iron VHLW shielding insert body. (This component is referred to as the shielding insert in the VHLW transportation SAR.) The cost of the VHLW shielding insert is a variable cost, however the lowest bidder quoted a one time set up cost. 


\subsection{Bases for Variable Costs}

Variable costs include costs which are not fixed with respect to time. but can vary as a function of time depending upon package usage. For the VHLW shielding insert and associated hardware, variable costs include the cost of procuring VHLW shielding inserts, VHLW cask overpacks and associated hardware required for transportation, and replacement parts such as seals, bolts, and test port plugs. Also included in variable costs are the costs of operation and maintenance of the VHLW cask transportation package and associated hardware required for transportation. Each of these is discussed in more detail in the following sections.

\subsubsection{Hardware Acquisition Costs}

Variable costs for hardware include the cost of procurement of the cast iron shielding inserts. cask overpacks, impact limiters, lifting yokes, and trailers, and procurement of replacement hardware. The bases for the hardware costs include vendor estimates and quotations, and the cost of similar hardware previously procured. Since the vendor quotations are for equipment yet to be delivered, these costs should also be treated as estimates. The bases for hardware acquisition costs are summarized in the following sections.

\subsubsection{Shielding Insert}

Competitive bids were obtained from three different vendors for the cast iron VHLW shielding insert body. The unit cost of the VHLW shielding insert provided by the lowest bidder is used as the basis for the VHLW shielding insert in this report. It is assumed that each shielding insert is shipped only once.

\subsubsection{Overpack}

Due to the simple design of the VHLW cask overpack. the cost per unit was estimated based on the overpack weight and an agreggate cost per pound for the fabricated product. The finished cost of the overpack body was estimated at $\$ 6.00$ /pound, and the finished cost of the overpack base plate at $\$ 7.00 /$ pound. The assumed limiting number of uses for the overpack is shown in Table 2-1.

\subsubsection{Trailer}

The trailer cost is developed based upon the cost of the GA 4/9 truck cask trailer developed by General Atomics for the DOE under contract DE-AC0188ID12698. The fabrication cost of the trailer was obtained in a meeting between Chem Nuclear and TRW Environmental Safety Systems (TESS) . The assumed limiting number of uses for the trailer is shown in Table 2-1.

\subsubsection{Impact Limiters}

Impact limiter acquisition costs were developed based on similar units purchased in 1990, with an appropriate adjustment for inflation. The assumed limiting number of uses for the impact limiters is shown in Table $2-1$. 


\begin{tabular}{|l|c|c|}
\hline \multicolumn{1}{|c|}{ Component } & Limiting Unit & Limit \\
\hline Overpack & $\begin{array}{c}\text { Transportation } \\
\text { round trips }\end{array}$ & 100 \\
\hline Trailer & $\begin{array}{c}\text { Transportation } \\
\text { round trips }\end{array}$ & 100 \\
\hline Impact Limiter (pair) & $\begin{array}{c}\text { Transportation } \\
\text { round trips }\end{array}$ & 100 \\
\hline Yoke & $\begin{array}{c}\text { Transportation } \\
\text { round trips }\end{array}$ & 500 \\
\hline $\begin{array}{l}\text { Assembly Verification Test } \\
\text { Apparatus }\end{array}$ & $\begin{array}{c}\text { Transportation } \\
\text { round trips }\end{array}$ & 100 \\
\hline Annual Test Apparatus & $\begin{array}{c}\text { Transportation } \\
\text { round trips }\end{array}$ & 100 \\
\hline
\end{tabular}

Table 2-1 Life Expectancies of Transportation Hardware

\subsubsection{Lifting Yoke}

The lifting yoke acquisition cost was based on a vendor quotation for a similar unit. The assumed limiting number of uses for the lifting yoke is shown in Table 2-1.

\subsubsection{Replacement Hardware}

Replacement hardware includes the following components:

$$
\begin{array}{ll}
\text { - } & \text { Seals } \\
\text { - } & \text { Closure bolts } \\
\text { - } & \text { Tase plates } \\
\text { - } & \text { Impact limiter attachment bolts }
\end{array}
$$

Current vendor quotes for similar items are used as a basis for determining seal costs. Vendor estimates are used as the basis for the costs for the other replacement items. It is assumed that one set of replacement items is required per cask overpack per year. An additional set of seals will be required after the third use of each new cask overpack, i.e. in the first year.

\subsubsection{Test Equipment}

Another cost is the test equipment acquisition. The test equipment includes the annual test apparatus (halogen detector. calibration source, vacuum pump, instrumentation and piping) and the assembly verification test apparatus (piping and instrumentation). These cost are based on vendor quotations. It is assumed that one set of annual test apparatus will be required per 10 cask overpacks, and that one set of assembly verification 
test apparatus will be required per cask overpack. The assumed limiting number of uses for the test equipment is shown in Table 2-1.

\subsubsection{Test Consumables}

Also included in this category are test consumables. specifically bottled sulfur hexafluoride gas for the annual containment verification test. The cost for this item is based on a vendor quotation. It is assumed one bottle of gas is required per annual inspection test performed.

\subsubsection{Hardware Dispositioning Costs}

Once the useful life of the components of the VHLW cask is over, each item must be dispositioned. The costs for dispositioning these components are included in the Life Cycle Cost calcuations for the VHLW cask. The following assumptions have been made regarding disposal costs:

- Since the shielding insert is intended to be used as the overpack for the VHLW canister at the repository, no decommissioning or disposal costs are incurred.

- None of the components of the VHLW cask will require decontamination prior to disposal.

- The large metal components of the VHILW cask. such as the stainless steel overpack and overpack baseplate. the trailer, and the lifting yoke. can be dispositioned by selling as scrap metal, and therefore will be a positive contributor to the Life Cylce Cost. However, since the market prices for scrap metal are volitile, the disposal cost for these components is conservatively assumed to be zero.

- No inflation is applied to the remaining component disposal costs as these will be offset by the positive contribution of items sold for scrap metal which are being ignored in this evaluation.

The only components of the which will incur disposal costs are the impact limiters and the test hardware.

\subsubsection{Impact Limiters}

Chem Nuclear has received a verbal quotation for disposal of each pair of overpacks of $\$ 3000$. This price includes labor for preparation and shipment for disposal as well as actual disposal costs.

\subsubsection{Test Hardware}

It is conservatively assumed that a modest cost for disposal of miscellaneous test equipment components will be required. This cost is estimated at $\$ 200$ per unit.

\subsubsection{Labor Costs}

Labor costs in this report are based upon expected durations of activities to be performed in conjunction with the preparation, loading, testing, unloading, assembly, maintenance, and repair of the transportation package and associated hardware, such as the lifting yoke and trailer. The durations 
used are based upon estimates provided by experienced cask handling and testing personnel. These costs do not include transportation costs, which are discussed separately below. Costs are based upon anticipated labor hours, frequency, and labor rates.

\subsubsection{Transportation Costs}

Transportation costs are developed based upon Chem Nuclear's extensive experience base in shipping radioactive waste in the U.S. Based on this experience, a typical cost per mile has been developed which is used in the life cycle cost calculations. This unit cost includes the cost for the driver, fuel, and other cost associated with transportation expense. The number of miles from each DHLW generation site to the anticipated repository site is used. The annual cost is a function of the cost per mile, the number of miles per trip, and the number of trips per year.

\subsection{Costs Not Included}

Costs which are not included in the life cycle cost estimate for the VHLW cask include the cost of a tractor for towing the VHLW cask transportation package, the costs associated with the VHLW canisters procurement and DHLW processing, and DOE overhead costs. In addition, all VHLW cask activities associated with storage or disposal functions of the cask are not included. This includes, for example. the welding of the secondary lid for storage and the welding of the primary and secondary lids for disposal. 


\section{UNIT COSTS FOR DEVELOPMENT OF LIFE CYCLE COSTS}

Each of the following sections provides the unit cost for each of the identified costs for the VHLW cask. The life cycle cost summary utilizing each of these unit costs is provided in Section 4. Note that all costs are developed in 1995 dollars. Adjustments for inflation are discussed in Section 3.3 of this report.

\subsection{Fixed Costs}

Each of the fixed costs identified in Section 2.1 are provided in Table 3-1.

\begin{tabular}{|l|l|r|}
\hline \multicolumn{1}{|c|}{ Component } & Frequency & Cost (\$) \\
\hline Design & one time & $265,300.00$ \\
\hline Initial Licensing & one time & $175,000.00$ \\
\hline Licensing Renewal & every 5 years & $10,000.00$ \\
\hline Shielding Insert Fabrication Set-Up Charge & one time & $15,500.00$ \\
\hline
\end{tabular}

Table 3-1 VHLW Transportation Package Fixed Costs

\subsection{Variable Costs}

This section develops the variable costs associated with acquisition. disposal, operation and maintenance of the VHLW cask and associated hardware. Costs for each of these categories are summarized in the following sections.

\subsubsection{Hardware Acquisition}

The variable costs identified in Section 2.2.1 are provided on a per-unit basis in Table 3-2.

\subsubsection{Hardware Disposition}

The variable costs for dispositioning the hardware identified in Section

2.2.2 are provided on a per-unit basis in Section 2.2.2.

\subsubsection{Operation and Maintenance}

As discussed in Section 2.2.3. costs associated with operating, repairing, and maintaining the VHILW cask package components depend on the amount of labor required. A detailed summary of the operational and maintenance steps required for VHLW cask use, along with the resulting costs, is provided in Table 3-3. As can be seen in the table, each task 
includes the time required to complete the task and the number of people required. This is used to develop the total labor required to perform the task. Next, the frequency of each activity on an annual basis is listed and . utilized as the basis for developing the annual cost of each activity. The costs developed assume that each overpack is used to complete 12 shipments per year. The annual costs of each operation and maintenance activity are summed to obtain the total annual cost of operating a single VHIW cask overpack and its associated hardware for transportation of VHLW shielding inserts. The total annual cost for operation and maintenance is obtained by multiplying the single overpack cost by the number of overpacks required, which is a function of shipping campaign length as discussed in Section 4.

\begin{tabular}{|l|c|r|}
\hline \multicolumn{1}{|c|}{ Component } & Unit & \multicolumn{1}{c|}{$\begin{array}{c}\text { Unít Cost } \\
\text { (\$) }\end{array}$} \\
\hline Shielding Insert & each & $69,000.00$ \\
\hline Overpack & each & $74,500.00$ \\
\hline Trailer & each & $50,000.00$ \\
\hline Impact limiters & pair & $19,200.00$ \\
\hline Yoke & each & $35,000.00$ \\
\hline Replacement closure seals & pair & 125.66 \\
\hline Replacement closure bolts & set & 227.72 \\
\hline Replacement base plates & each & $11,500.00$ \\
\hline Replacement test port plug & each & 20.00 \\
\hline Replacement impact limiter attachment bolts & set & 10.55 \\
\hline Halogen leak detector and calibration source & each & $4,700.00$ \\
\hline Bottled halogen & each & 100.00 \\
\hline Vacuum pump & each & 625.00 \\
\hline Associated annual test apparatus & each & 100.00 \\
\hline Assembly verification test apparatus & each & 100.00 \\
\hline
\end{tabular}

Table 3-2 Hardware and Consumables Acquisition Costs 


\begin{tabular}{|c|c|c|c|c|c|c|}
\hline Operation Description & & $\begin{array}{l}\text { Persons } \\
\text { Req'd }\end{array}$ & $\begin{array}{l}\text { Labor } \\
\text { (MH) }\end{array}$ & $\begin{array}{c}\text { Cost } \\
(s)\end{array}$ & $\begin{array}{c}\text { Froquency } \\
\text { of } \\
\text { operation } \\
\text { (x per } y r)\end{array}$ & $\begin{array}{c}\text { Annual Cost } \\
\text { (\$) }\end{array}$ \\
\hline $\begin{array}{l}\text { Package Removal and Disassemoly } \\
\text { Remove impact limiters }\end{array}$ & 2 & 3 & 6 & 210 & 1 & 5040 \\
\hline Disconnect cask to traller tre down equipment & 2 & 2 & 4 & 140 & 24 & 3360 \\
\hline Remove package from traller & 2 & 5 & 10 & 350 & $\overline{24}$ & 8400 \\
\hline Remove overpack barre! & 2 & 3 & $\overline{6}$ & 210 & 24 & 5040 \\
\hline Install shield insert lifting trunnions & 1 & 2 & 2 & 70 & 12 & 840 \\
\hline \multicolumn{7}{|l|}{ Package Assembly tor Shipment } \\
\hline Place loaded shield insert on overpack base plate & 1 & 2 & 2 & 70 & 12. & 840 \\
\hline Remove shield inser trunnions and install plugs & 1 & 2 & 2 & 70 & 12 & 840 \\
\hline Place and secure overpack barrel to base plate & 2 & $\overline{3}$ & $\overline{6}$ & 210 & 24 & 5040 \\
\hline Install and torque closure bolls & 2 & 3 & 6 & 210 & 24 & 5040 \\
\hline Perform Assembly Verification Leak Test (see below) & & & & & & \\
\hline \multicolumn{7}{|l|}{ Package Loading onto raller } \\
\hline Lift package with yoke. place and downend on trailer & 2 & 3 & 6 & 210 & 24 & 5040 \\
\hline Attach tie-down equipment and remove yoke & -2 & -2 & 4 & $14 \overline{0}$ & 24 & 3360 \\
\hline Install impact limiters & 2 & -3 & $\overline{6}$ & 210 & 24 & 5040 \\
\hline Pertorm pre-shipment radiological survey & 2 & -2 & & 140 & 24 & 3360 \\
\hline Install tamperproof seals & 0.5 & 2 & 1 & 35 & 24 & 840 \\
\hline \multirow{2}{*}{\multicolumn{7}{|c|}{$\begin{array}{l}\text { Assembly Ventication Leak Test - Closure Seals } \\
\text { Set up / attach test apparatus }\end{array}$}} \\
\hline & 1 & 2 & 2 & 70 & 12 & 840 \\
\hline - Pressurize annulus & 0.5 & $\overline{1}$ & $0 . \overline{5}$ & 17.5 & 12 & 210 \\
\hline Perform test . . . . & 1 & 2 & 2 & 70 & -12 & 840 \\
\hline Release pressure & 0.1 & 1. & 0.1 & 3.5 & -12 & 42 \\
\hline Remove test apparatus & 0.5 & 2 & $\overline{1}$ & 35 & 12 & $\overline{420}$ \\
\hline Install test port plug & 0.5 & 2 & $\dot{i}$ & 35 & 12 & 420 \\
\hline \multicolumn{7}{|l|}{ Assembiy Venication Leak lest - Tesi Por } \\
\hline Altach test apparatus & 1 & 2 & 2 & 70이 & 12 & 840 \\
\hline it port plug. & 0.5 & 1 & & 17.5 & $\sqrt{12}$ & 210 \\
\hline Pertorm test & & 2 & & 70 & 12 & 840 \\
\hline Release pressure & 0.1 & -1 & & 3.5 & 12 & 42 \\
\hline Remove test apparatus & 0.5 & 1 & 0.5 & 17.5 & 12 & 210 \\
\hline \multirow{2}{*}{\multicolumn{7}{|c|}{$\begin{array}{l}\text { Annual Containment Venification Leak Test } \\
\text { Calibrate leak detector }\end{array}$}} \\
\hline & 2. & 2 & 4 & 140 & 1 & 140 \\
\hline Check test surfaces of overpack for residual hatides & & 2 & & $70]$ & 1 & 70 \\
\hline Clean test suriaces to remove residual halides & & & & $\overline{140}$ & 1 & 140 \\
\hline Examine 0 -rings and test port plug for damage & 0.5 & - & ב & 35 & -- & 35 \\
\hline Place and secure overpack barrel to base plate_ & $-\overline{2}$ & 二 & & 210 & 1 & 210 \\
\hline Set up / attach test apparatus & 1 & [ & 2 & 70 & - & 70 \\
\hline Pressurize annulus & $0 . \overline{1}$ & & & & 1 & \\
\hline Check for leakage around base plate with detector & 0.5 & 2 & 1 & $3 \overline{5}$ & 1 & 35 \\
\hline Tum off and remove leak test equipment & 0.5 & & $\overline{0.5}$ & 17.5 & 1 & 17.5 \\
\hline Remove gas source and release pressure & 0.1 & & 0.1 & 3.5 & 1 & 3.5 \\
\hline Install test port plug & 0.1 & 2 & 0.2 & 7 & 1 & \\
\hline Attach test apparatus with vacuum source & 0.5 & 2 & 1 & 35 & 1 & 35 \\
\hline Apply vaccum and check for leakage & 0.2 & $\overline{2}$ & & 14 & 1 & 14 \\
\hline Tum off and remove leak lest equipment & 0.5 & 1 & 05 & 17.5 & 1 & $\overline{17.5}$ \\
\hline \multicolumn{7}{|l|}{ Annual Yoke Compliance Venitication Testing } \\
\hline Set up test for yoke & 2 & 3 & 6 & 210 & 1 & 210 \\
\hline Apply required load to yoke & 0.2 & 3 & 0.6 & -21 & 1 & 21 \\
\hline Periorm yoke visual defect and deformation inspection & 2 & 2 & 4 & 140 & 1 & $\overline{140}$ \\
\hline \multicolumn{7}{|l|}{ Annual Overpack Irunnion NDE } \\
\hline Set up for test & 2 & 1 & 2 & 70 & 1 & 70 \\
\hline Perform PT of trunnions at comers and shoulder & 2 & 2 & 4 & 140 & 1 & 140 \\
\hline \multicolumn{7}{|l|}{ Annual Overpack Maintenance } \\
\hline Replace closure seals & 2 & 2 & 4 & 140 & 1 & 140 \\
\hline Replace closure bolts & 0.5 & 2 & 1 & 35 & 1 & 35 \\
\hline Replace impact limiter attachment bolts & 0.5 & 2 & 1 & 35 & 1 & 35 \\
\hline Replace test port plug & 0.5 & 2 & 1 & 35 & 1 & 35 \\
\hline \multicolumn{7}{|l|}{ Annual Trailer Maintenance } \\
\hline & 8 & 2 & 16 & 560 & 1 & 560 \\
\hline Routine maintenance and reoair & 40 & $\overline{2}$ & 80 & 2800 & 1 & 2800 \\
\hline \multicolumn{6}{|l|}{ TOTAL ANNUAL LABOR COST PER OVERPACK } & 1.50 \\
\hline
\end{tabular}

Table 3-3 Operations and Maintenance Labor Costs 


\subsubsection{Transportation Costs}

As discussed in Section 2.2.4, the annual cost for transportation is a function of the cost per mile, the number of miles per trip, and the number of trips per year. A unit cost per mile is used to determine the transportation costs. The unit cost used is $\$ 2.00$ per mile. which has been developed based on Chem Nuclear's extensive experience in transporting high level radioactive waste.

The number of miles per trip is based on the round trip distance from the waste producer's site to the assumed disposal site, Yucca Mountain. The one-way mileage from each VHLW production site to Yucca Mountain is provided in Table $3-4$.

\begin{tabular}{|l|c|}
\hline \multicolumn{1}{|c|}{ Site } & $\begin{array}{c}\text { Miles to } \\
\text { Yucca } \\
\text { Mtn. }\end{array}$ \\
\hline Savannah River (SRS) & 2000 \\
\hline West Valley (WVDP) & 2250 \\
\hline Hanford & 1000 \\
\hline Idaho (INEL) & 700 \\
\hline
\end{tabular}

Table 3-4 One-Way Mileage from VHLW Production Sites to Yucca Mountain

The cost per mile, the number of trips per year from each site, and the round trip mileage from each site is used to determine the total annual cost of transportation from each site, which are then summed to get the total annual transportation cost. The number of trips per year from each waste producer's site is a function of the shipping campaign length, as discussed in Section 4.

\subsection{Inflation}

As discussed above and shown in Tables 3-1 through 3-4, all costs have been developed in 1995 dollars. However, inflation will effect the total cost of using the VHLW cask. Since the transportation of VHLW shielding inserts to Yucca Mountain will not occur until the repository is open and available, it will be several years before the VHLW shielding inserts, overpacks, and associated hardware will be required. It is therefore likely, based on historical precedent, that costs for goods and services will continue to rise until then. Therefore the life cycle cost calculations provided in Section 4 of this report include total costs for assumed average inflation rates. Average annual inflation rates of $3 \%, 5 \%$ and $7 \%$ are included. In addition, assumed repository opening dates of 2010 and 2020 are used. The total cost in 1995 dollars, i.e. a zero inflation rate, is also included for comparison. Since zero inflation results in the same total regardless of the repository opening date, the zero inflation rate life cycle costs are only computed for the 2010 repository opening date. 


\section{SUMMARY OF LIFE CYCLE COSTS}

This section of the VHLW Life Cycle Cost Report summarizes the total life cycle cost for transportation of VHLW waste to the repository. In addition, a cost per VHIW cask shipped is provided. The total life cycle cost is developed based upon the unit costs discussed in Section 3 of this report and the total quantity of waste canisters to be transported.

\subsection{Quantity of Waste to Be Transported}

As discussed in Section 1 of this report, the waste to be transported consists of DHIW which has been vitrified and placed into VHLW canisters. The projected number of VHLW canisters to be produced by production site is summarized in Table 4-1. Information in Table 4-1 is obtained from Reference 1.

\subsection{Quantity of Hardware Required}

Based on the number of canisters to be shipped. the duration of the shipping campaign, and the number of transportation trips which can be completed per year. the required number of transportation cask overpacks is developed. It is assumed that a set of impact limiters, a trailer, and a lifting yoke are required for each overpack. Also, as discussed in Section 2.2, it is assumed that the overpacks and associated hardware are suitable for 100 transportation cycles. It is assumed that each overpack can make 12 shipments per year. This information is summarized in Table 4-2.

\subsection{Total Life Cycle Cost}

Spreadsheets showing the life cycle cost calculations for shipping campaign durations of 10 years, 15 years, 20 years. and 25 years are provided in Appendices A through $\mathrm{D}$, respectively. Within each Appendix. calculations are performed for assumed repository availability dates of 2010 and 2020 . For each of these repository dates, calculation of the life cycle cost is performed for the inflation rates identified in Section 3.3.

For each combination of shipping campaign length, repository availability date, and inflation rate, a total life cycle cost for completion of the transportation of VHLW canisters from the four producing sites is determined. The total life cycle costs are summarized in Table 4-3

In addition to the total life cycle cost, a unit life cycle cost is developed for each VHLW shielding insert. This unit cost is developed by dividing the total life cycle cost by the number of VHLW shielding inserts transported. As a result, the unit cost includes the cost of the VHLW shielding insert itself plus an equal portion of all other costs associated with the VHLW transportation package design, licensing, fabrication, shipment, and disposal. The unit cost represents an average over the length of the shipping campaign, as inflation increases costs over time. Unit life cycle costs are summarized in Table 4-4. 


\begin{tabular}{|c|c|c|c|c|c|}
\hline $\begin{array}{c}\text { Calendar } \\
\text { Year }\end{array}$ & WVDP & SRS & Hanford & INEL & Total \\
\hline 1992 & & 136 & & & 136 \\
\hline 1993 & 25 & 308 & & & 333 \\
\hline 1994 & 200 & 376 & & & 576 \\
\hline 1995 & 50 & 410 & & & 460 \\
\hline 1996 & & 410 & & & 410 \\
\hline 1997 & & 383 & & & 383 \\
\hline 1998 & & 369 & & & 369 \\
\hline 1999 & & 369 & & & 369 \\
\hline 2000 & & 342 & 240 & & 582 \\
\hline 2001 & & 342 & 370 & & 712 \\
\hline 2002 & & 342 & 345 & & 687 \\
\hline 2003 & & 342 & 185 & & 527 \\
\hline 2004 & & 302 & 370 & & 672 \\
\hline 2005 & & 273 & 370 & & 643 \\
\hline 2006 & & 273 & 80 & & 353 \\
\hline 2007 & & 273 & & & 273 \\
\hline 2008 & & 32 & & & 32 \\
\hline 2009 & & & & & 0 \\
\hline 2010 & & & & & 0 \\
\hline 2011 & & & & & 0 \\
\hline 2012 & & & & 500 & 500 \\
\hline 2013 & & & & 600 & 600 \\
\hline 2014 & & & & 700 & 700 \\
\hline 2015 & & & & 1000 & 1000 \\
\hline 2016 & & & & 1000 & 1000 \\
\hline 2017 & & & & 1000 & 1000 \\
\hline 2018 & & & & 1000 & 1000 \\
\hline 2019 & & & & 1000 & 1000 \\
\hline 2020 & & & & 1000 & 1000 \\
\hline TOTAL & 275 & 5,282 & & 15,317 \\
\hline
\end{tabular}

Table 4-1 Quantity of VHLW Canisters to Be Shipped 


\begin{tabular}{|c|c|c|c|c|c|}
\hline \multirow[t]{2}{*}{ Site } & \multirow[t]{2}{*}{ No. Canisters } & \multicolumn{4}{|c|}{$\begin{array}{c}\text { Shipments per Year for Campaign } \\
\text { Length of (yrs) }\end{array}$} \\
\hline & & 10 & 15 & 20 & 25 \\
\hline SRS & 5,282 & 528 & 352 & 264 & 211 \\
\hline WVDP & 275 & 28 & 18 & 14 & 11 \\
\hline Hanford & 1,960 & 196 & 131 & 98 & 78 \\
\hline INEL & 7,800 & 780 & 520 & 390 & 312 \\
\hline Total & 15,317 & 1532 & 1021 & 766 & 613 \\
\hline \multicolumn{2}{|c|}{ No. of shield inserts per year } & 1532 & 1021 & 766 & 613 \\
\hline \multicolumn{2}{|c|}{ No of trips/overpack/year } & 12 & 12 & 12 & 12 \\
\hline \multicolumn{2}{|c|}{ No. of overpacks required } & 128 & 85 & 64 & 51 \\
\hline \multicolumn{2}{|c|}{ Req'd no. of trips/overpack } & 120 & 180 & 240 & 300 \\
\hline
\end{tabular}

Table 4-2 Hardware Quantity Requirements

\begin{tabular}{|c|c|c|c|c|}
\hline Inflation Rate & \multicolumn{4}{|c|}{ Shipping Campaign Length (yrs) } \\
\hline & 10 & 15 & 20 & 25 \\
\hline \multicolumn{5}{|c|}{ Repository Availability Date $=2010$} \\
\hline 0 & 1,231 & 1,218 & 1,220 & 1,214 \\
\hline 3 & 2,262 & 2,416 & 2,626 & 2,833 \\
\hline 5 & 3,374 & 3,808 & 4,392 & 5,037 \\
\hline 7 & 5,011 & 5,990 & 7,360 & 9,015 \\
\hline \multicolumn{5}{|c|}{ Repository Availability Date $=2020$} \\
\hline 3 & 3,040 & 3,247 & 3,529 & 3,808 \\
\hline 5 & 5,496 & 6,203 & 7,154 & 8,205 \\
\hline 7 & 9,857 & 11,783 & 14,478 & 17,734 \\
\hline
\end{tabular}

Table 4-3 Total Life Cycle Costs (\$M) 


\begin{tabular}{|c|c|c|c|c|}
\hline Inflation Rate & \multicolumn{4}{|c|}{ Shipping Campaign Length (yrs) } \\
\hline \multicolumn{5}{|c|}{ Repository Availability Date $=2010$} \\
\hline 0 & 80,372 & 79,488 & 79,661 & 79,274 \\
\hline 3 & 147,684 & 157,766 & 171,454 & 184,987 \\
\hline 5 & 220,305 & 248,637 & 286,769 & 328,874 \\
\hline 7 & 327,173 & 391,091 & 480,528 & 588,583 \\
\hline \multicolumn{5}{|c|}{ Repository Availability Date $=2020$} \\
\hline 3 & 198,445 & 212,002 & 230,396 & 248,586 \\
\hline 5 & 358,799 & 404,962 & 467,071 & 535,663 \\
\hline 7 & 643,514 & 769,271 & 945,201 & $1,157,771$ \\
\hline
\end{tabular}

Table 4-4 Unit Life Cycle Costs (per VHLW Cask) (\$) 


\section{REFERENCES}

1. Characteristics Database System, High Level Waste Database, DOE/RW0184-R1, July 1992 
Appendix A

Life Cycle Cost Calculations

for 10 Year Shipping Campaign

A.0 


\section{Appendix A.1 Life Cycle Cost Calculations for 10 Year Shipping} Campaign for Assumed Repository Availability Date of 2010

Table A.1-1 Average Annual Inflation Rate $=0 \%$

Table A.1-2 Average Annual Inflation Rate $=3 \%$

Table A.1-3 Average Annual Inflation Rate $=5 \%$

Table A.1-4 Average Annual Inflation Rate $=7 \%$

A.1 
Repository open date:

2010

Inflation rate $=0$

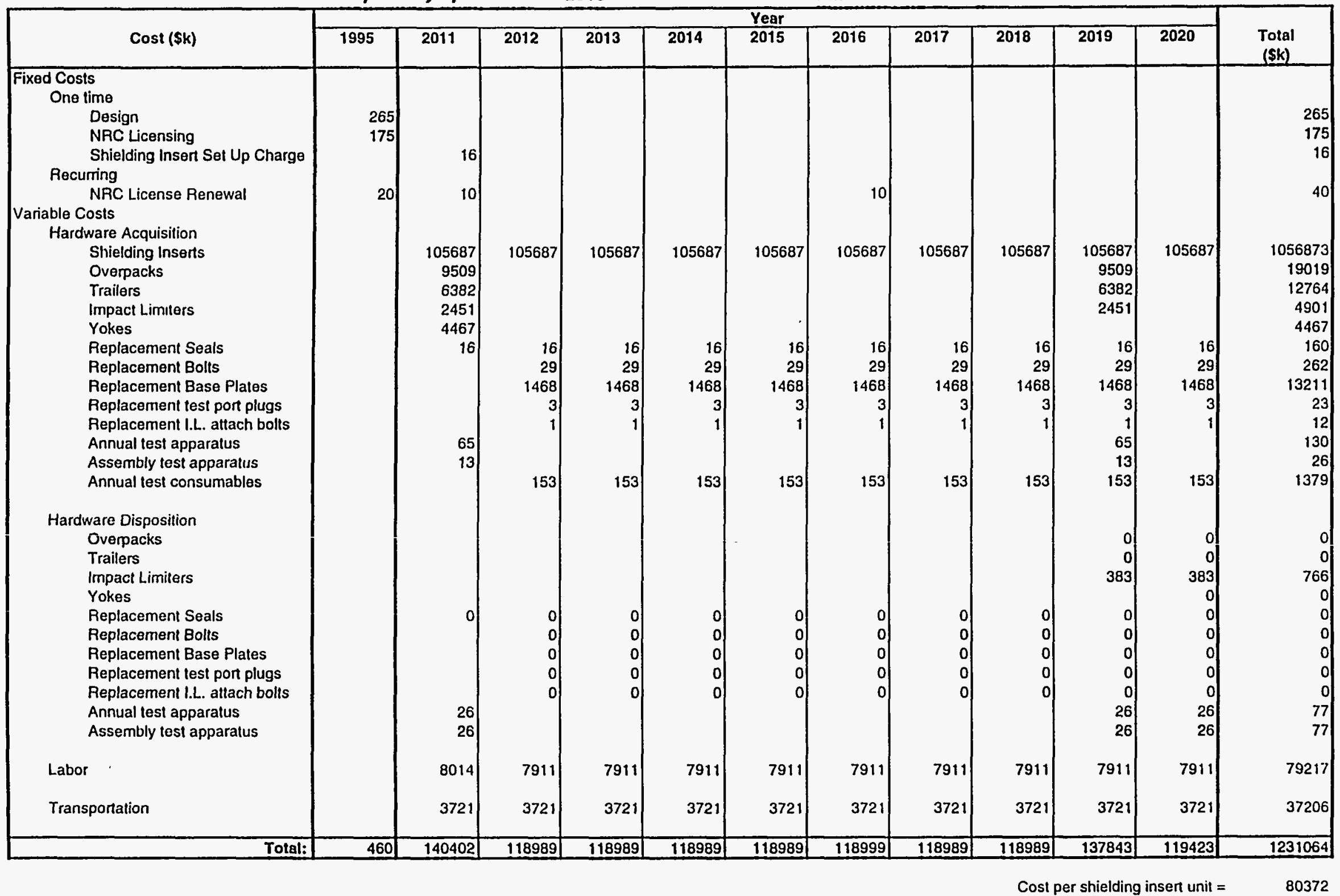


Repository open date: 2010

Inflation rate $=3 \%$

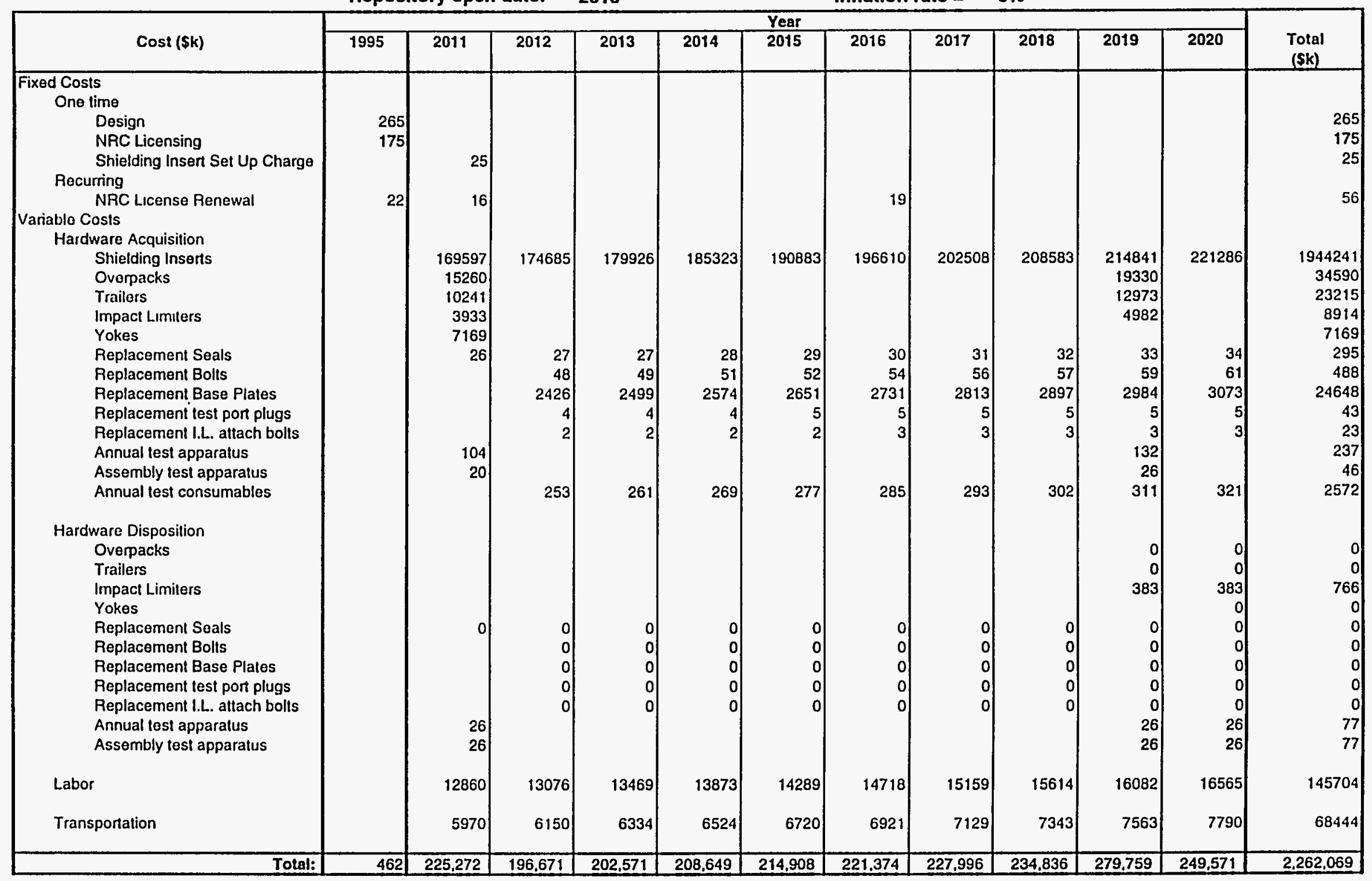


Repository open date: 2010

Inflation rate $=5 \%$

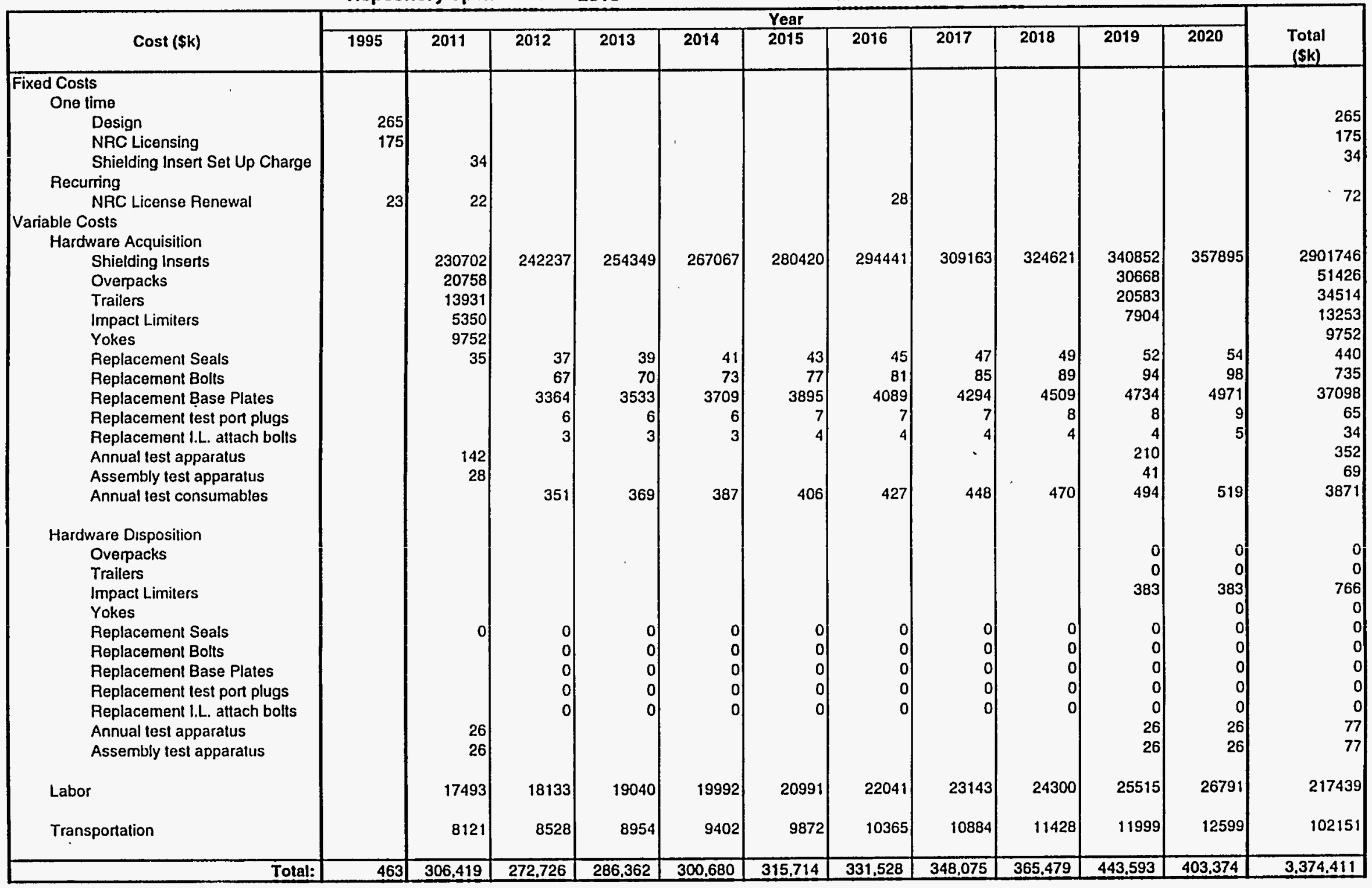


Repository open date: 2010

Inflation rate $=\quad 7 \%$

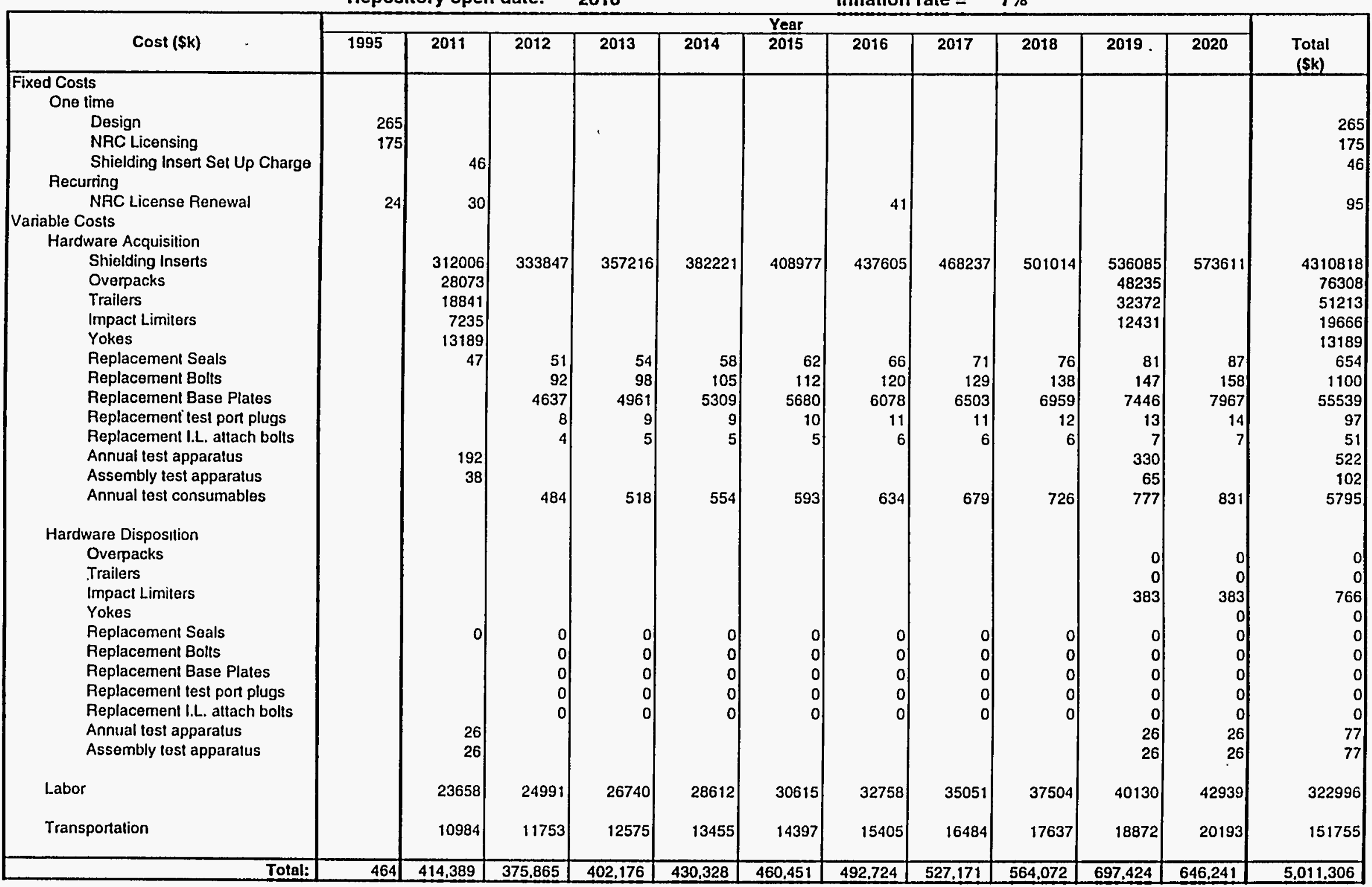

Cost per shielding insert unit $=\$ \quad 327,173$ 
Appendix A.2 Life Cycle Cost Calculations for 10 Year Shipping Campaign for Assumed Repository Availability Date of 2020

Table A.2-1 Average Annual Inflation Rate $=3 \%$

Table A.2-2 Average Annual Inflation Rate $=5 \%$

Table A.2-3 Average Annual Inflation Rate $=7 \%$ 


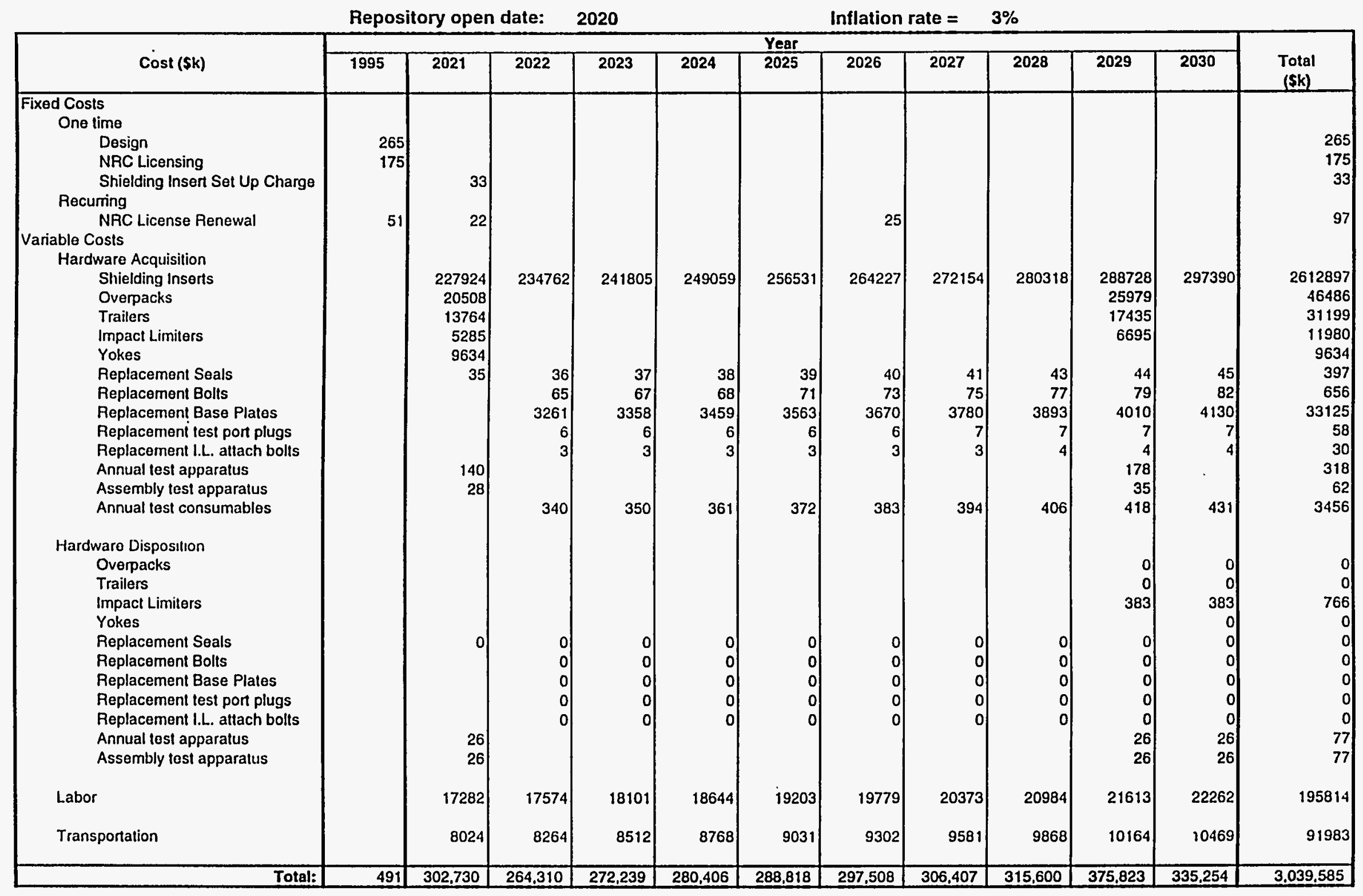


Repository open date: 2020

Inflation rate $=5 \%$

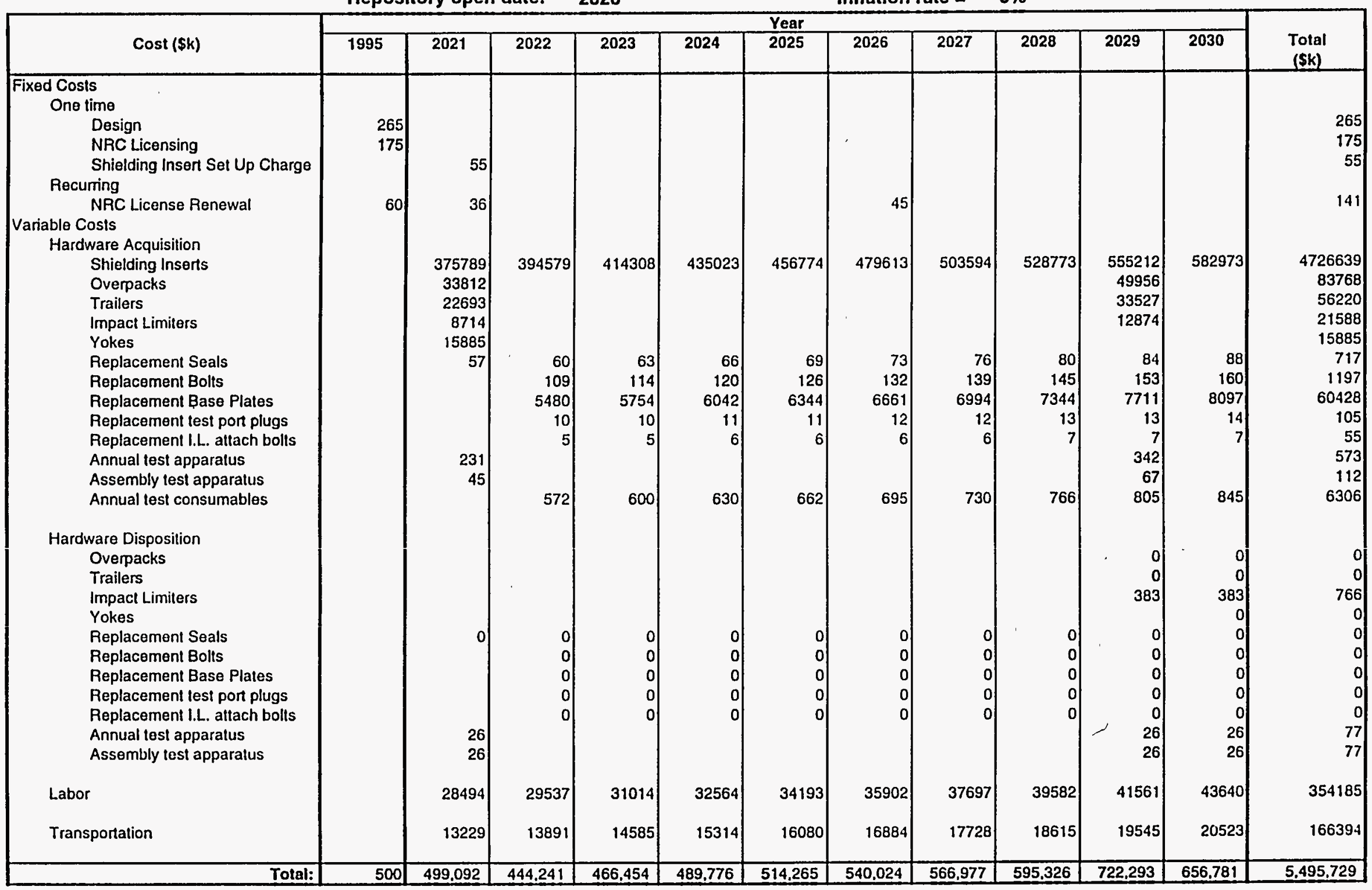

Cost per shielding insert unit $=\mathbf{\$} \quad \mathbf{3 5 8 , 7 9 9}$ 
Repository open date: 2020

Inflation rate $=\quad 7 \%$

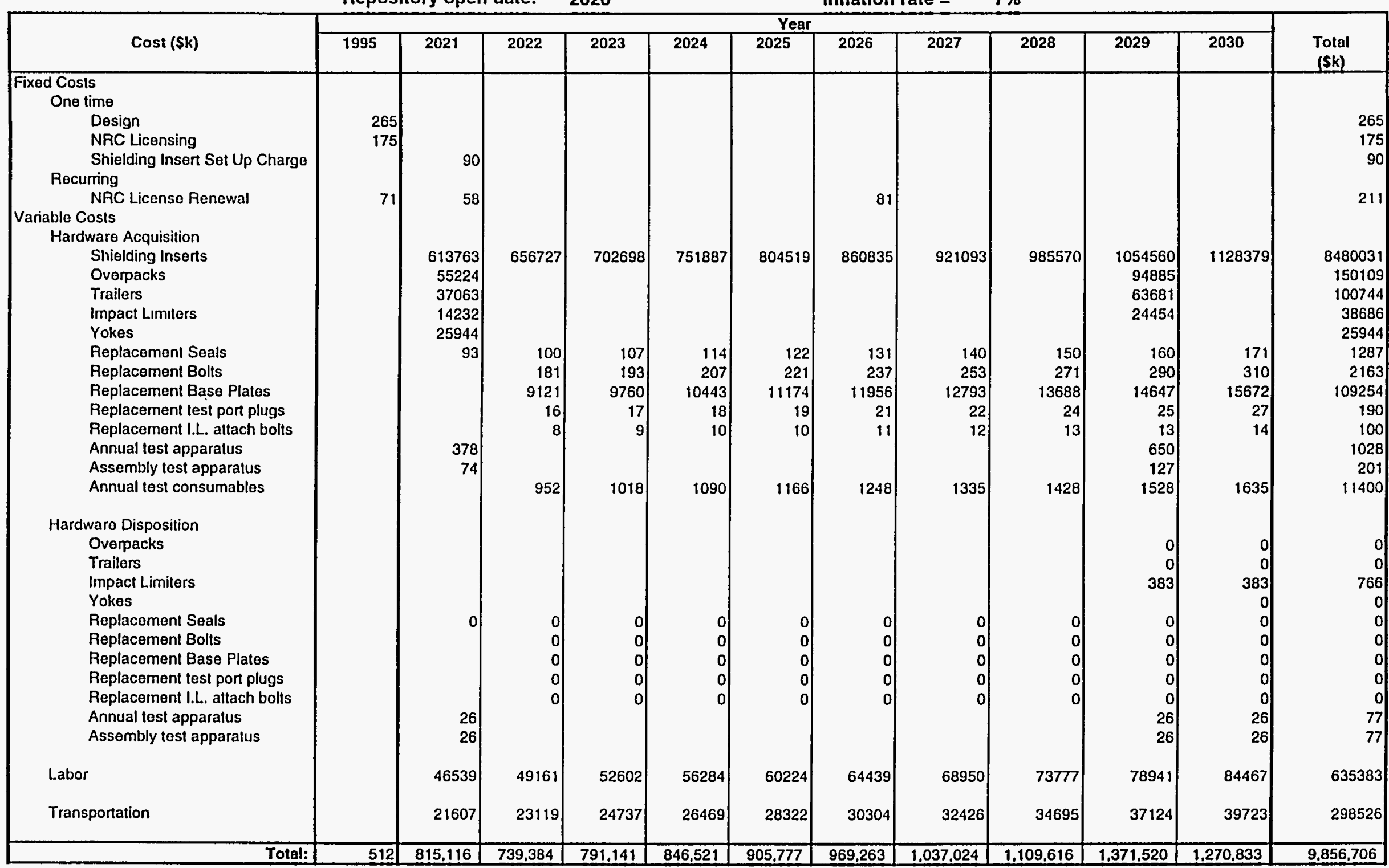



VHLW Cask

June 30. 1995

Life Cycle Cost Report

Revision 0

Appendix B

Life Cycle Cost Calculations

for 15 Year Shipping Campaign

B. 0 


\section{Appendix B.1 Life Cycle Cost Calculations for 15 Year Shipping} Campaign for Assumed Repository Availability Date of 2010

Table B.1-1 Average Annual Inflation Rate $=0 \%$

Table B.1-2 Average Annual Inflation Rate $=3 \%$

Table B.1-3 Average Annual Inflation Rate $=5 \%$

Table B.1-4 Average Annual Inflation Rate $=7 \%$ 


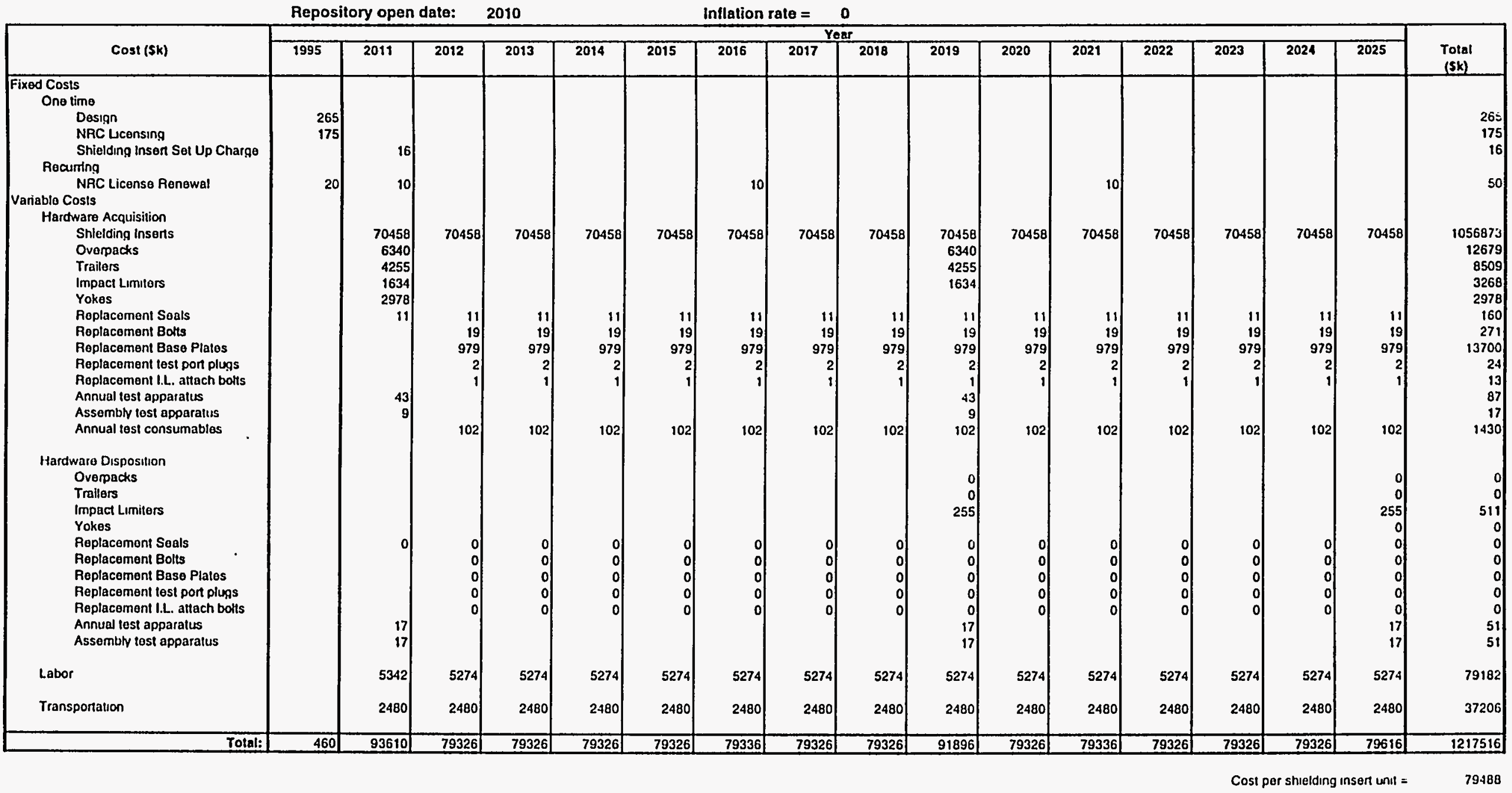




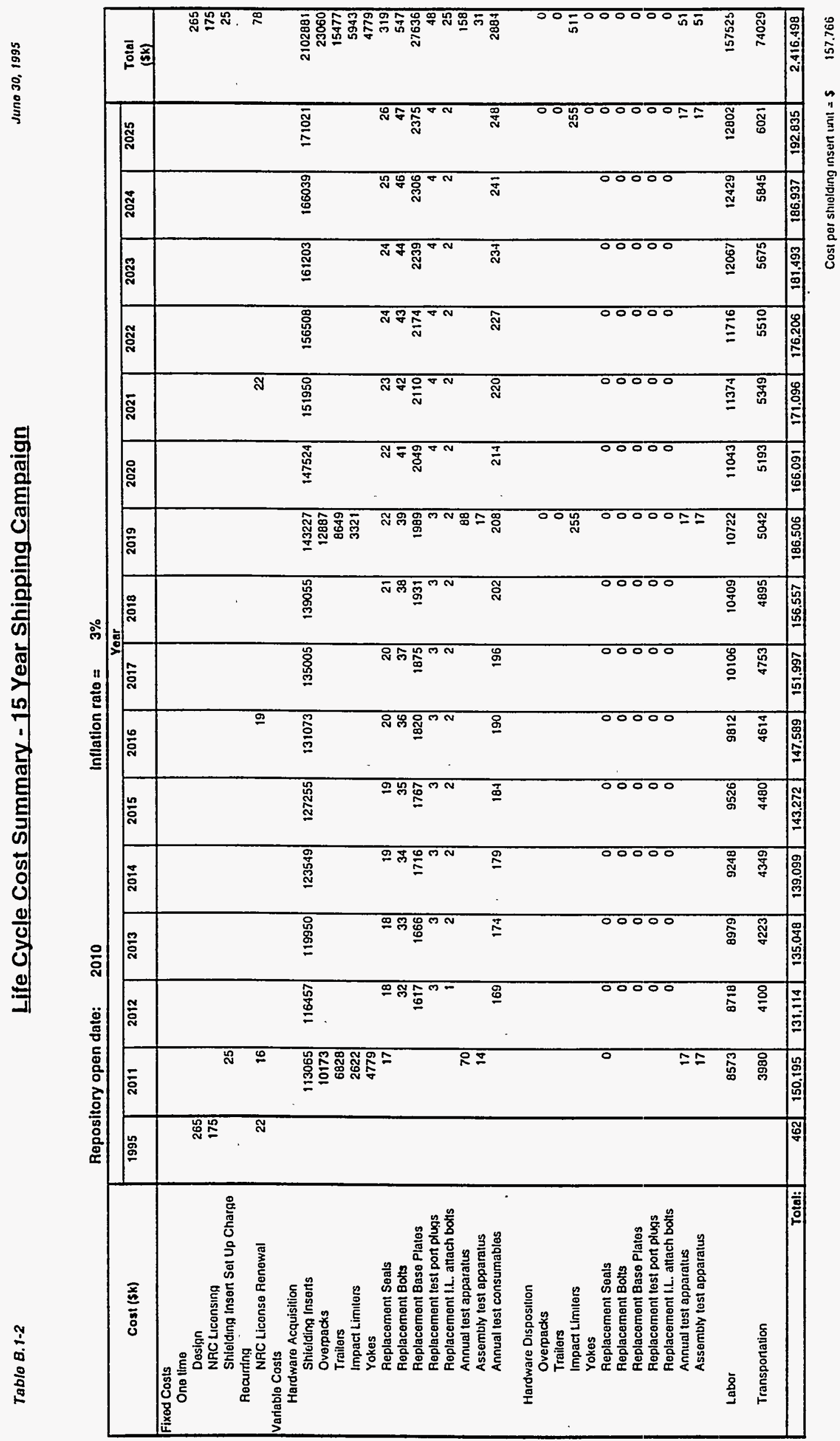




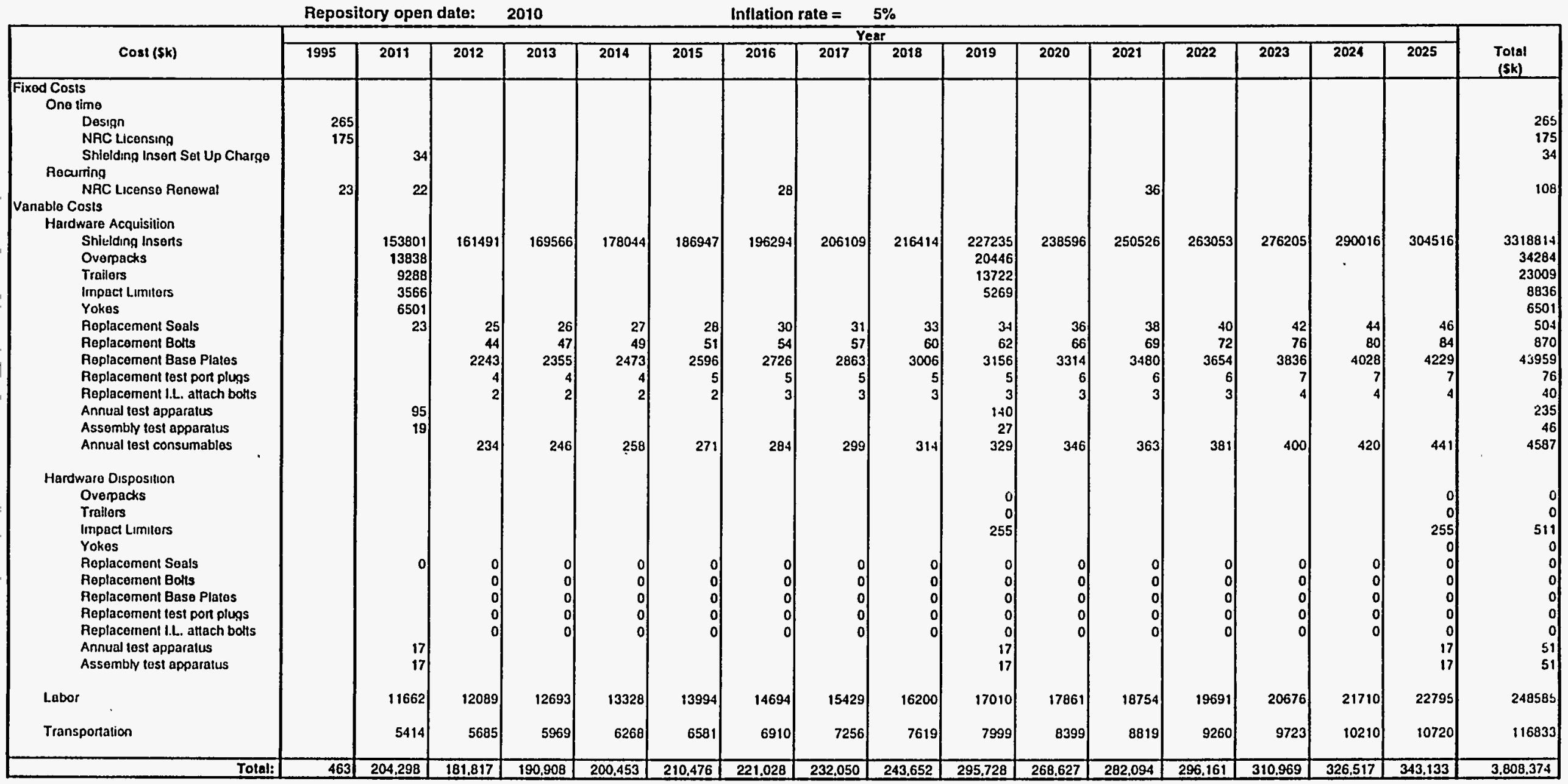


Reposttory open date: 2010

Inflation rate $=\quad 7 \%$

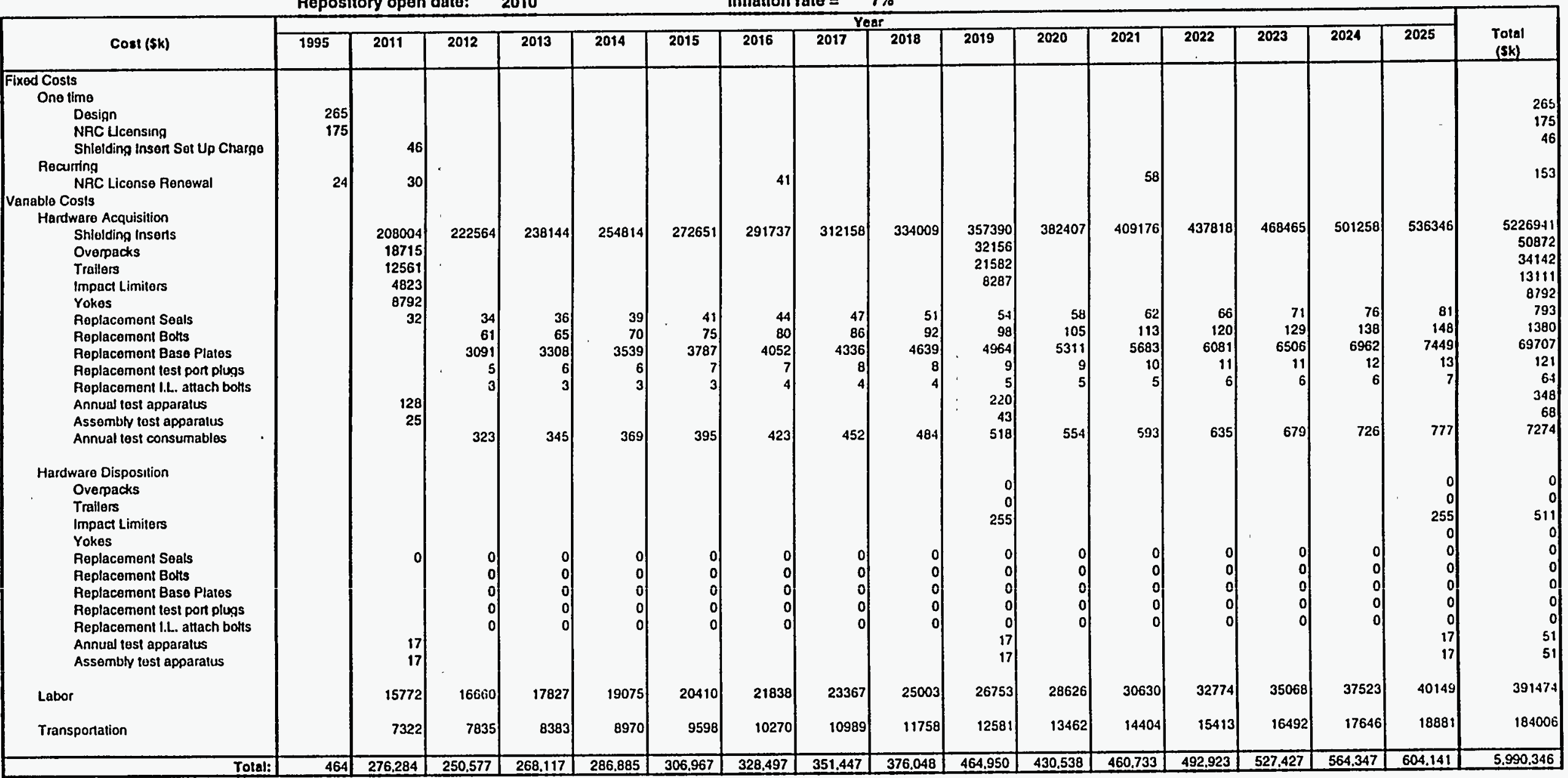




\section{Appendix B.2 Life Cycle Cost Calculations for 15 Year Shipping Campaign for Assumed Repository Availability Date of 2020}

Table B.2-1 Average Annual Inflation Rate $=3 \%$

Table B.2-2 Average Annual Inflation Rate $=5 \%$

Table B.2-3 Average Annual Inflation Rate $=7 \%$ 


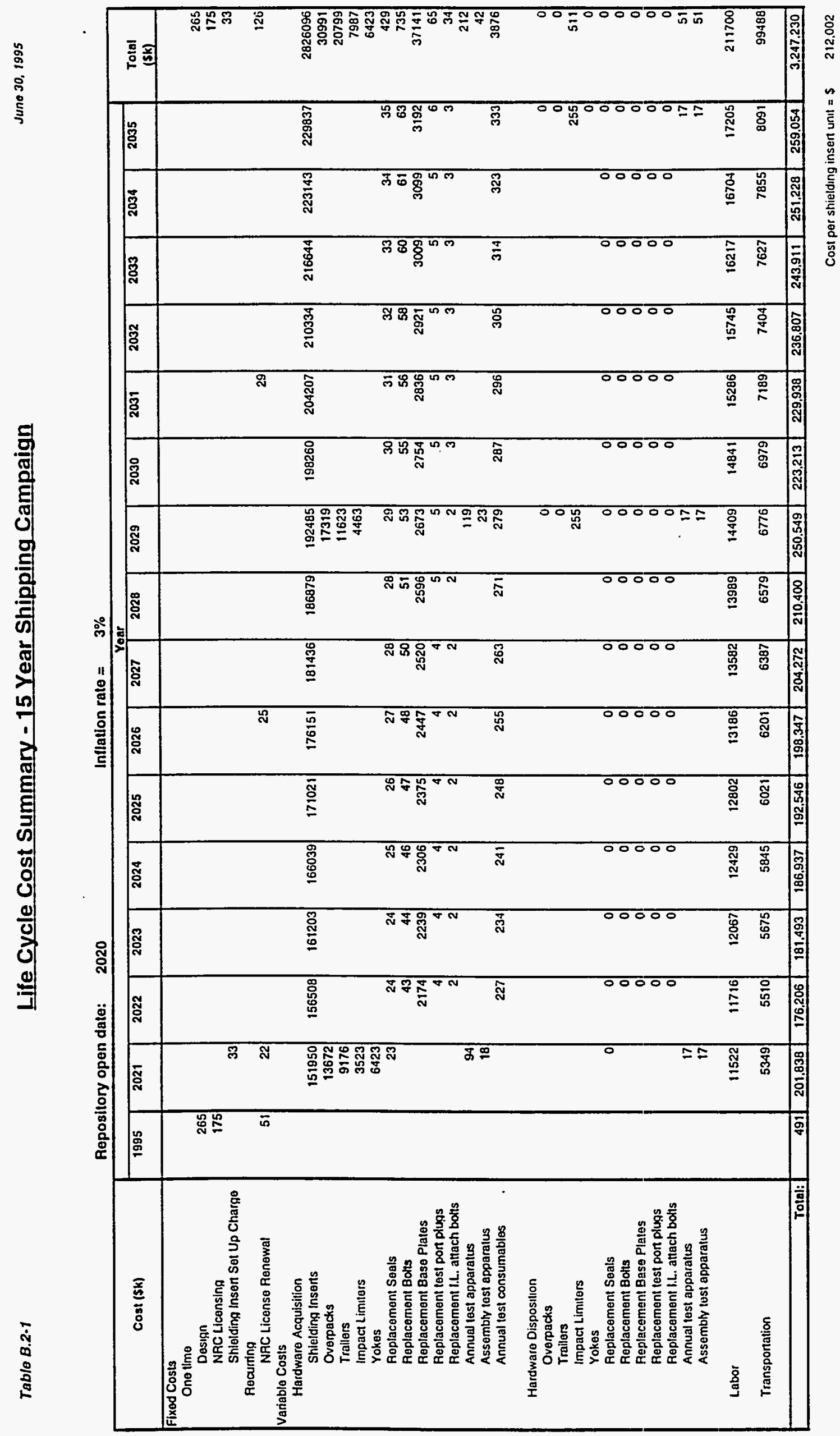




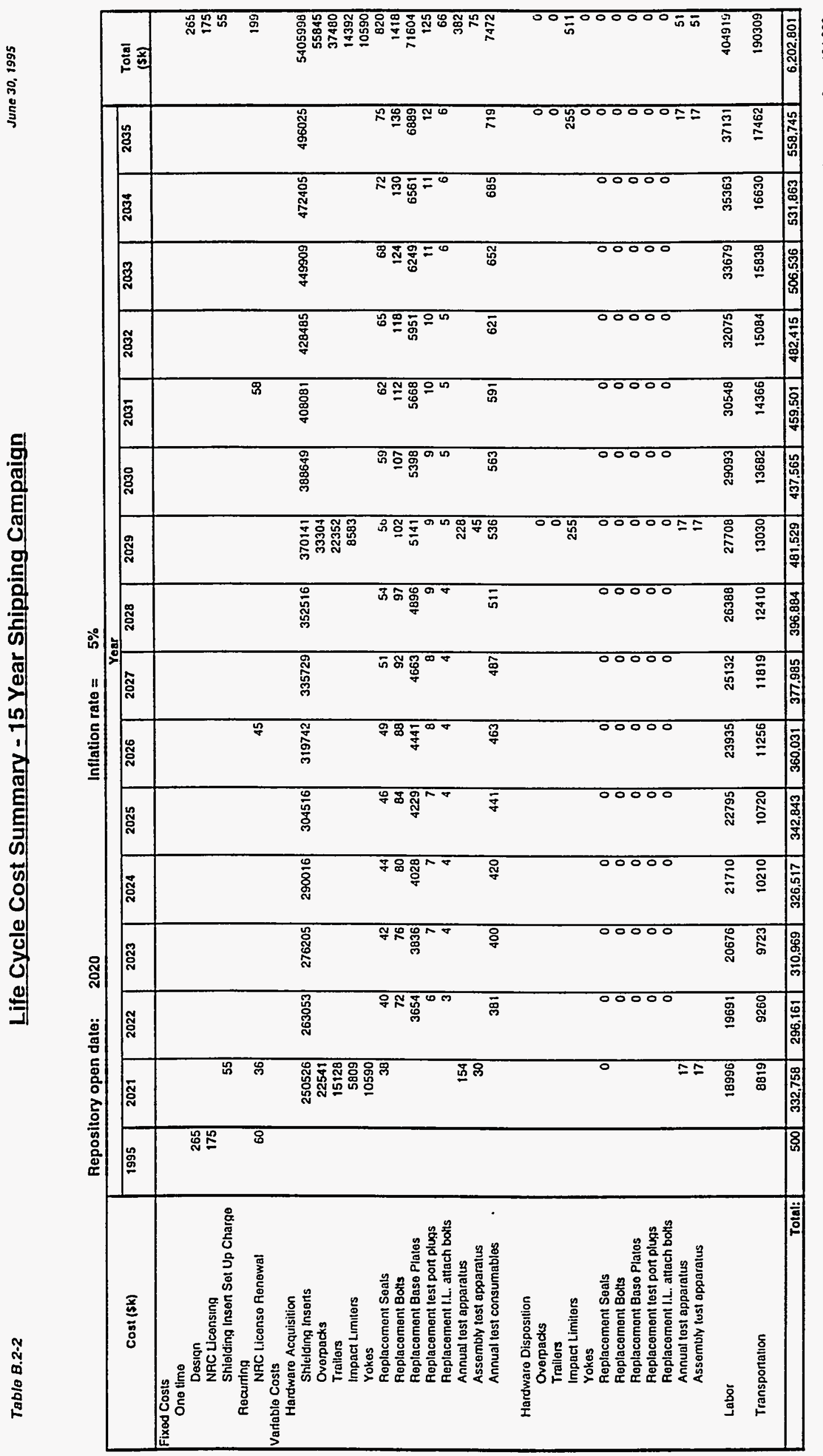




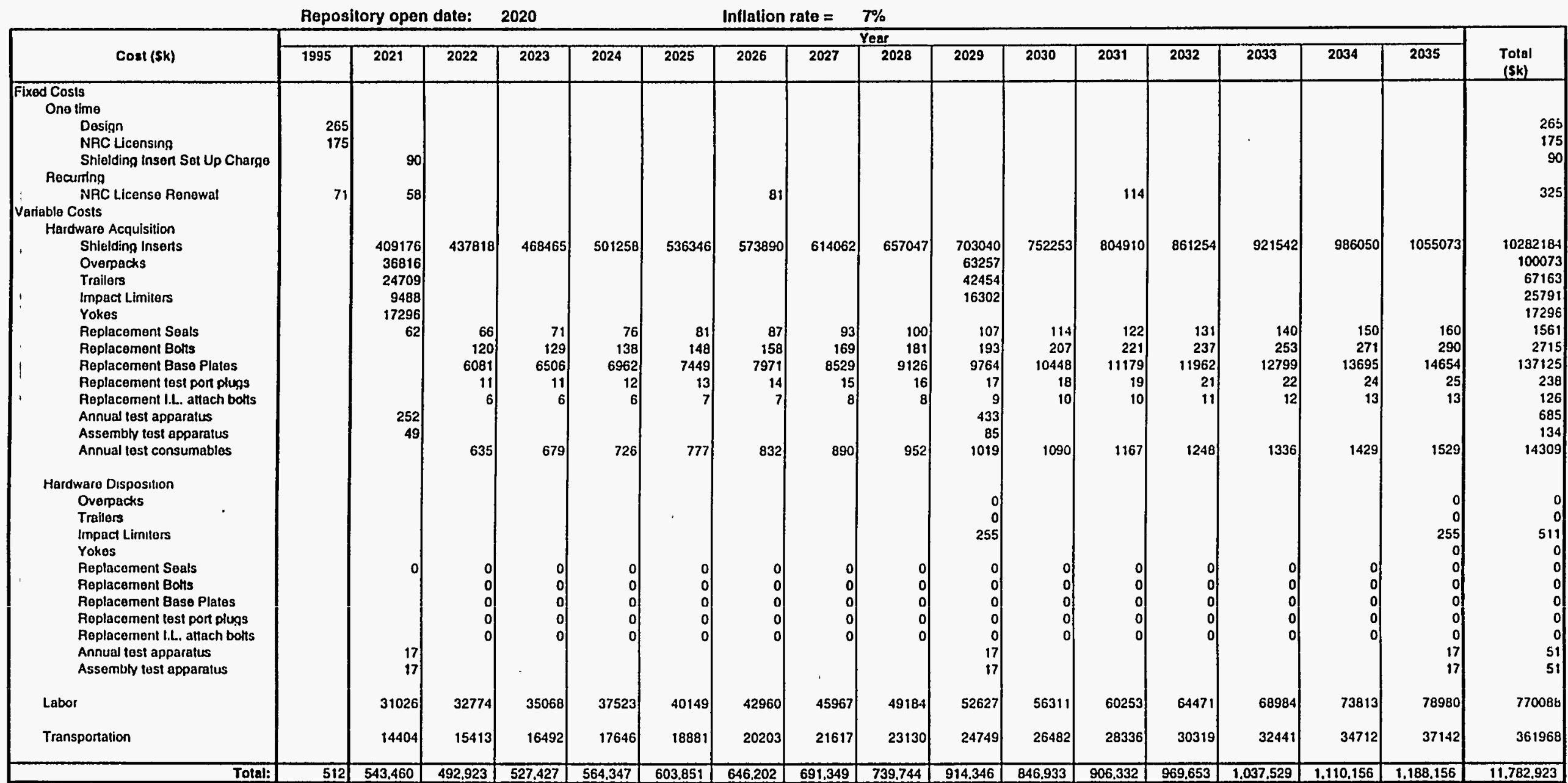


VHLW Cask

June 30. 1995

Life Cycle Cost Report

Revision

Appendix C

Life Cycle Cost Calculations

for 20 Year Shipping Campaign

C. 0 
Appendix C.1 Life Cycle Cost Calculations for 20 Year Shipping Campaign for Assumed Repository Availability Date of 2010

Table C.1-1 Average Annual Inflation Rate $=0 \%$

Table C.1-2 Average Annual Inflation Rate $=3 \%$

Table C.1-3 Average Annual Inflation Rate $=5 \%$

Table C.1-4 Average Annual Inflation Rate $=7 \%$ 


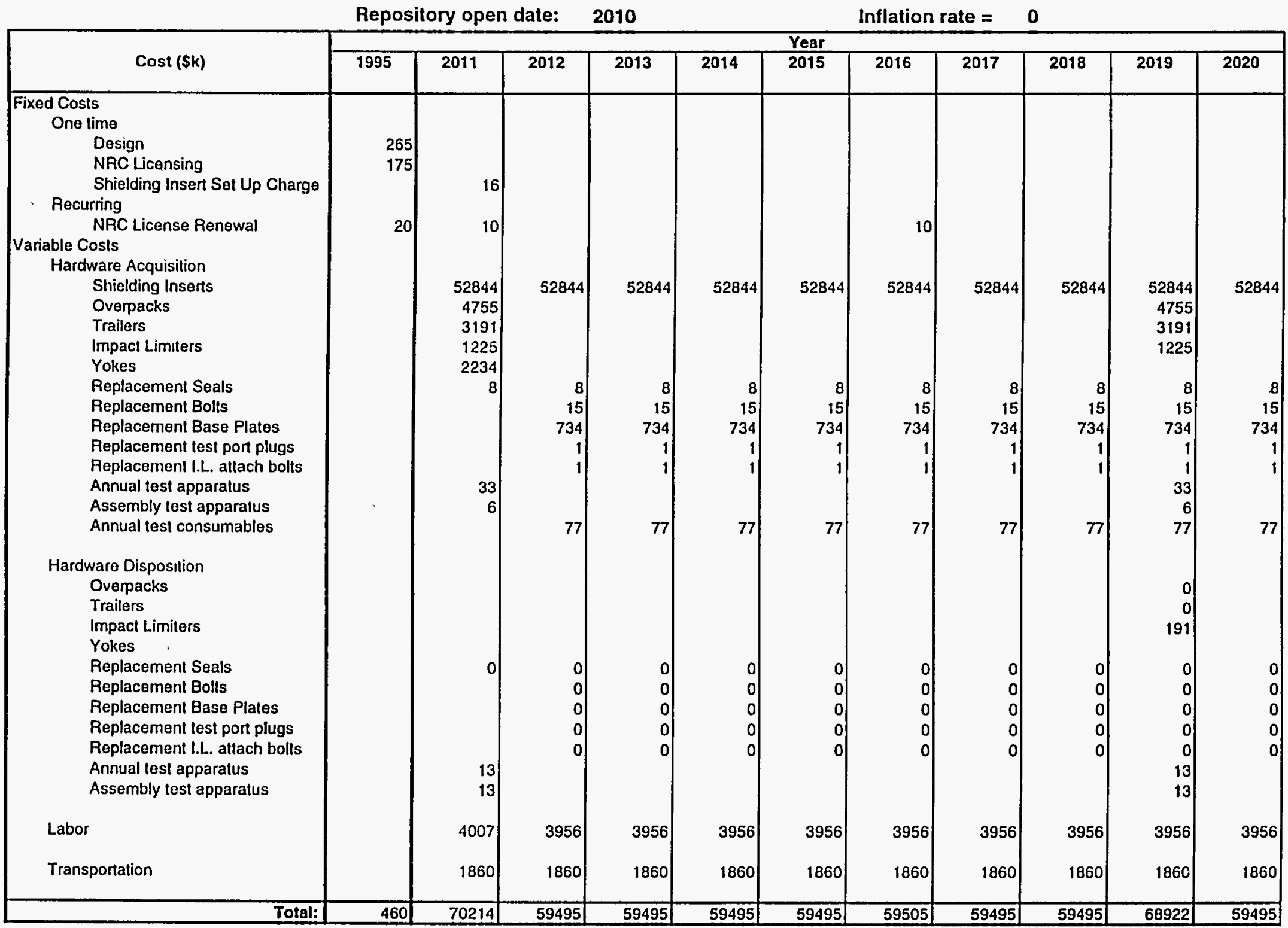




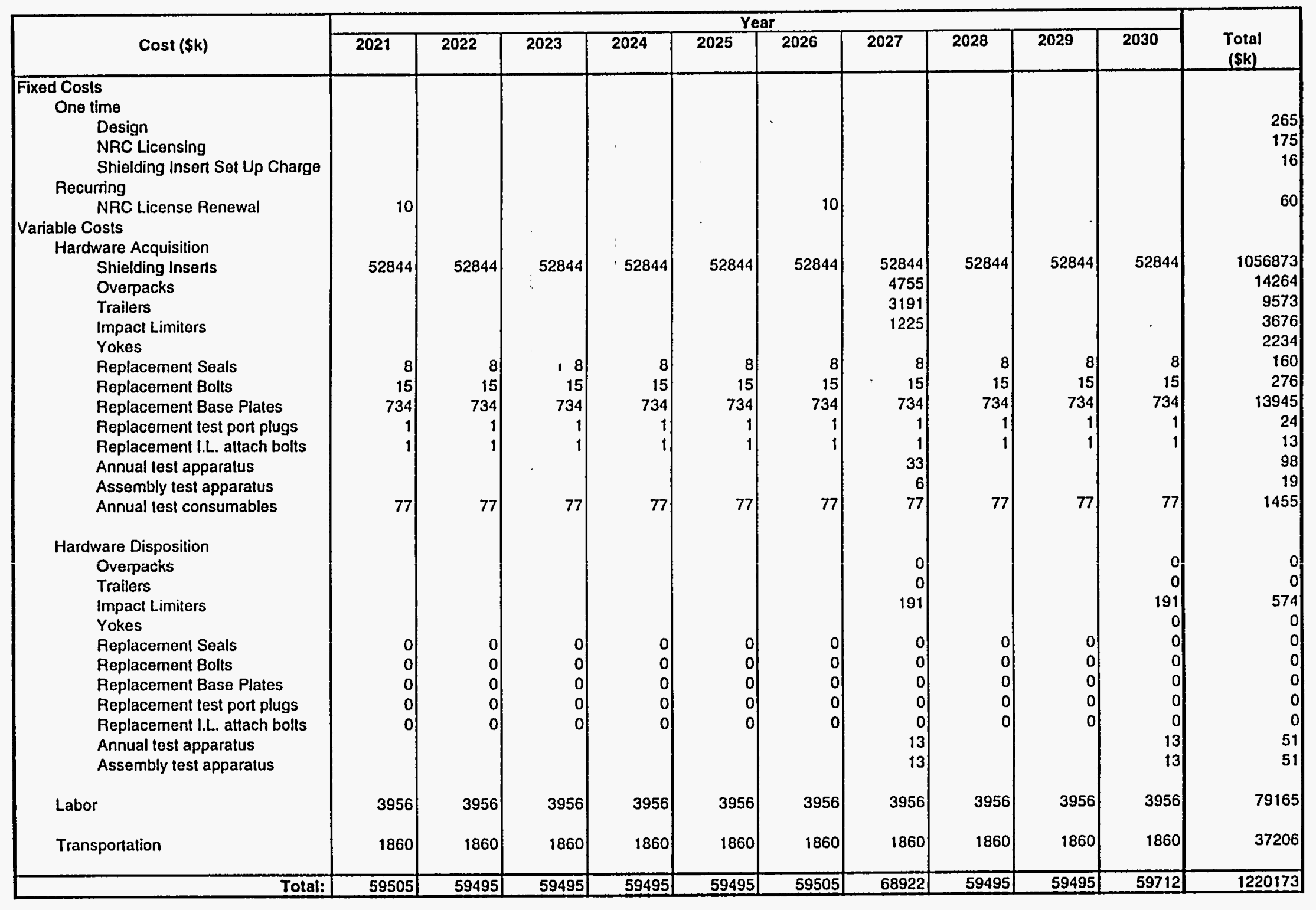


Repository open date: 2010

Inflation rate $=3 \%$

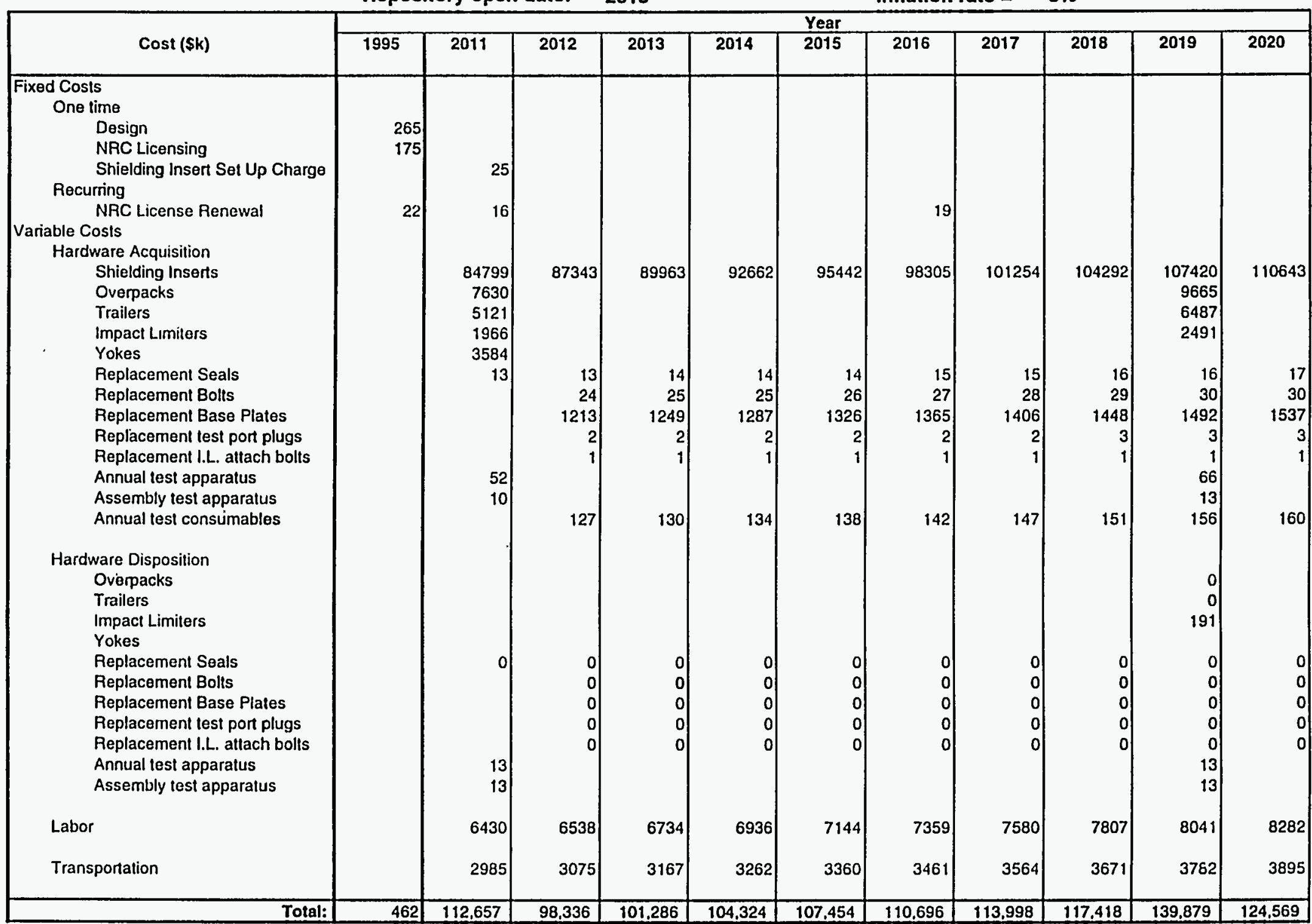




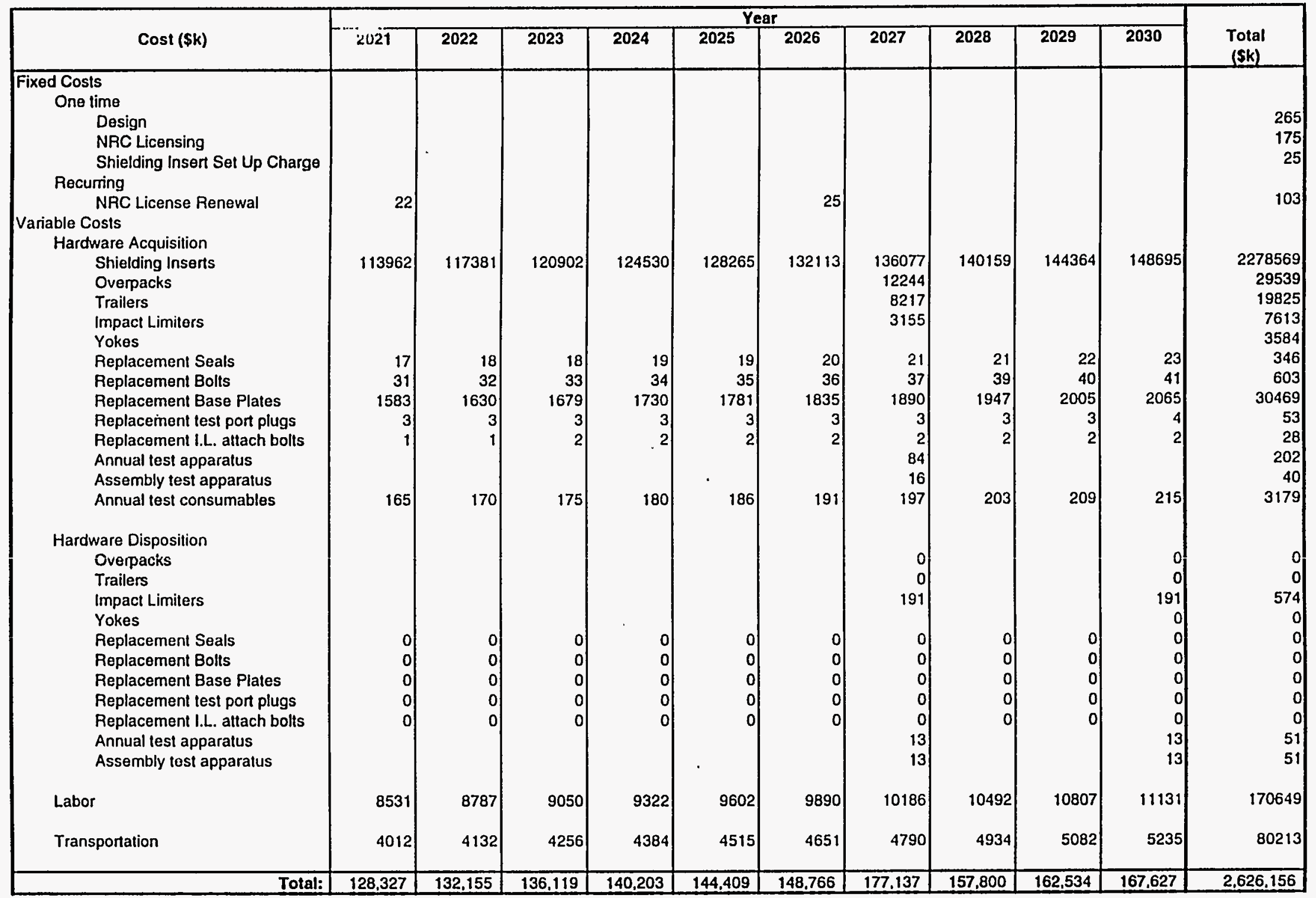


Repository open date: 2010

Inflation rate $=\quad 5 \%$

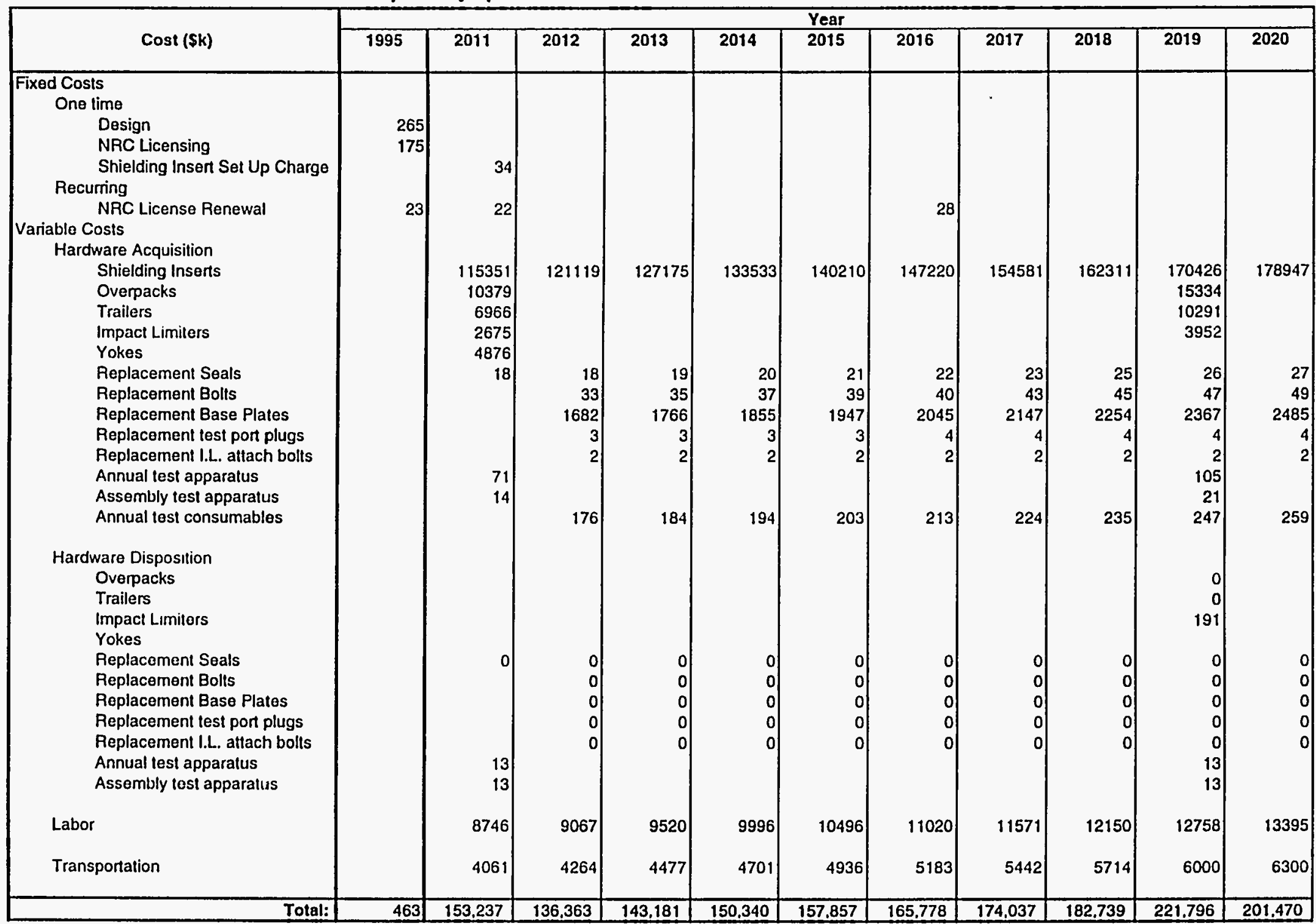




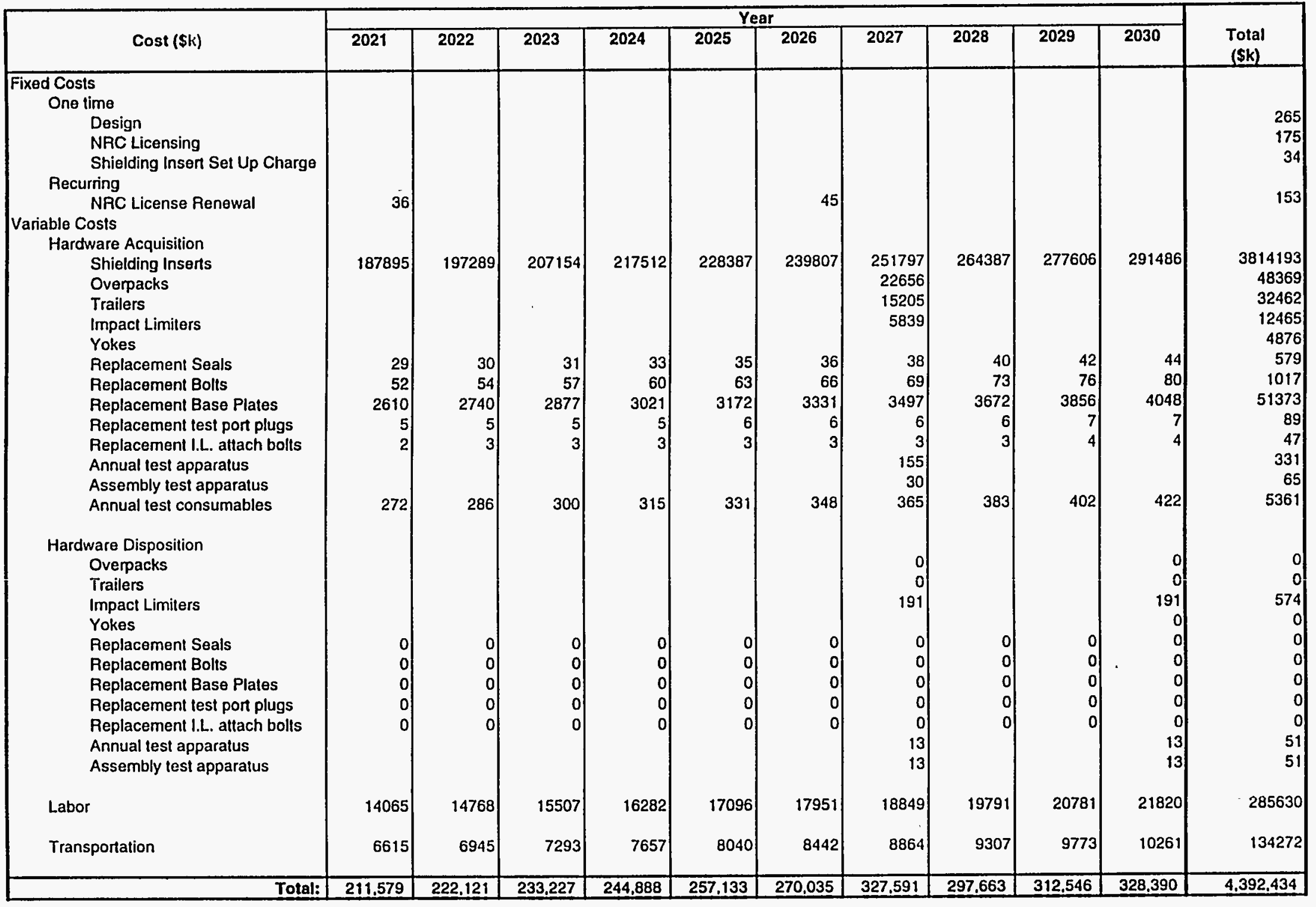


Repository open date: 2010

Inflation rate $=\quad 7 \%$

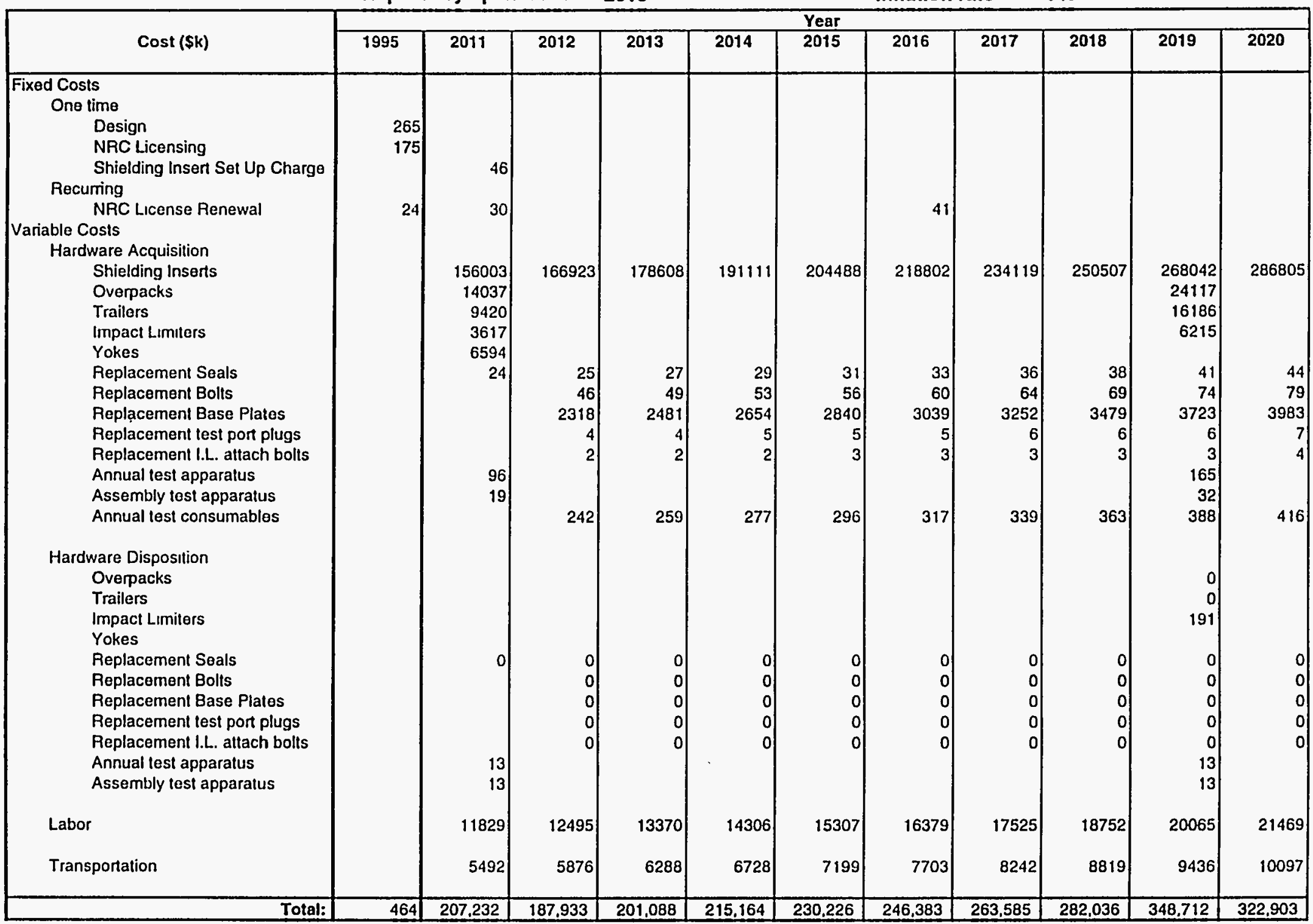




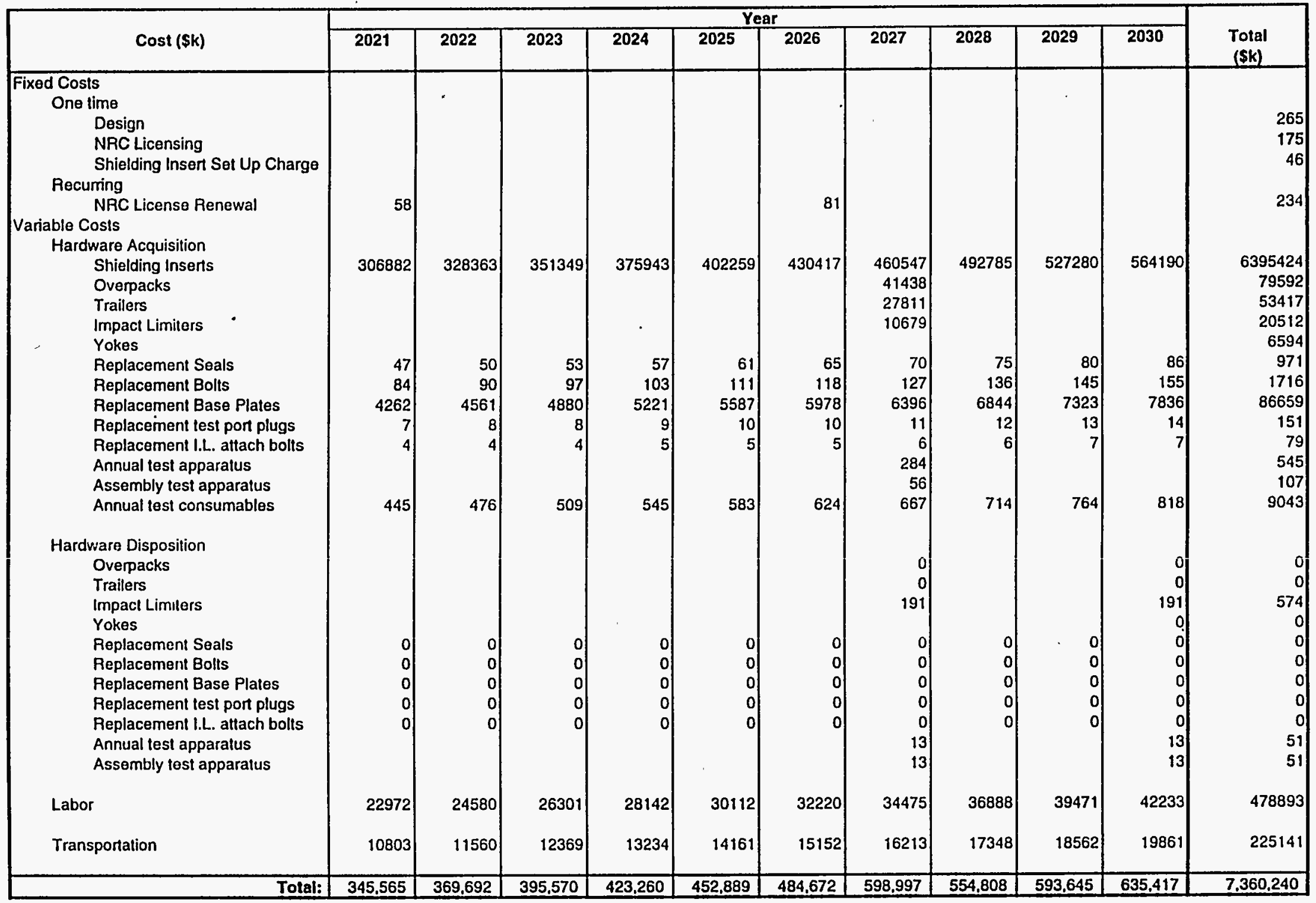




\section{Appendix C.2 Life Cycle Cost Calculations for 20 Year Shipping Campaign for Assumed Repository Availability Date of 2020}

Table C.2-1 Average Annual Inflation Rate $=3 \%$

Table C.2-2 Average Annual Inflation Rate $=5 \%$

Table C.2-3 Average Annual Inflation Rate $=7 \%$ 


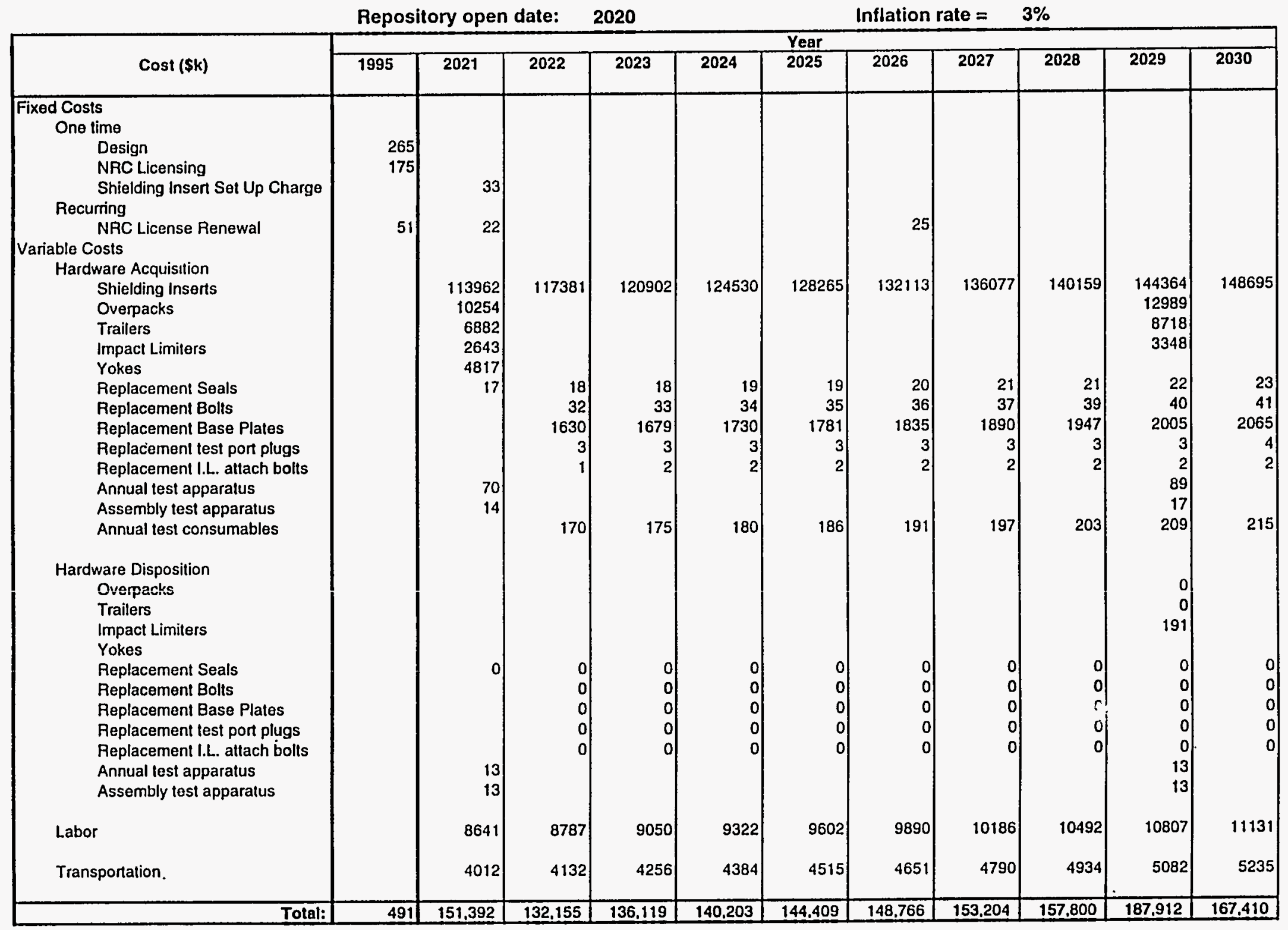




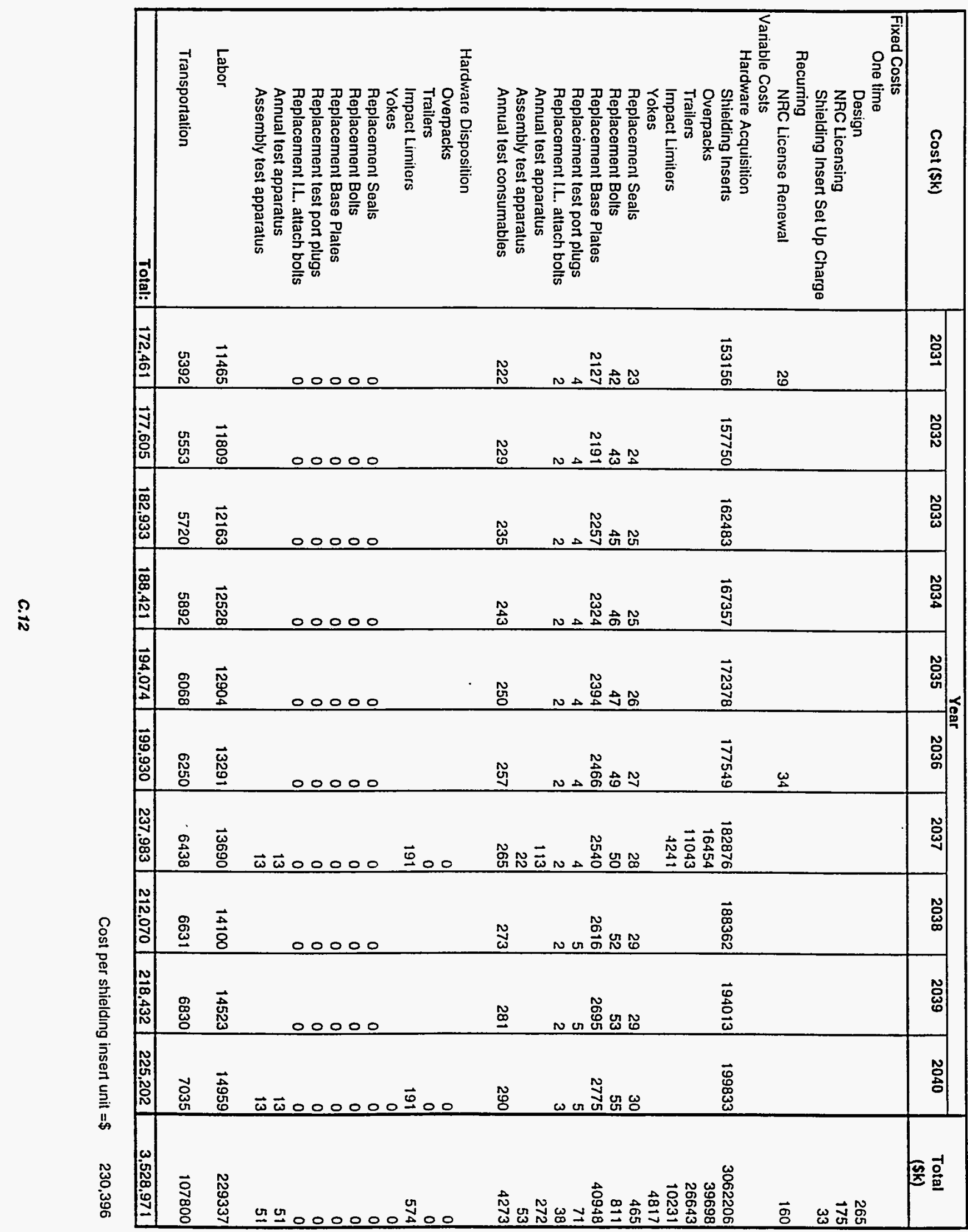

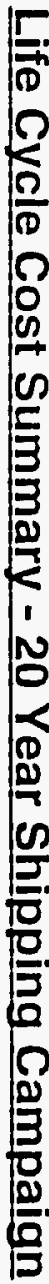




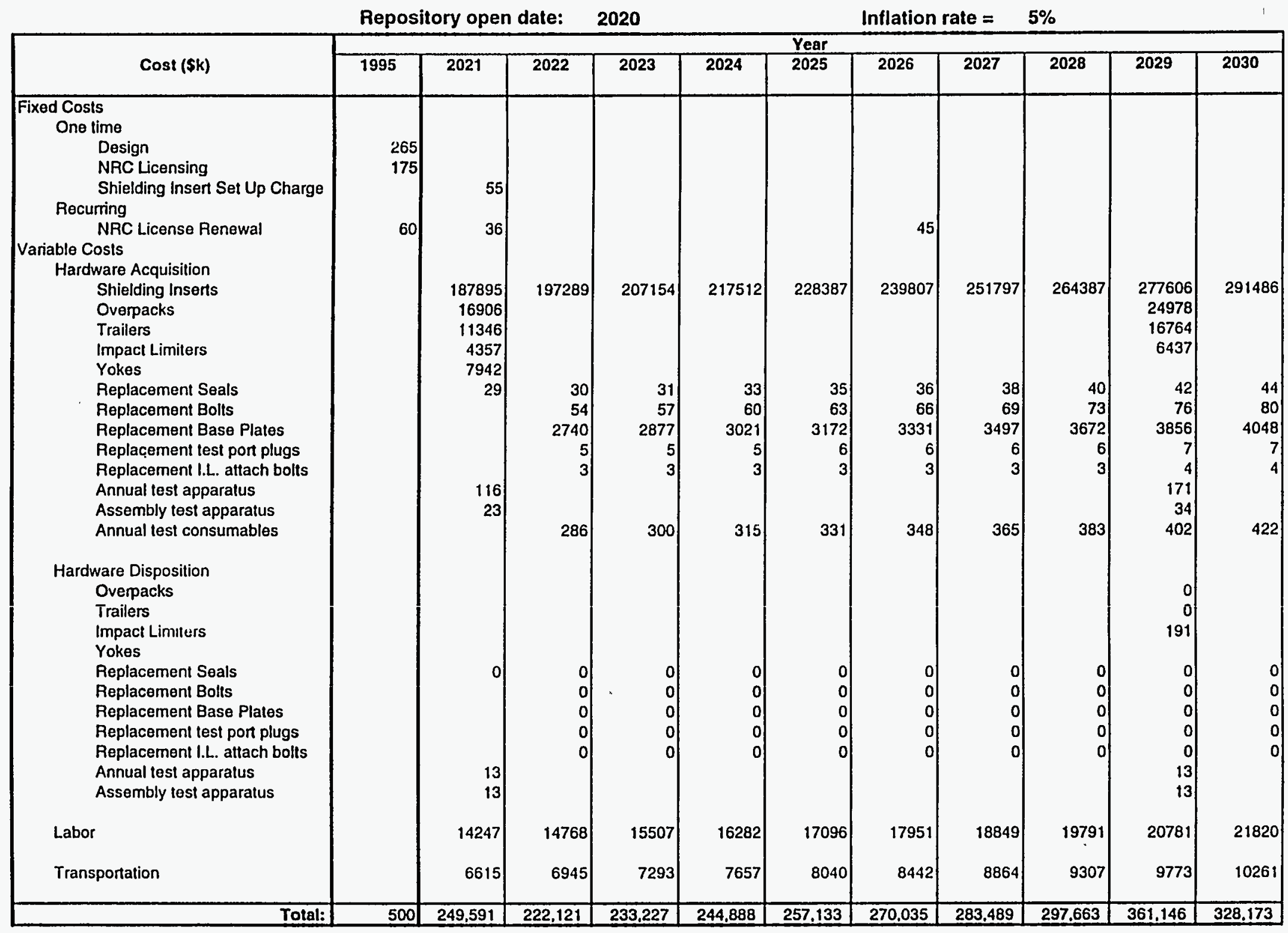




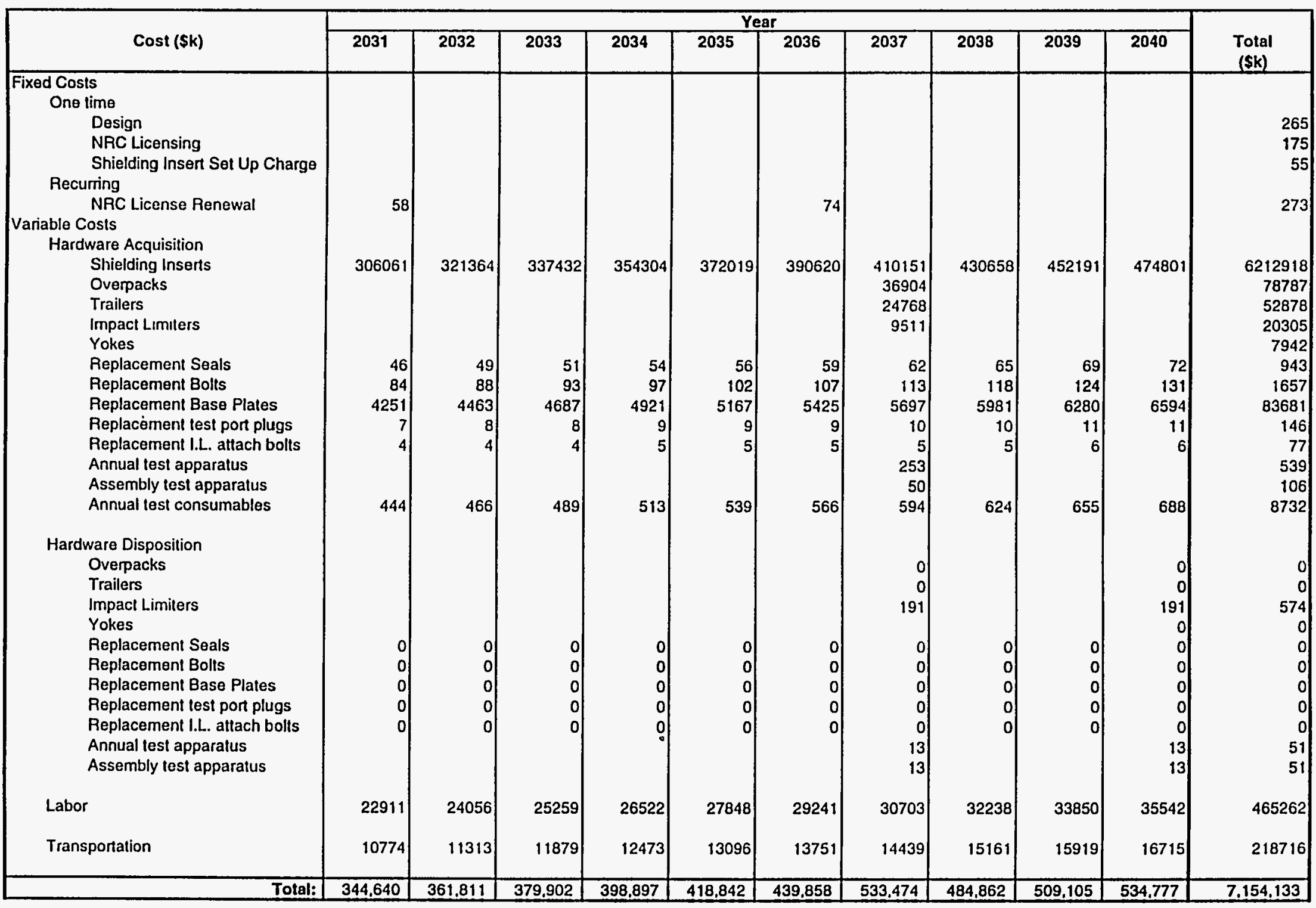


Repository open date: 2020

Inflation rate $=\quad 7 \%$

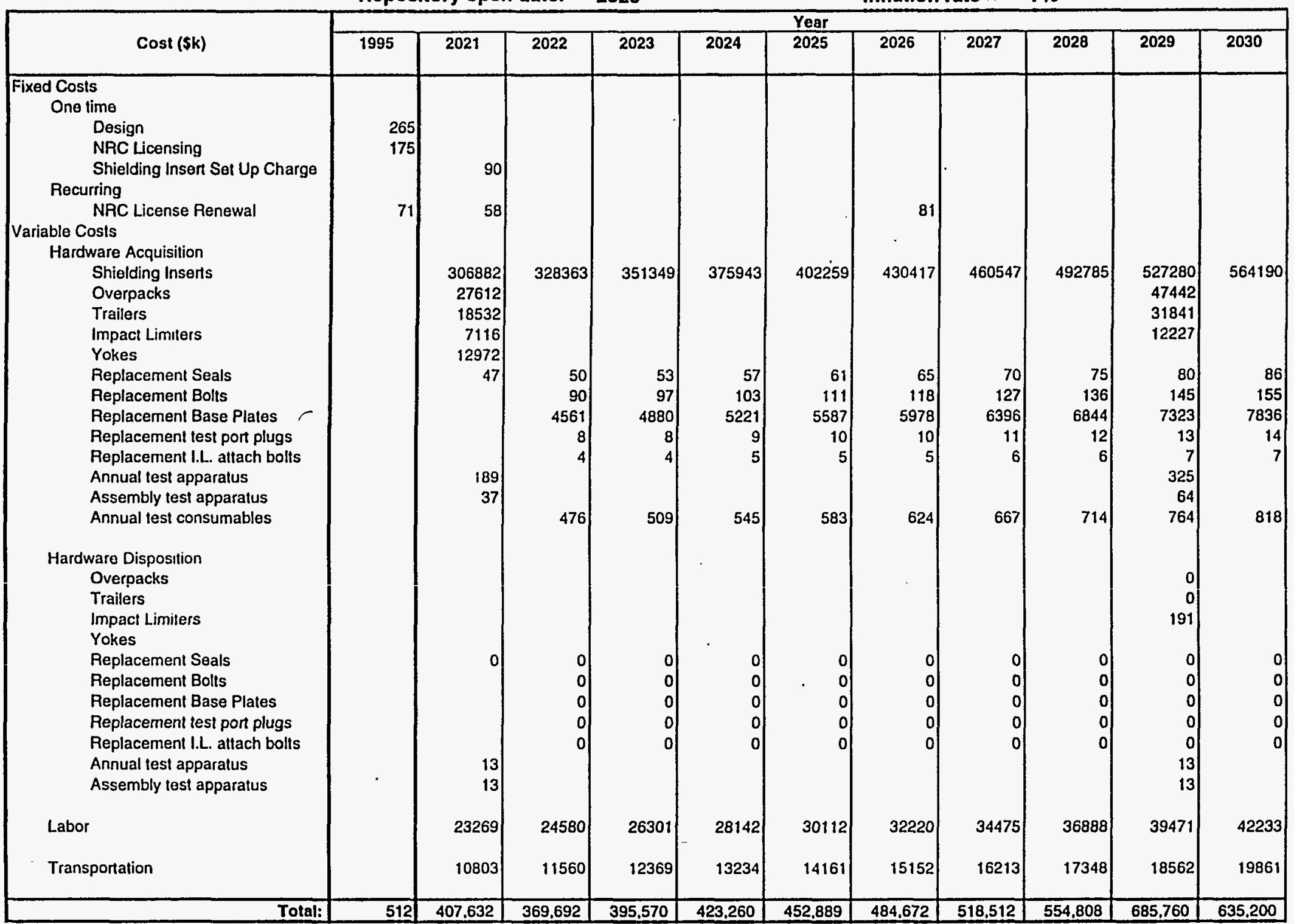




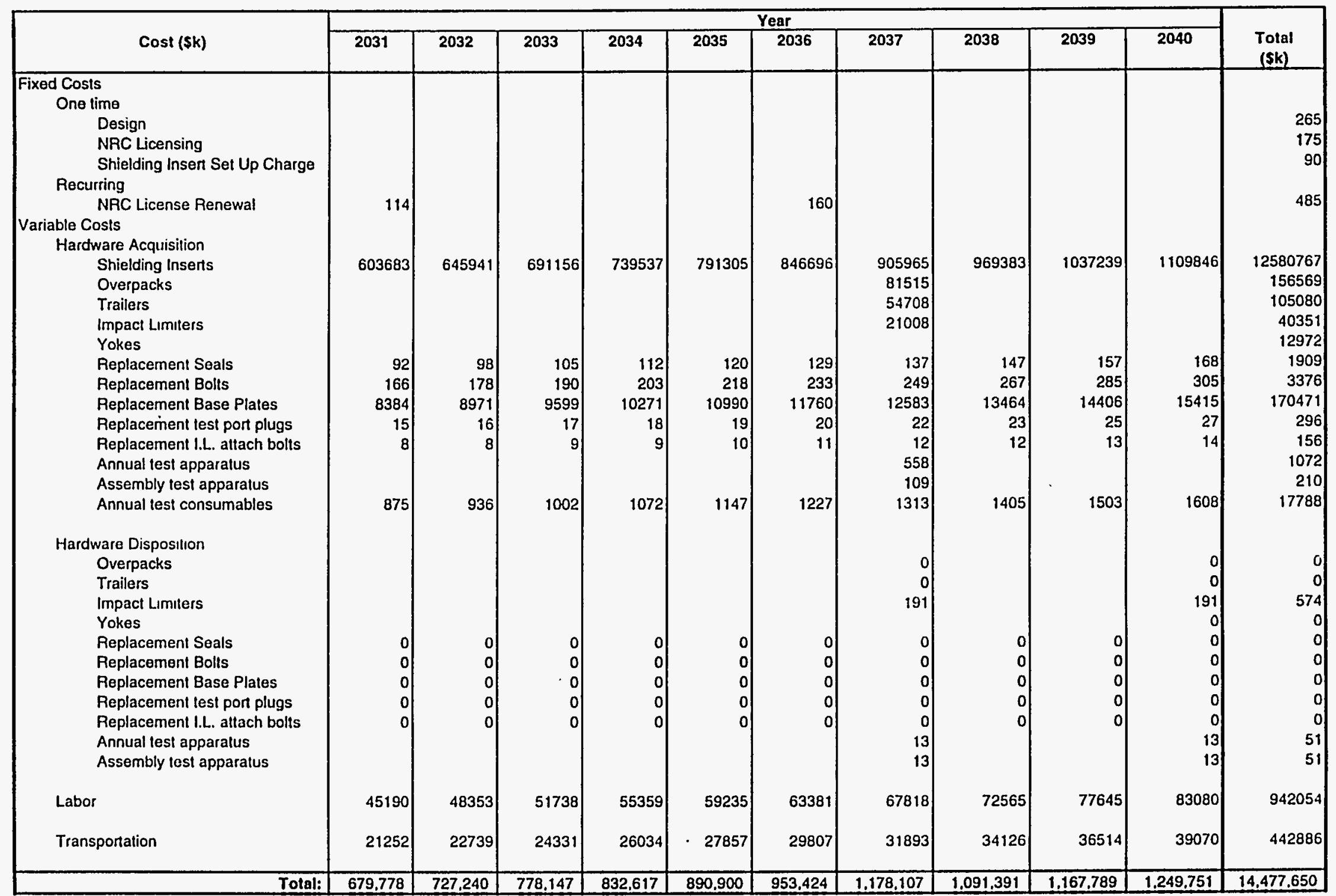




\section{Appendix D}

\section{Life Cycle Cost Calculations \\ for 25 Year Shipping Campaign}




\section{Appendix D.1 Life Cycle Cost Calculations for 25 Year Shipping} Campaign for Assumed Repository Availability Date of 2010

Table D.1-1 Average Annual Inflation Rate $=0 \%$

Table D.1-2 Average Annual Inflation Rate $=3 \%$

Table D.1-3 Average Annual Inflation Rate $=5 \%$

Table D.1-4 Average Annual Inflation Rate $=7 \%$ 


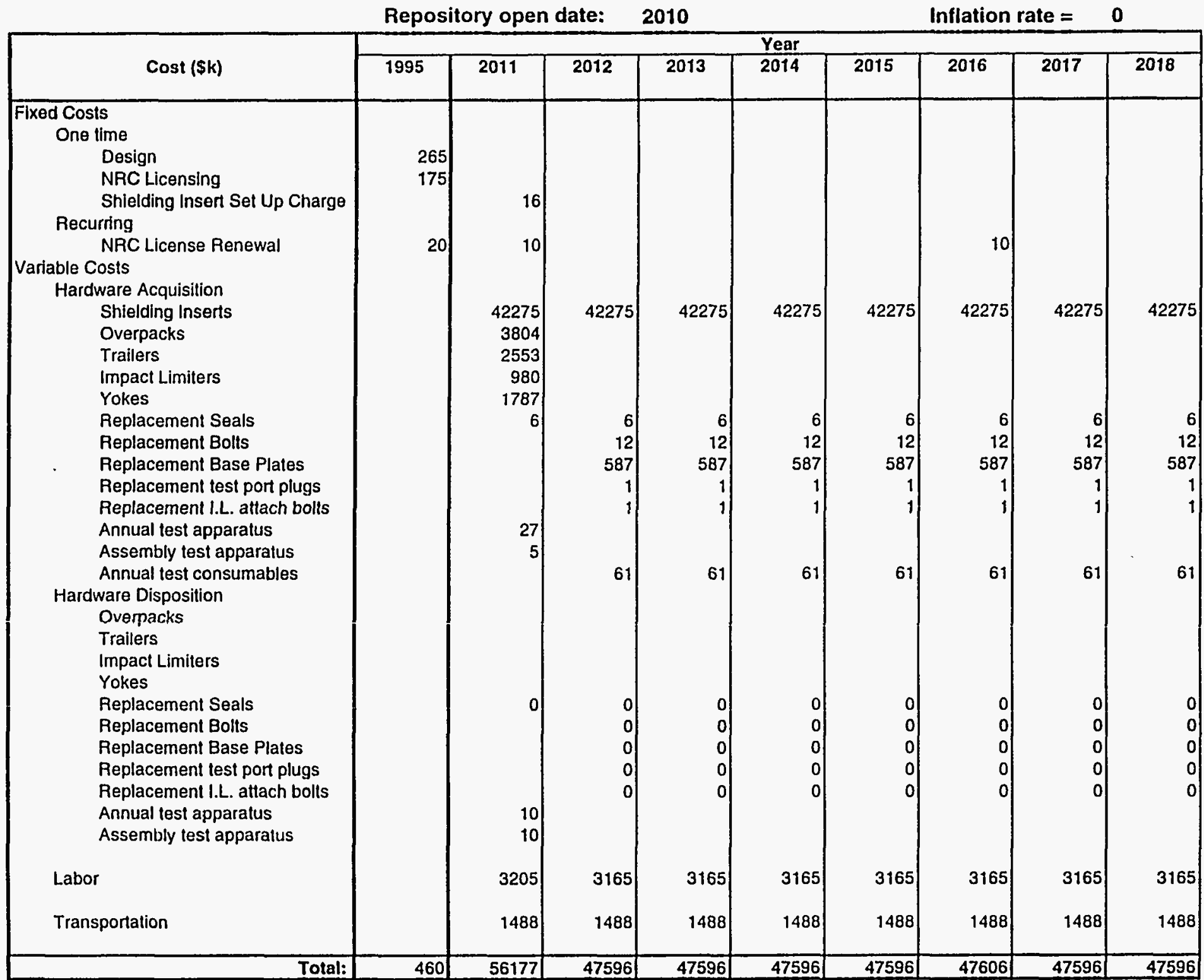




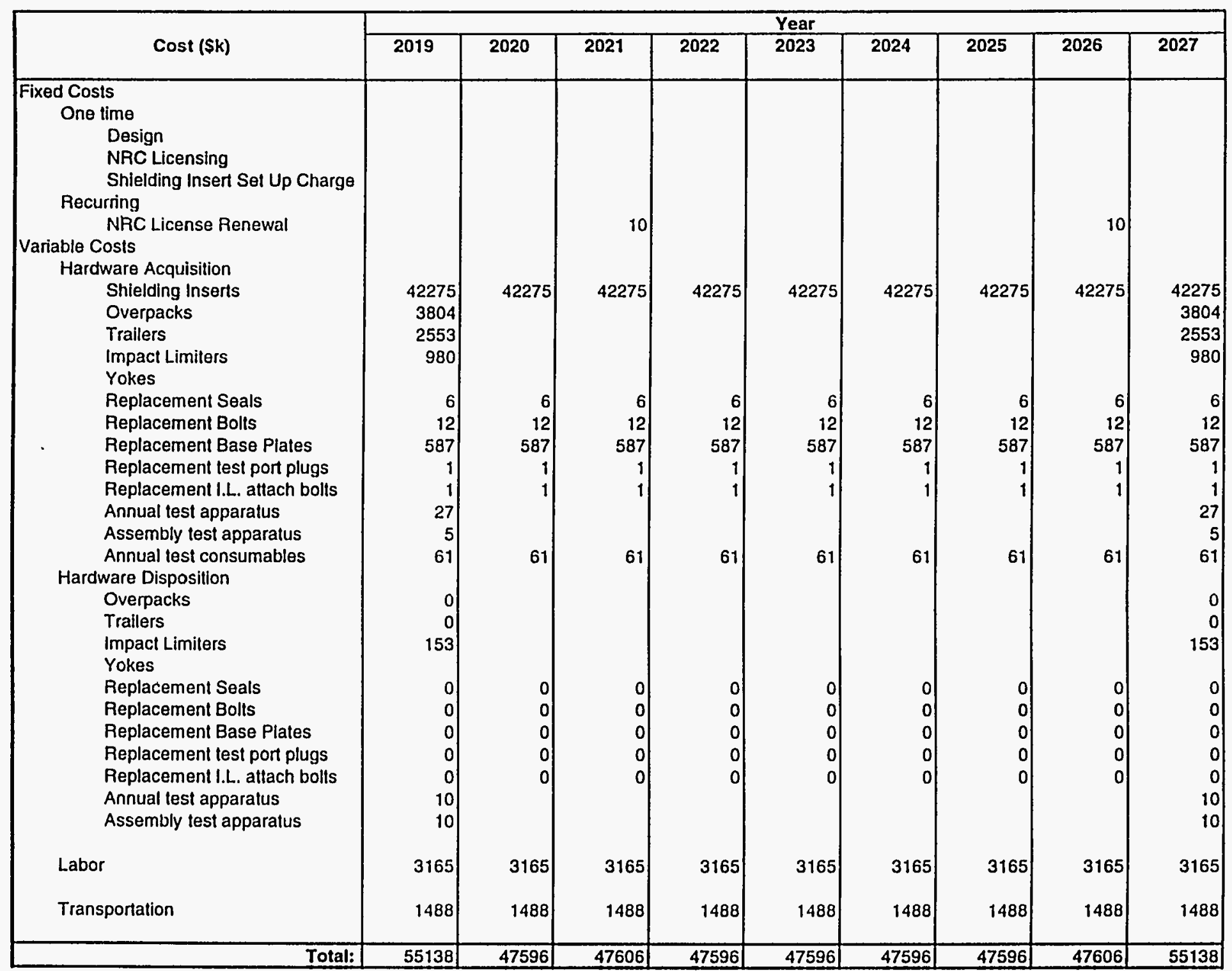




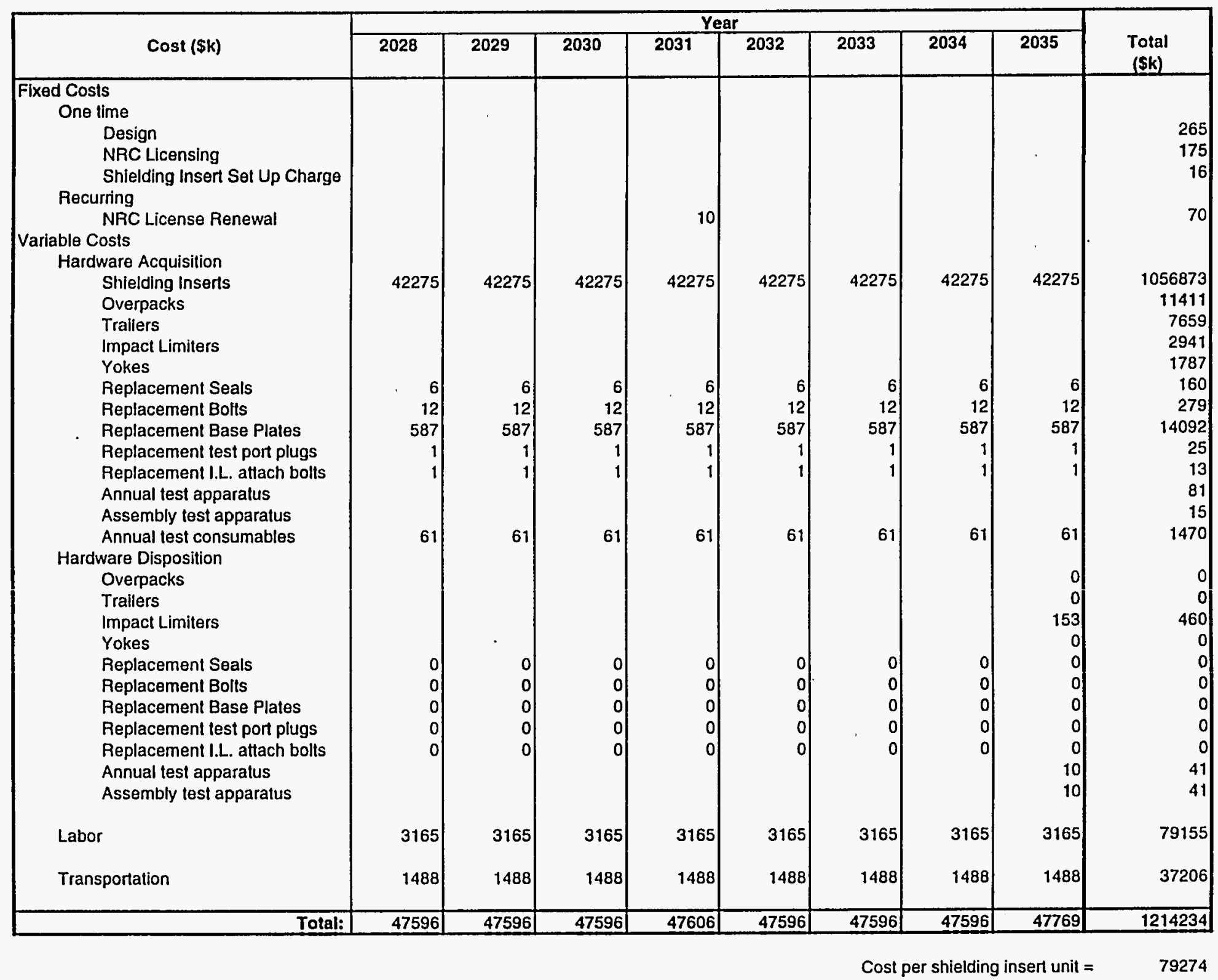


Repository open date: $\quad 2010$

Inflation rate $=3 \%$

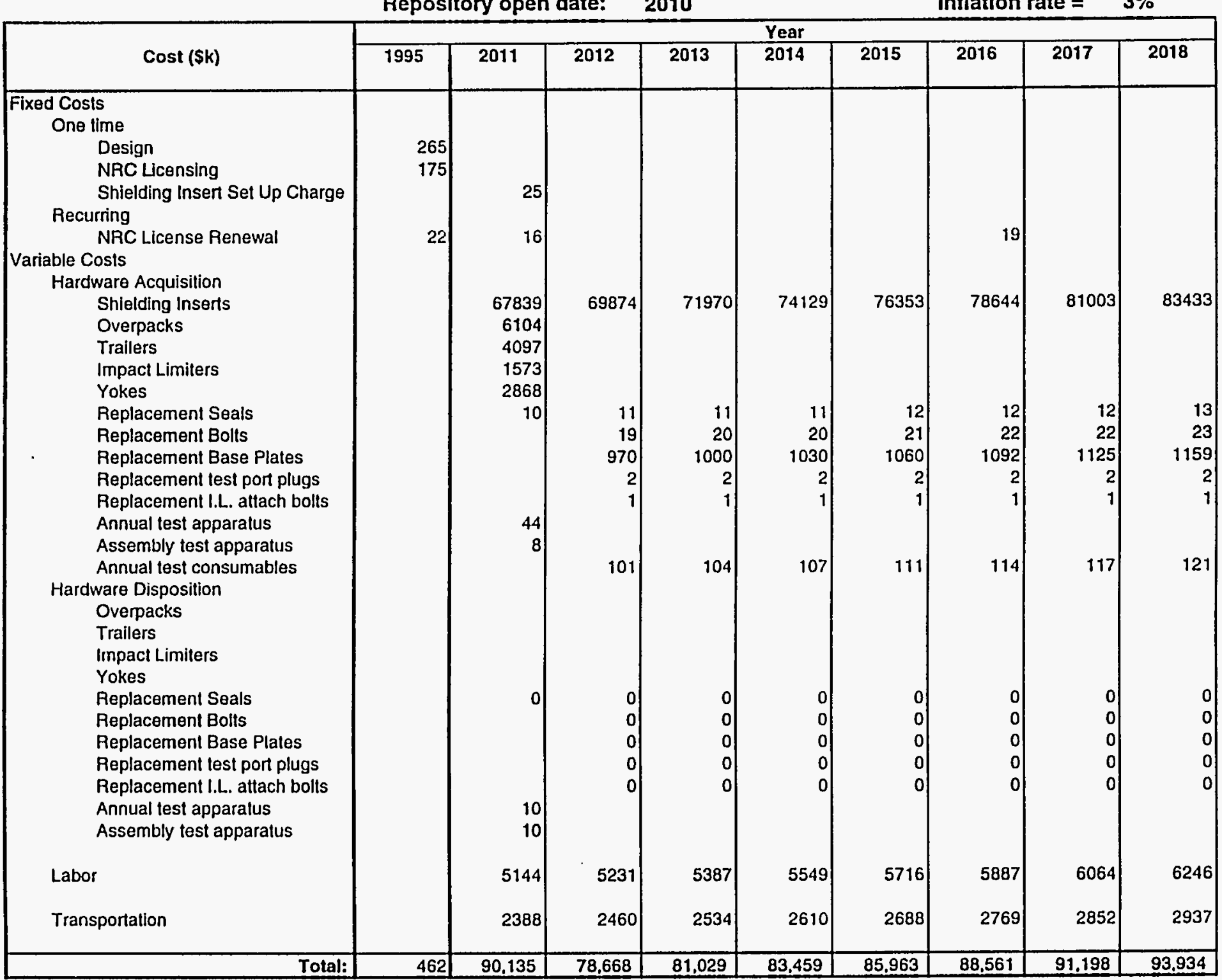




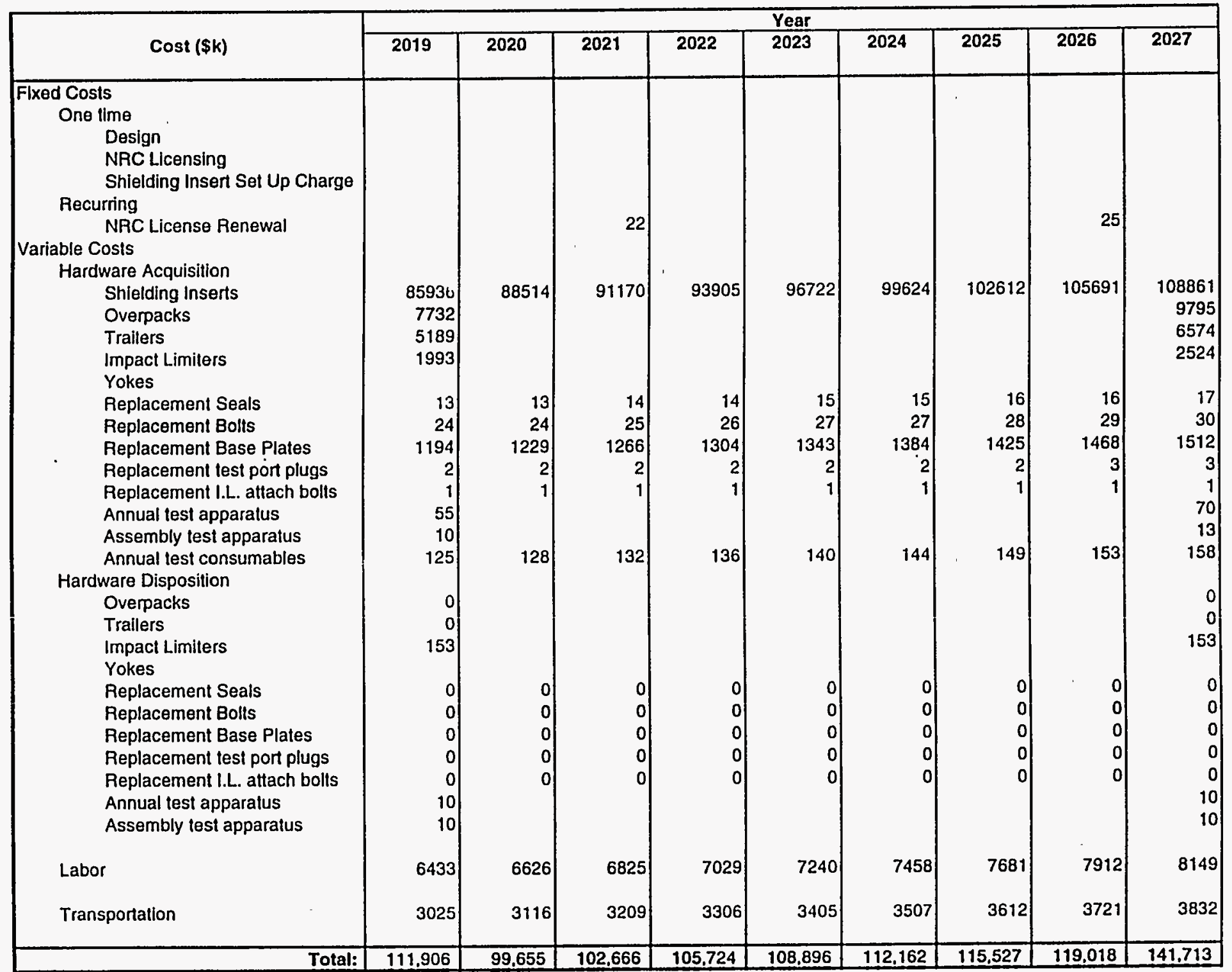




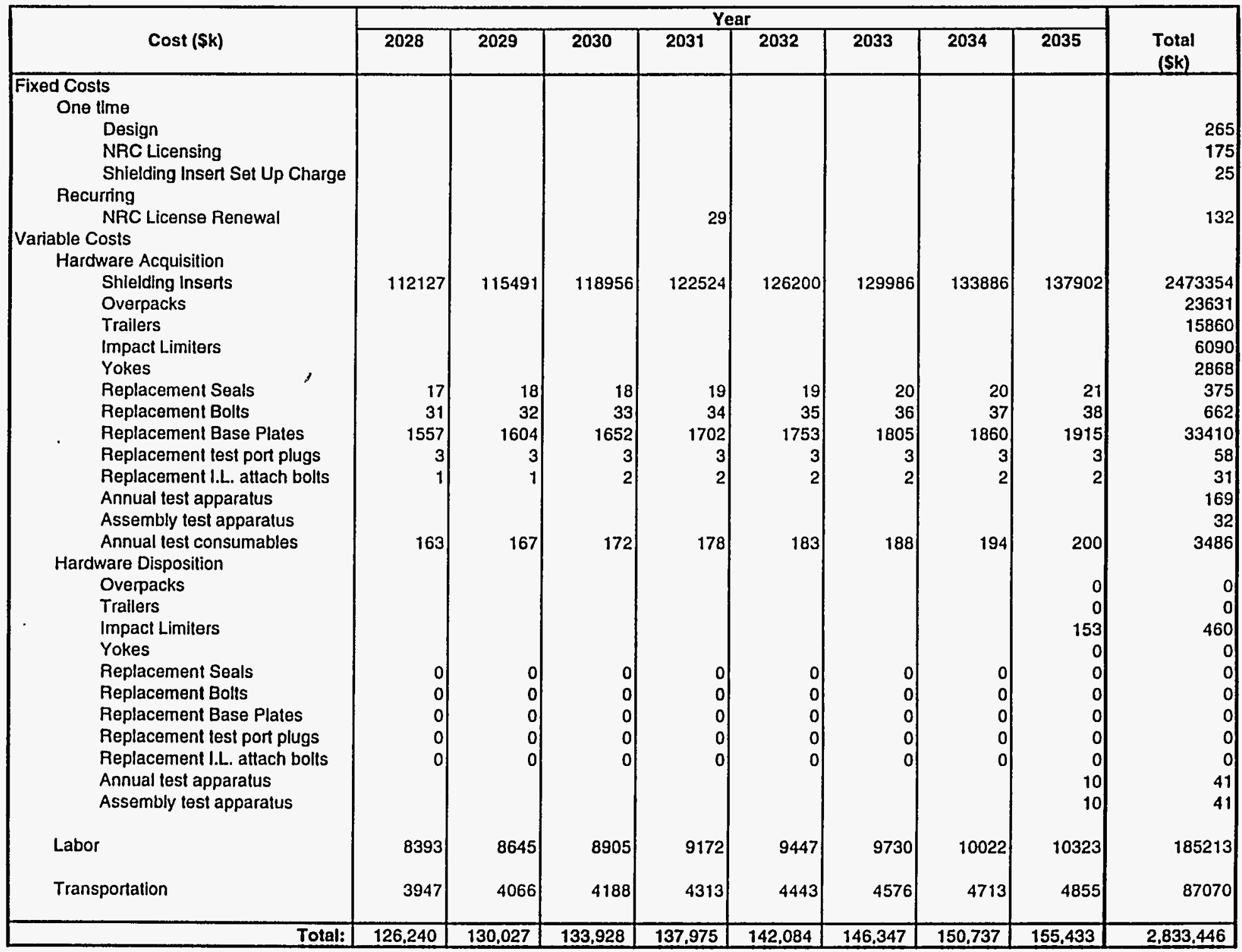




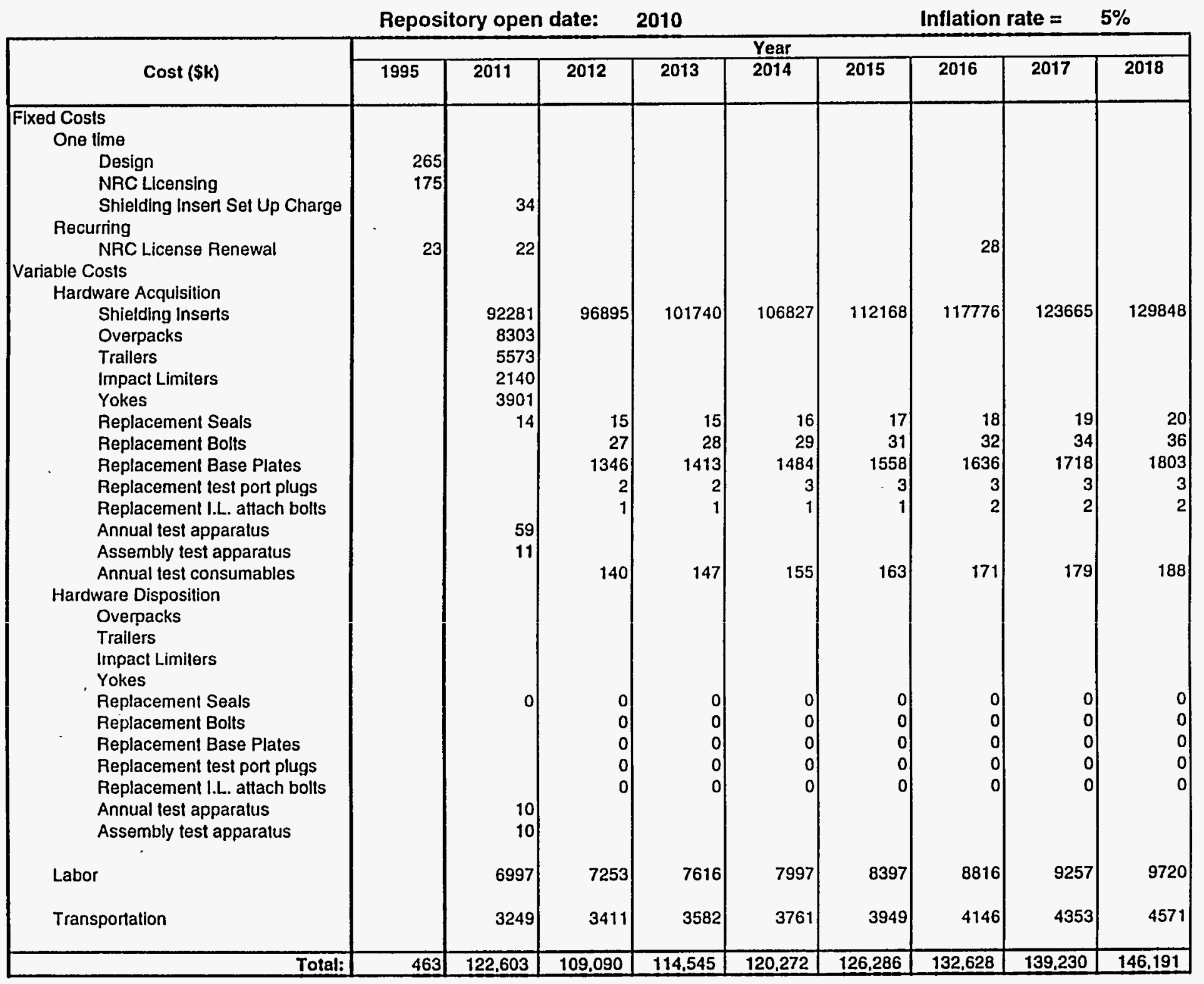




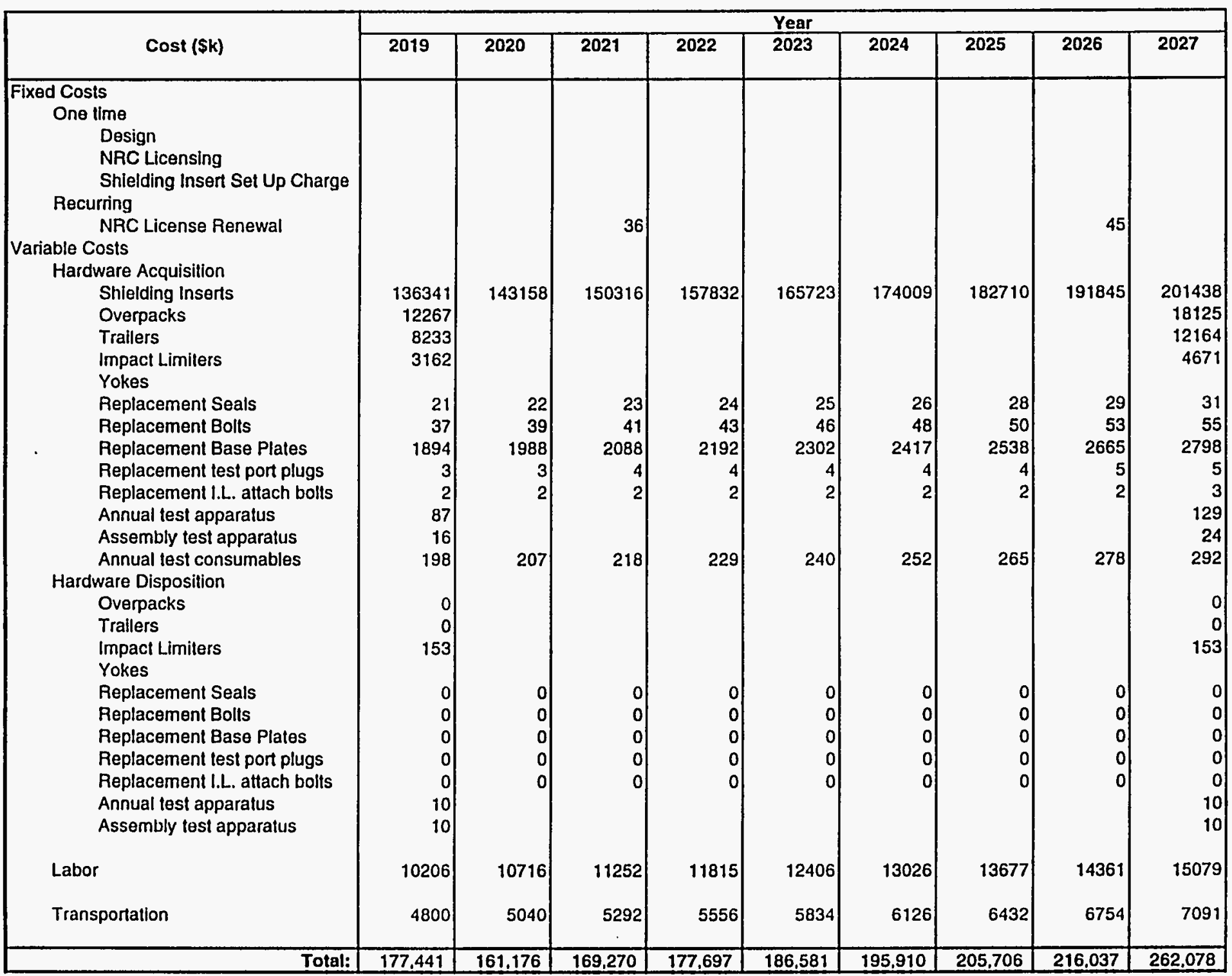




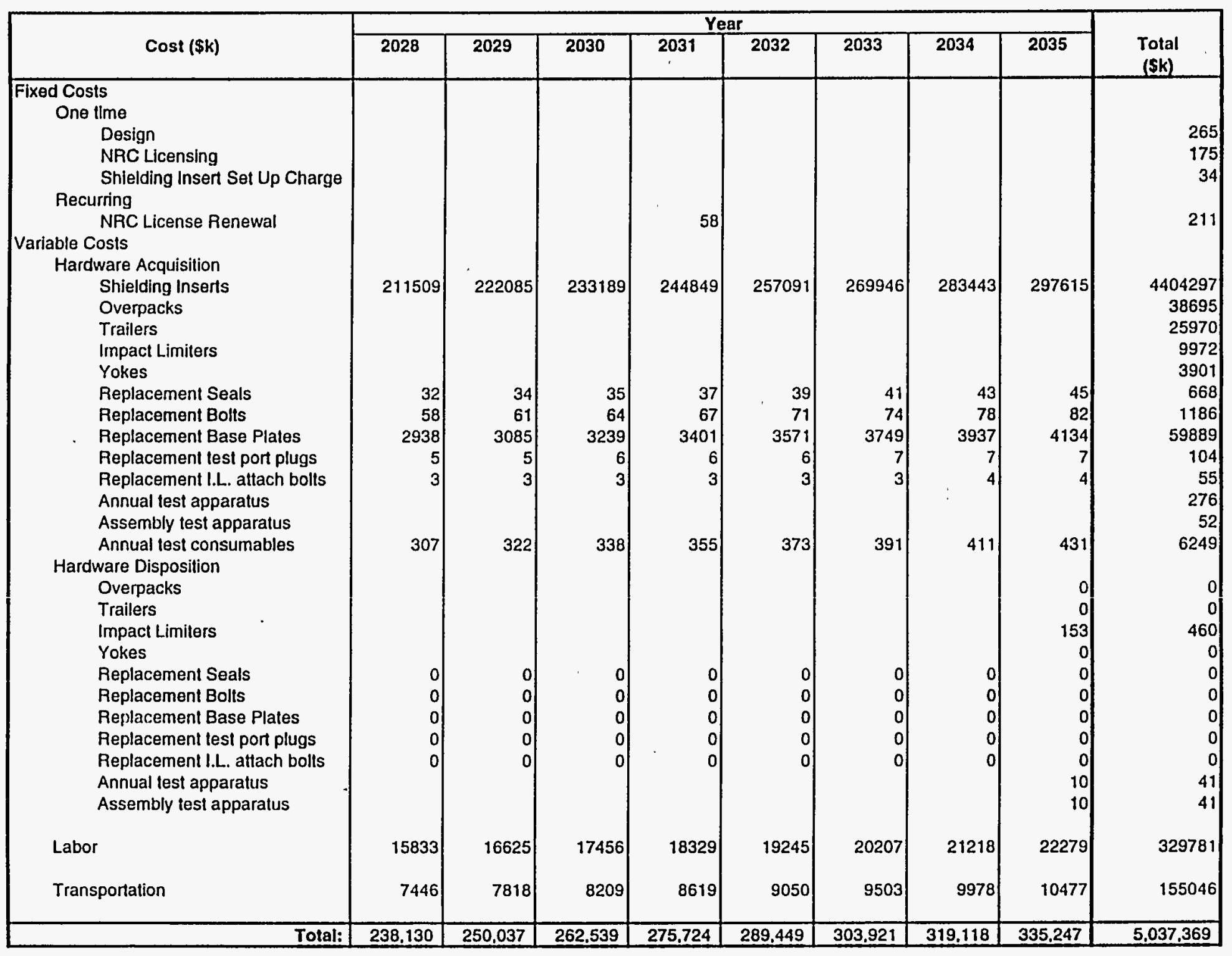


Repository open date: $\quad 2010$

Inflation rate $=\quad 7 \%$

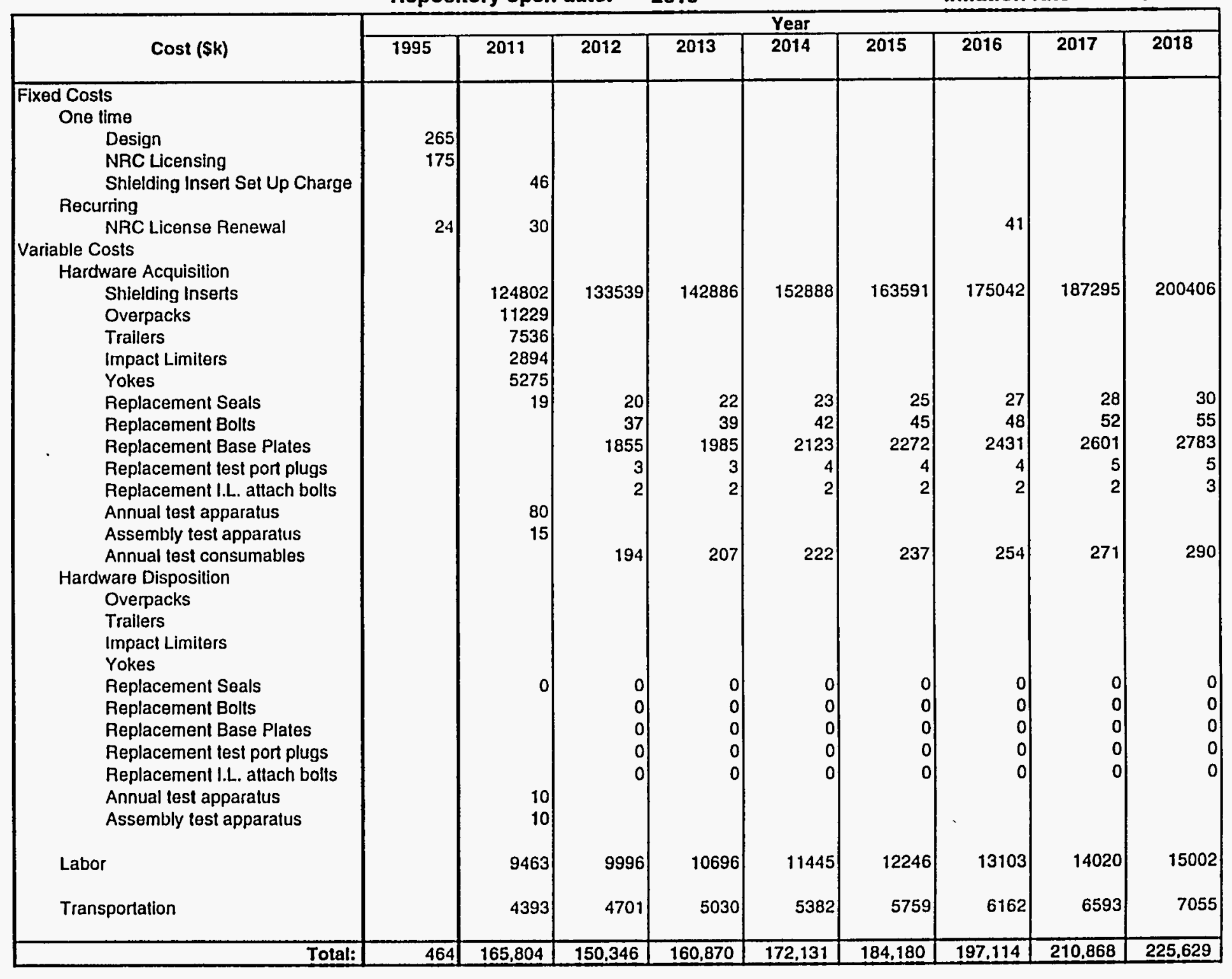




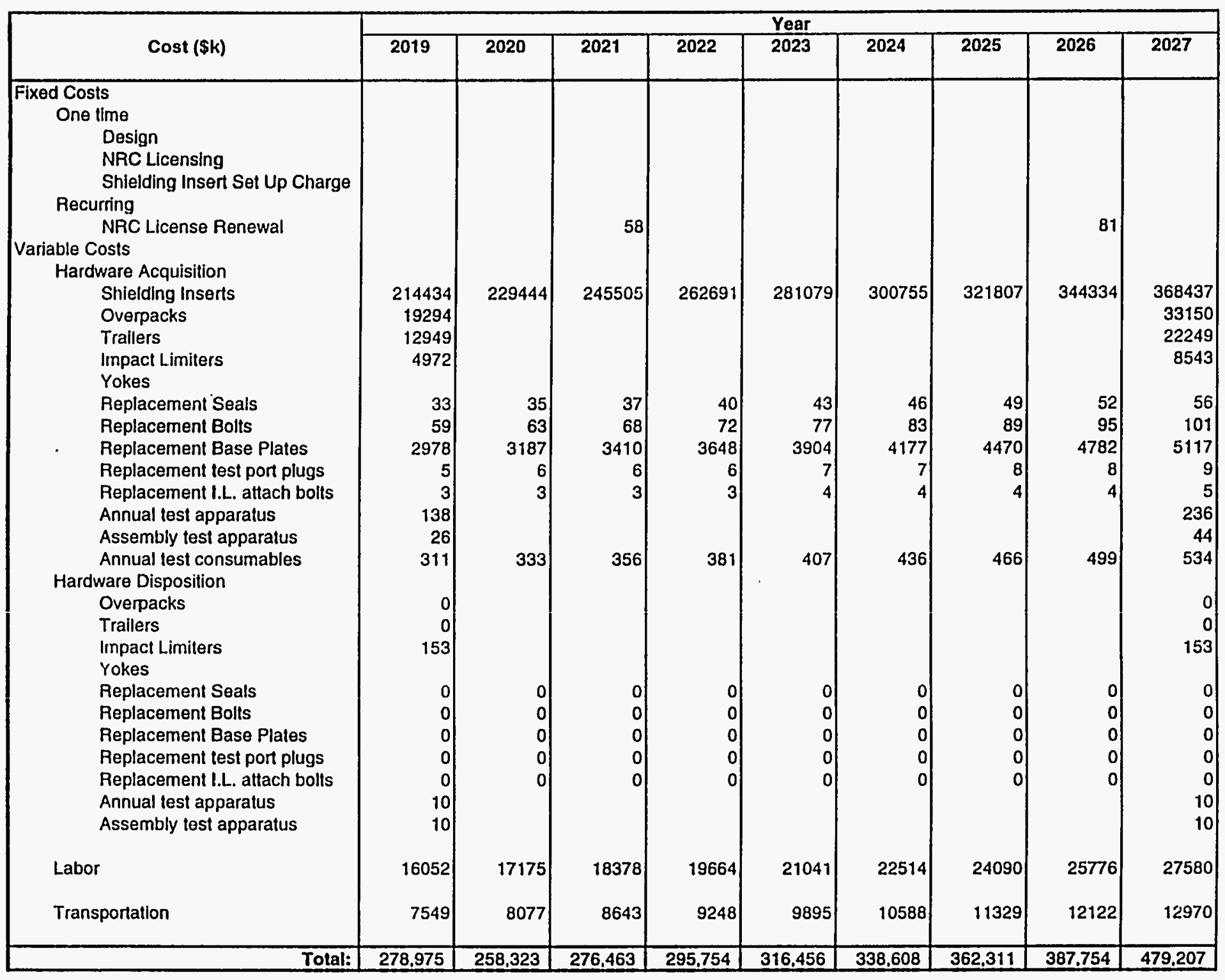




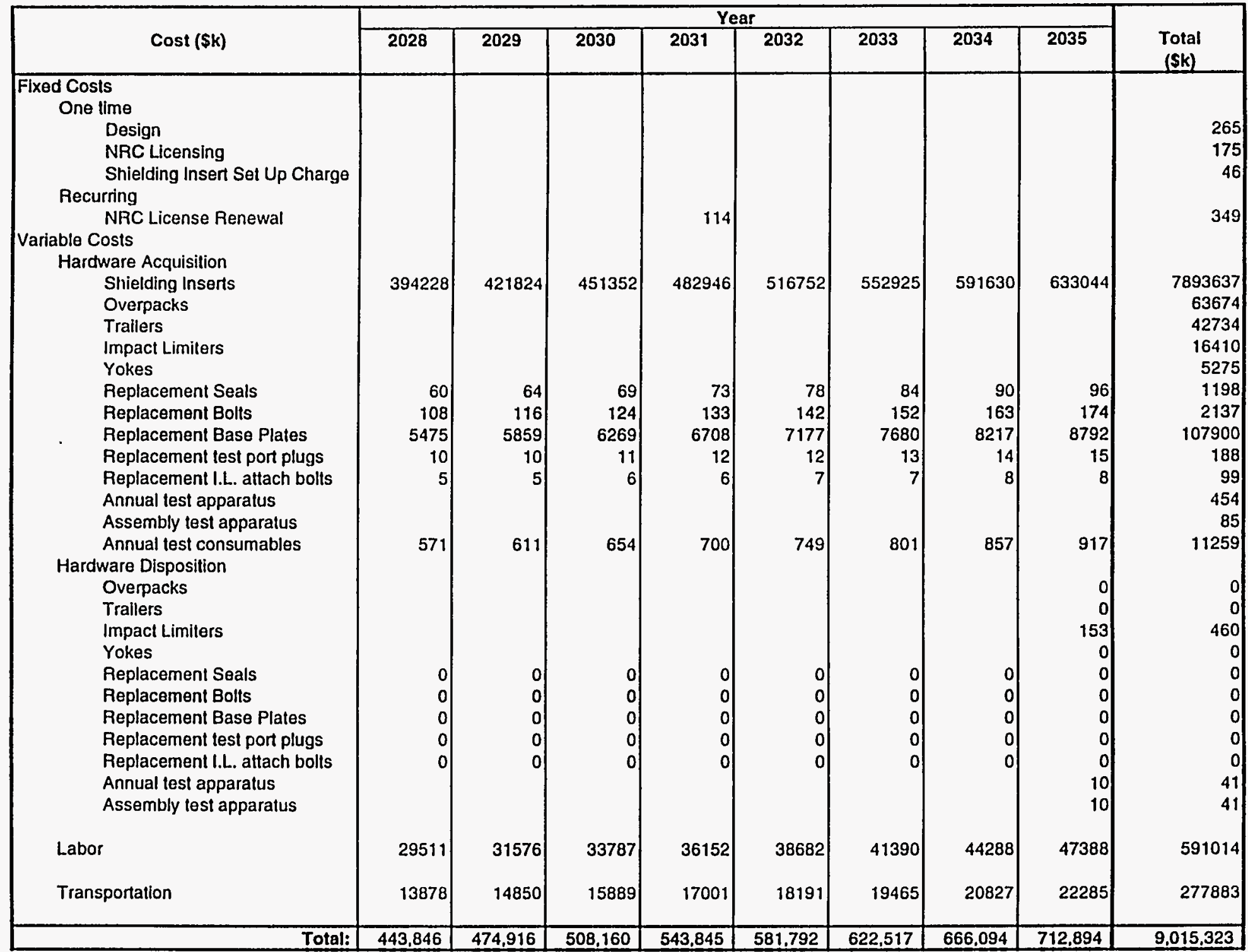




\section{Appendix D.2 Life Cycle Cost Calculations for 25 Year Shipping} Campaign for Assumed Repository Availability Date of 2020

Table D.2-1 Average Annual Inflation Rate $=3 \%$

Table D.2-2 Average Annual Inflation Rate $=5 \%$

Table D.2-3 Average Annual Inflation Rate $=7 \%$ 
Repository open date:

2020

Inflation rate $=3 \%$

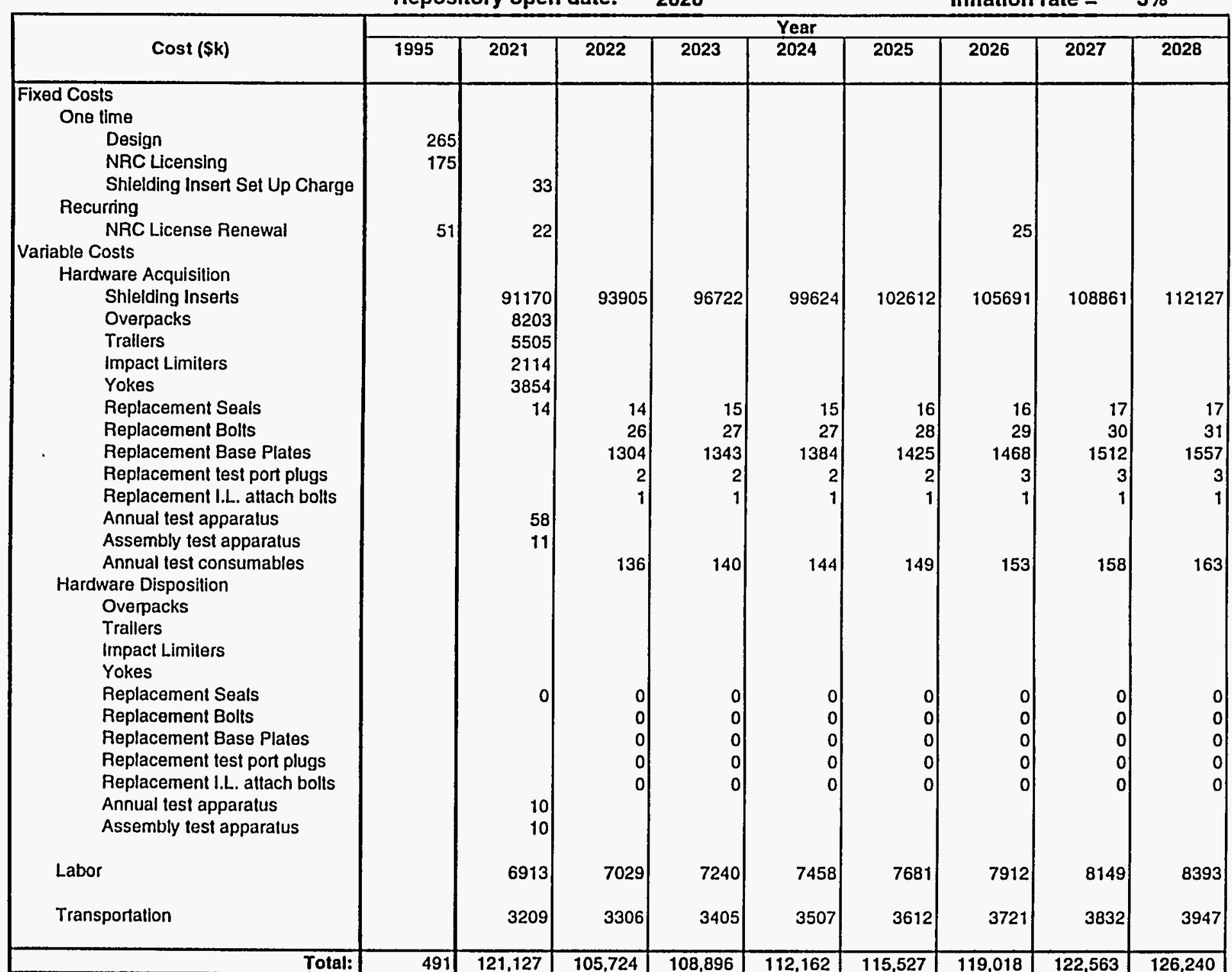




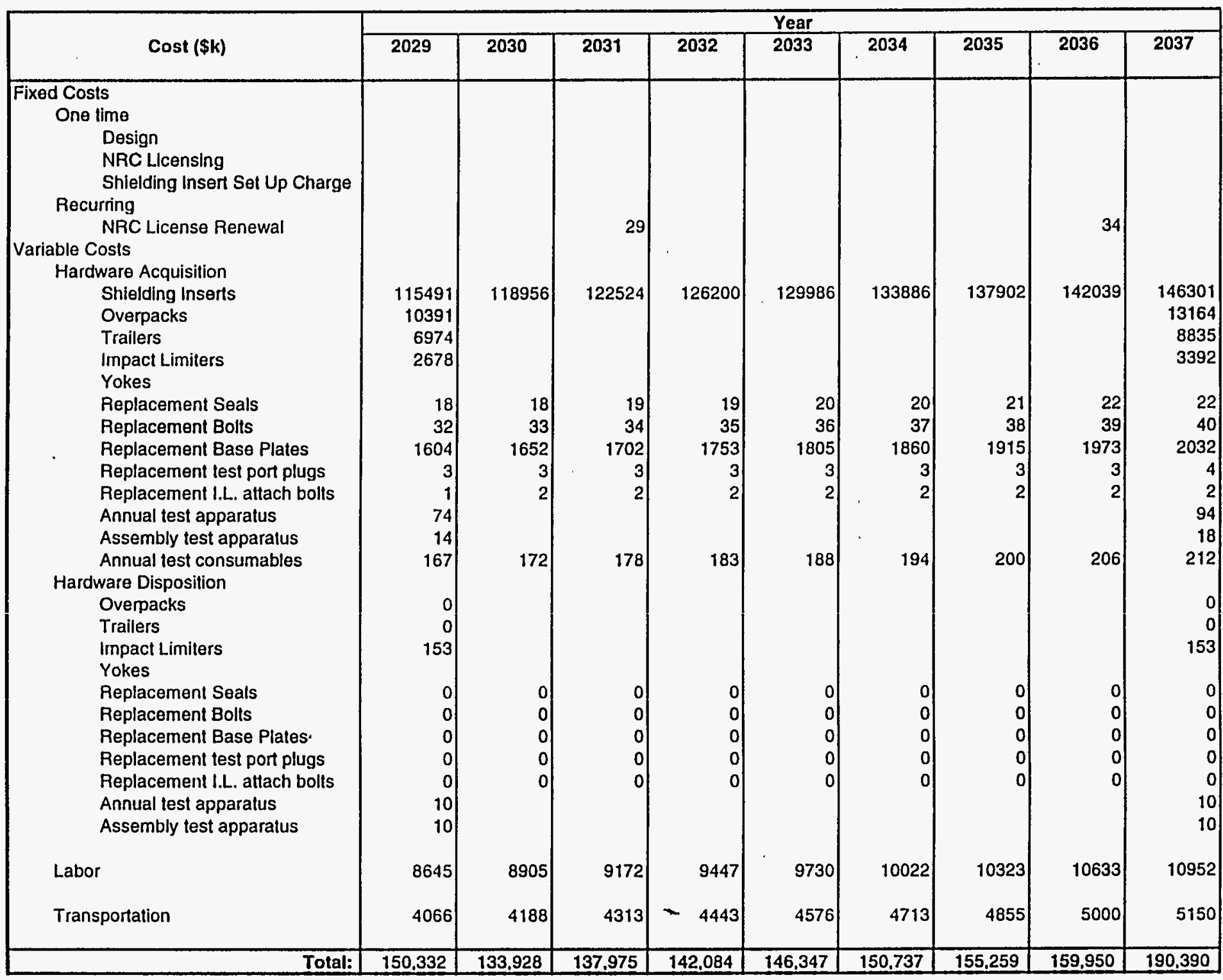




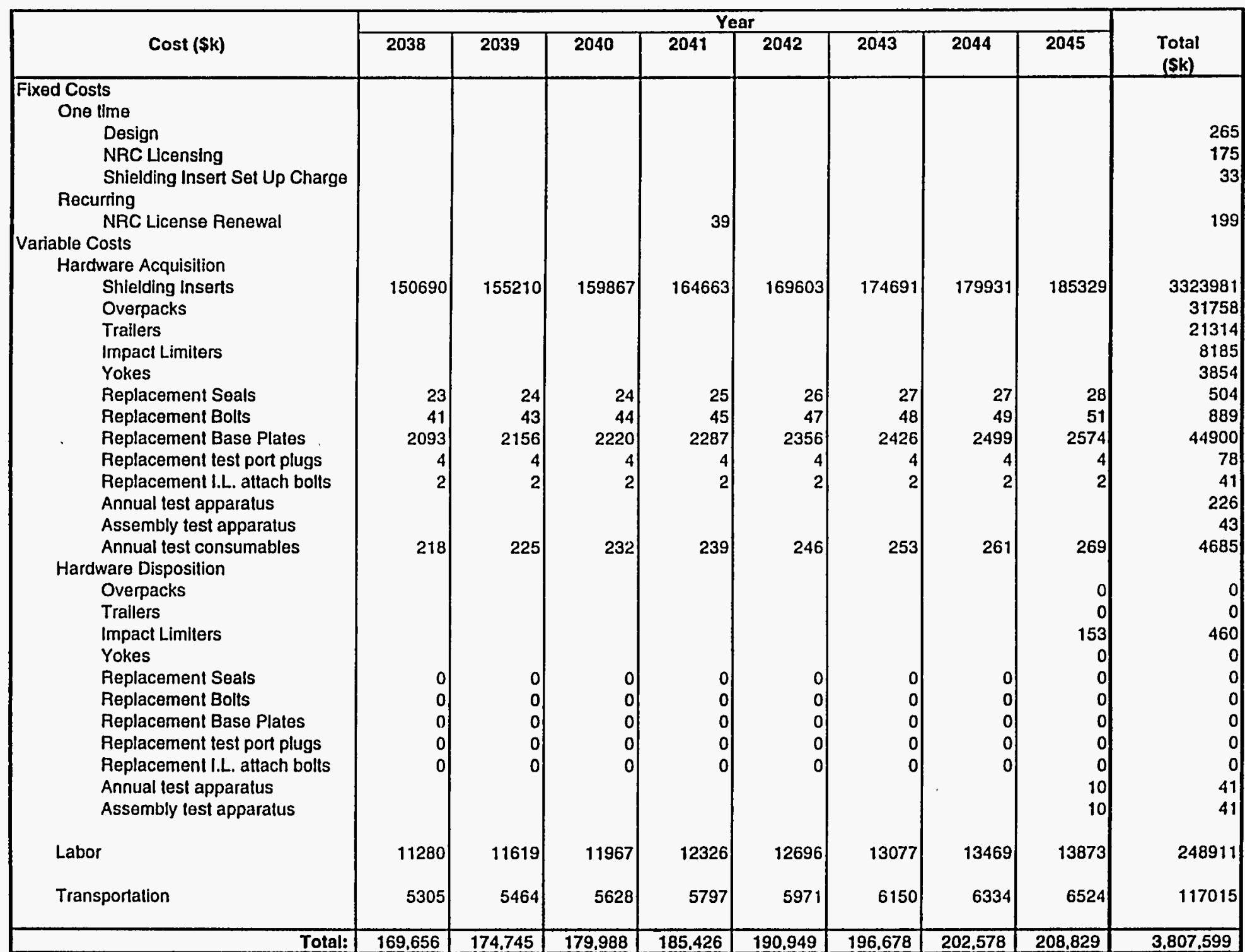




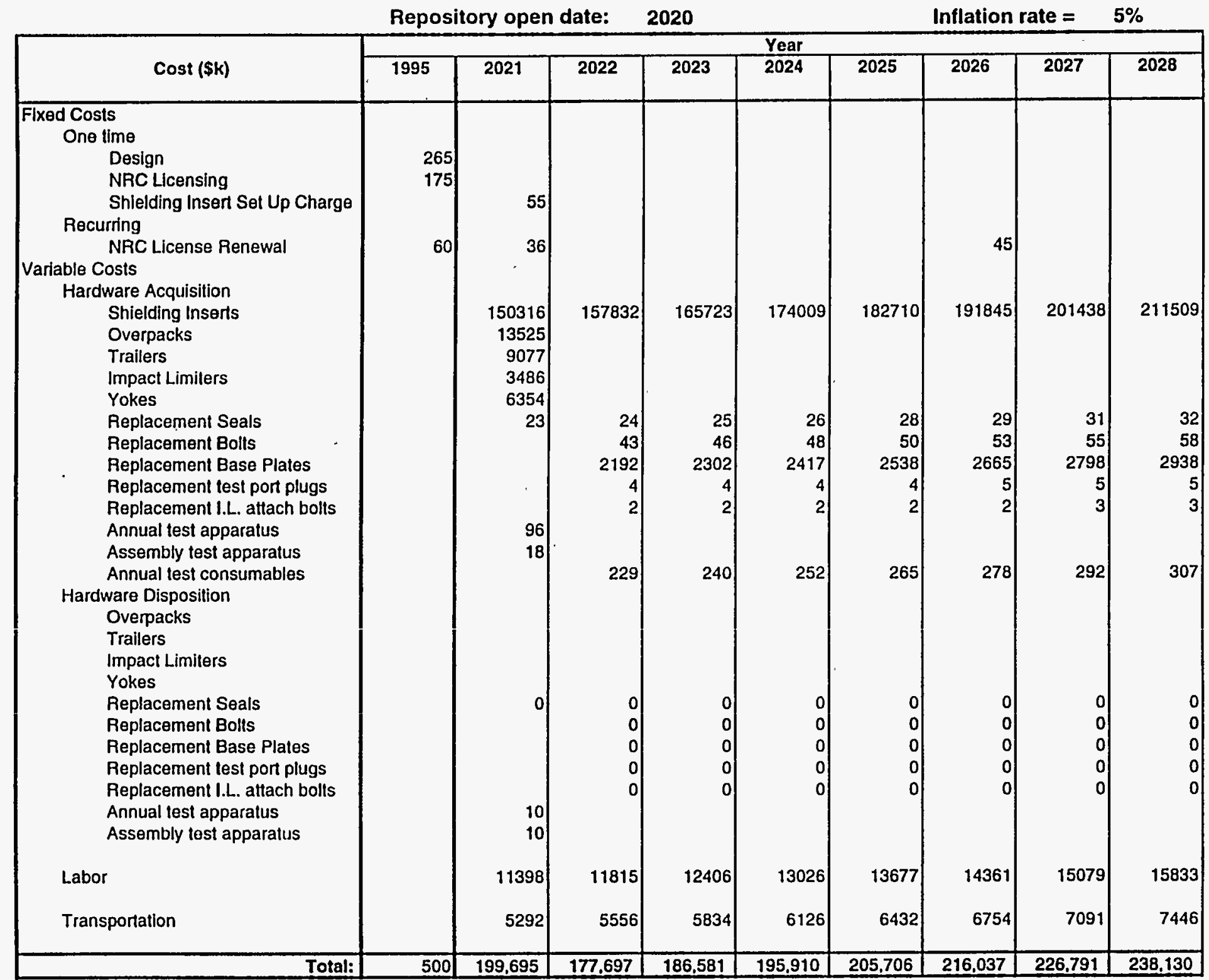




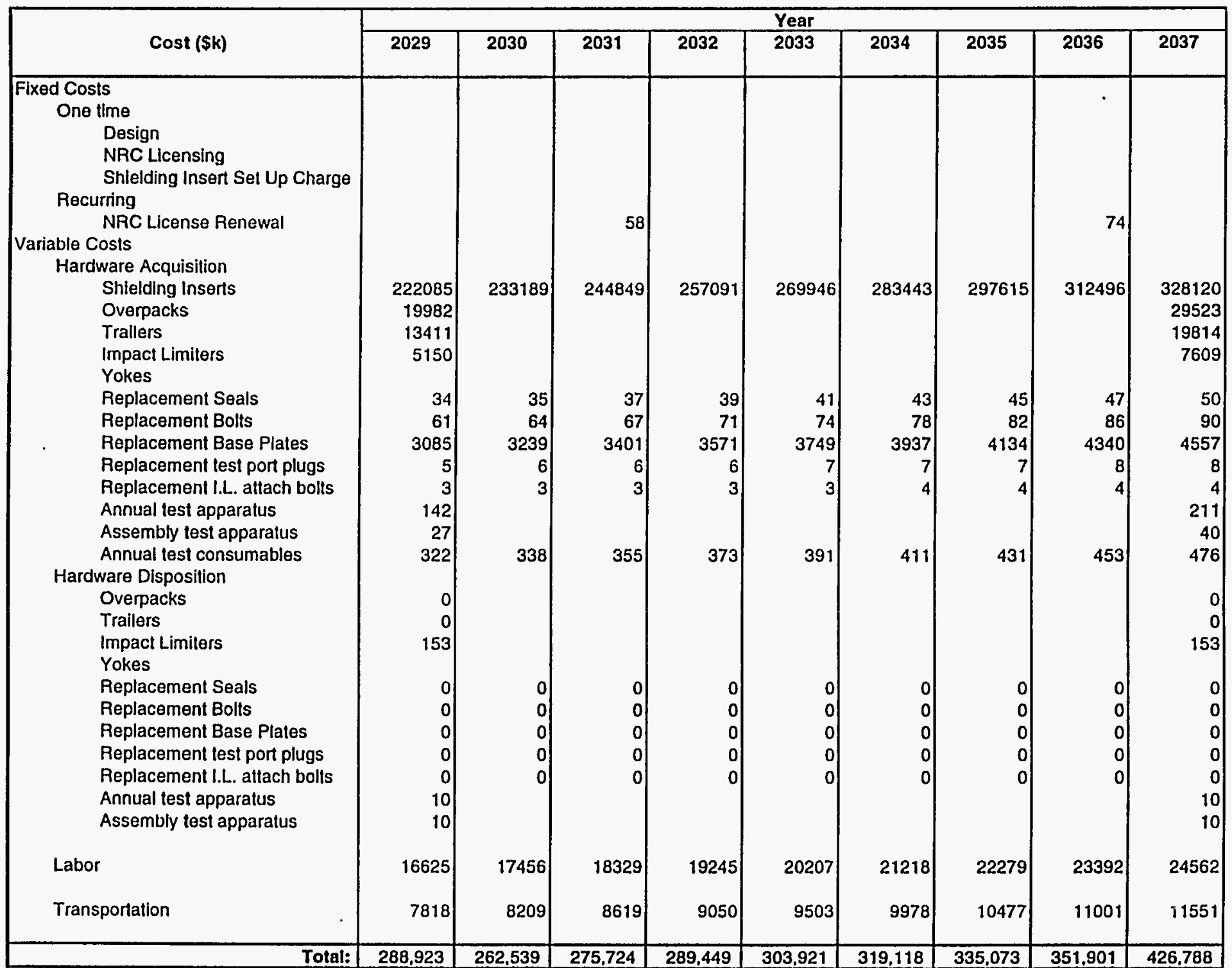




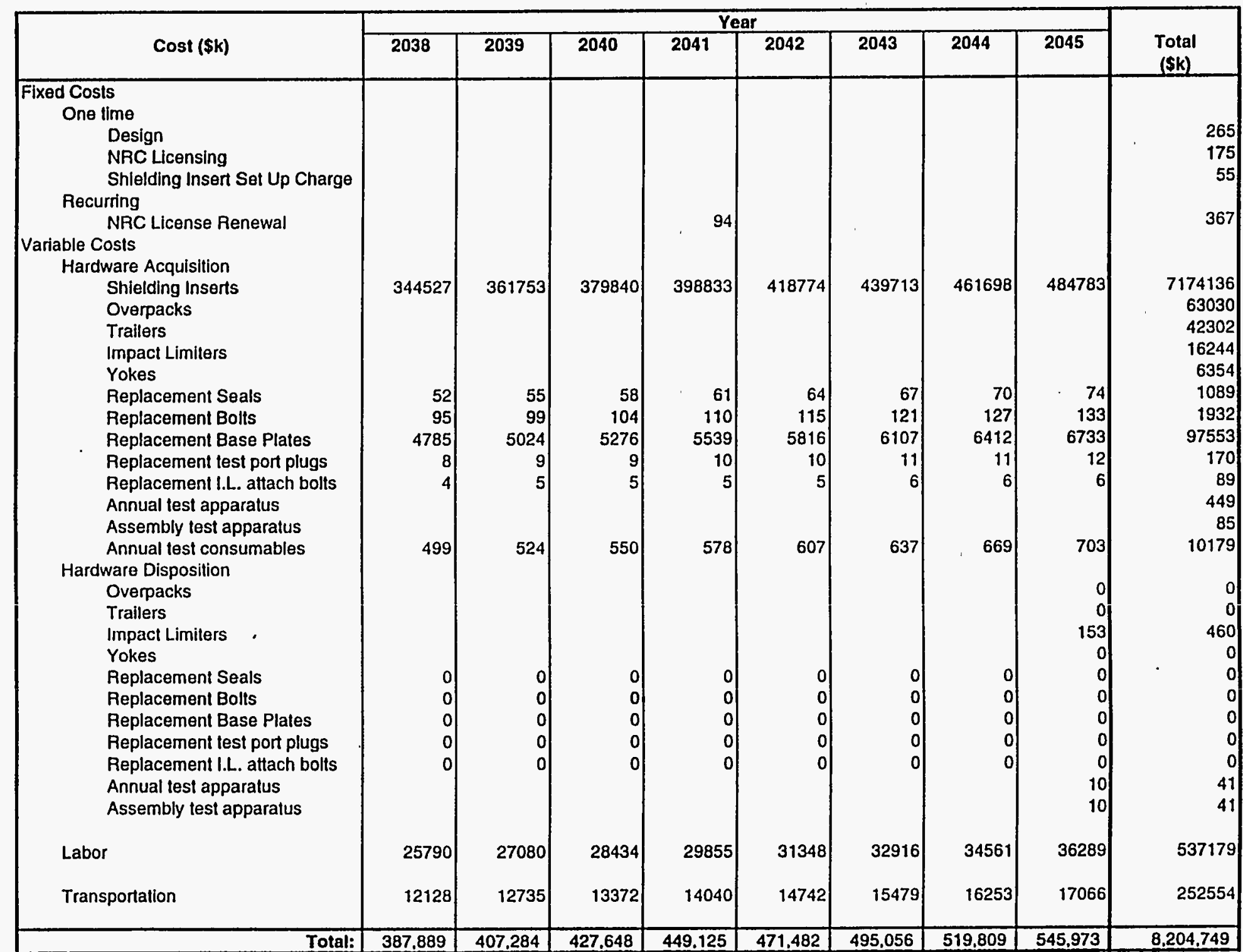


Repository open date:

2020

Inflation rate $=\quad 7 \%$

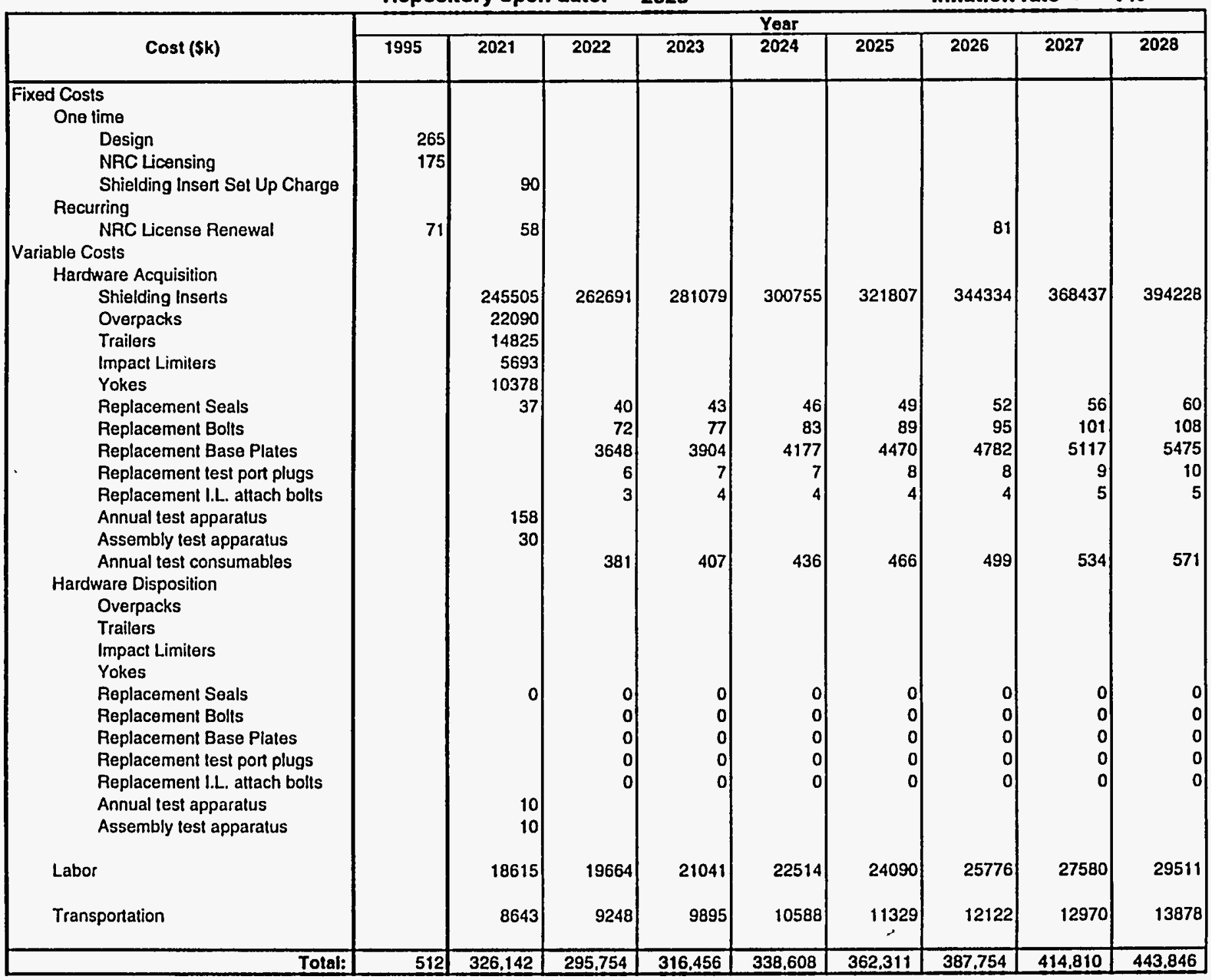




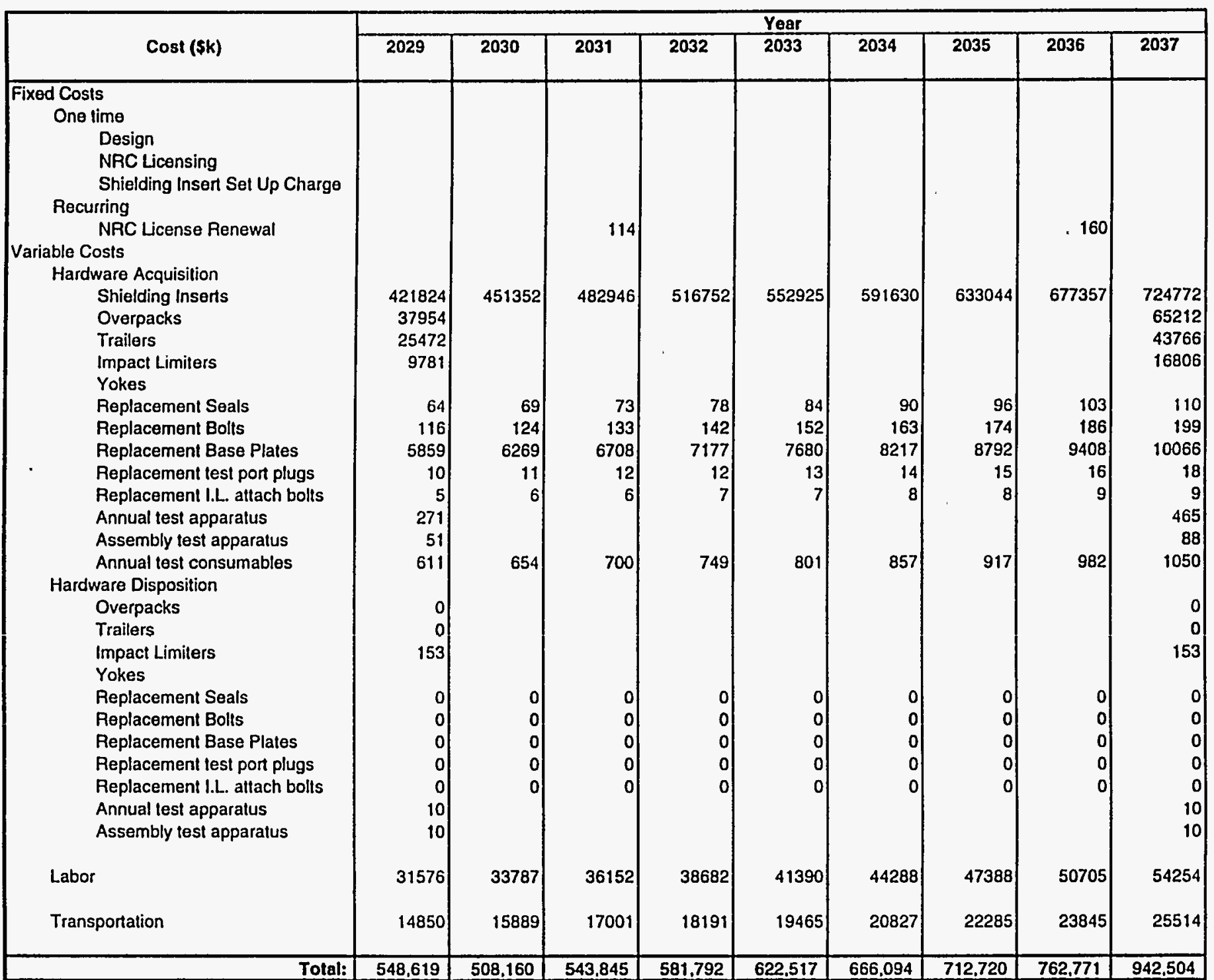




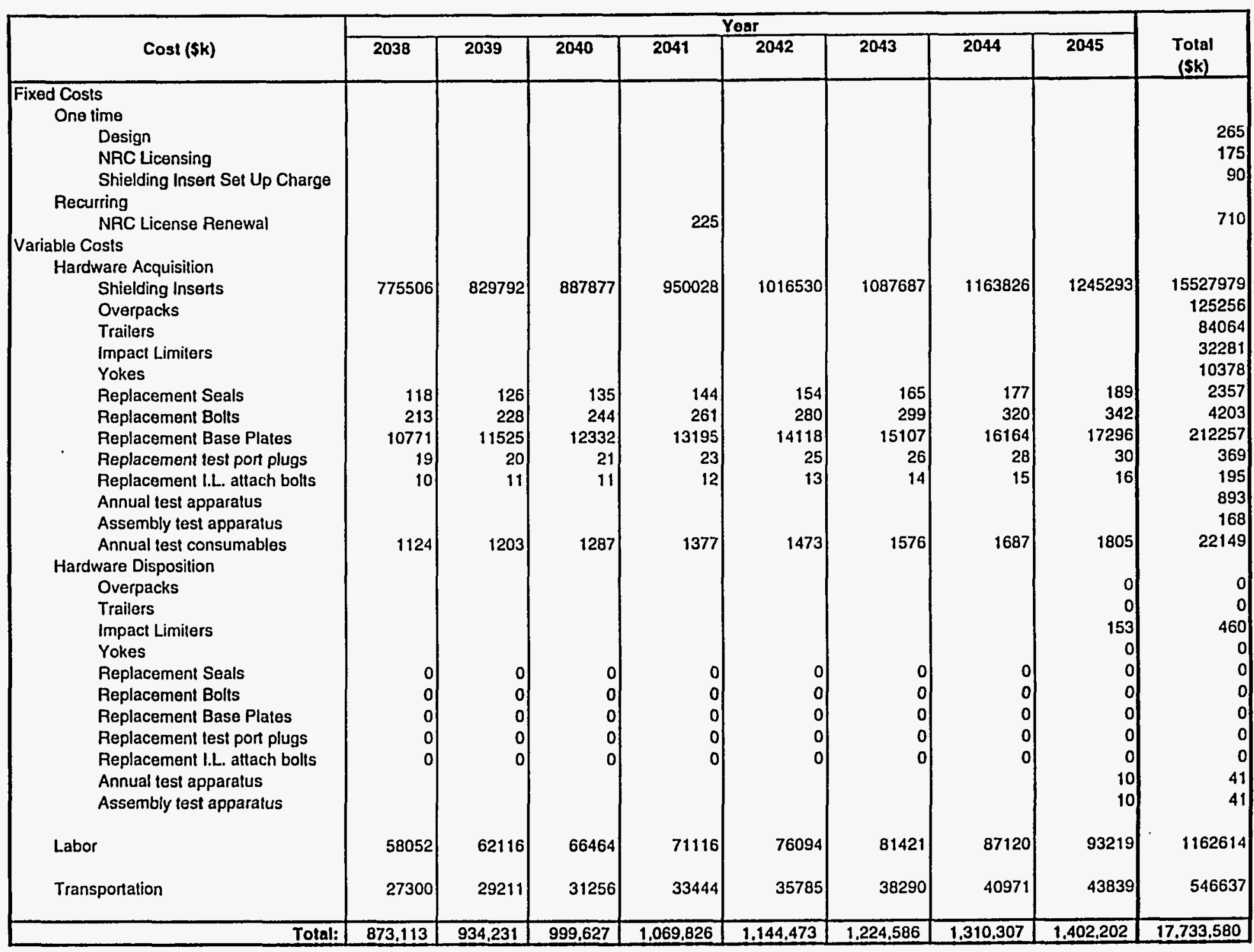




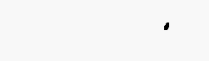

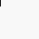

